
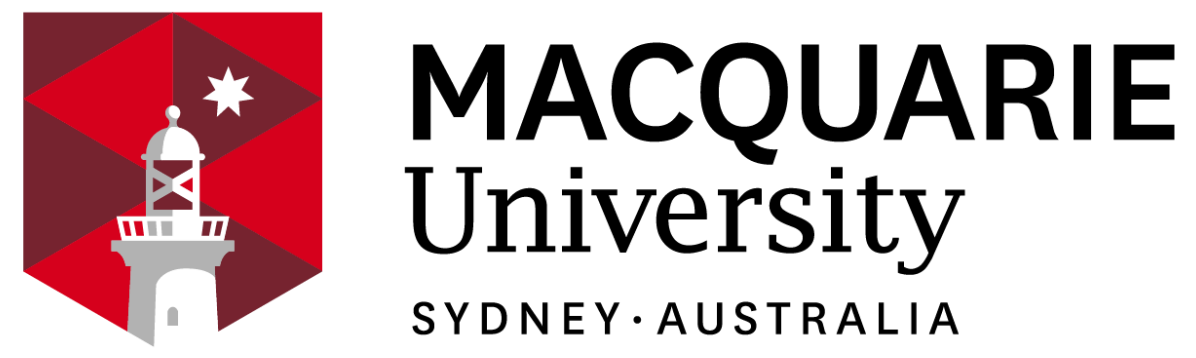

SYDNEY·AUSTRALIA

\title{
Possible compositional effects on the electrical conductivity of olivine: A preliminary study
}

\author{
Anthony William Lanati \\ Department of Earth and Planetary Sciences, \\ Macquarie University \\ A thesis submitted in partial fulfilment of the \\ requirements for the degree of Master of Research
}

Submitted: $13 / 11 / 2015$

Revised: 18/06/2016

Accepted: 29/06/2016

Printed: 07/07/2016
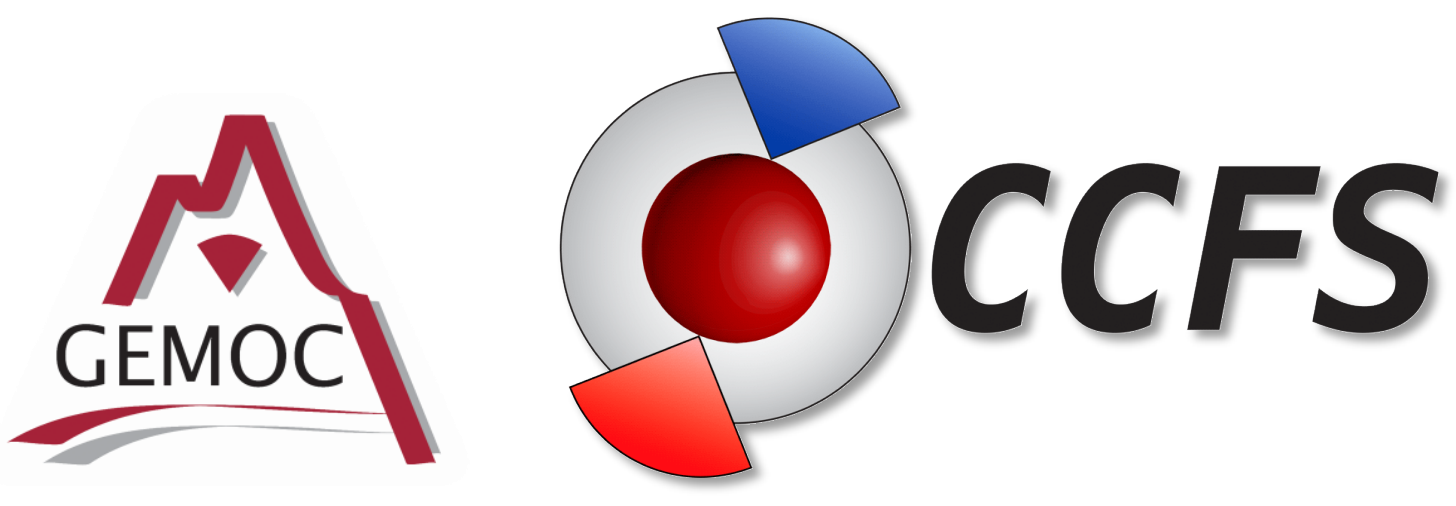



\begin{abstract}
:
Volatile sensitive probes of the upper mantle, such as magnetotellurics, are being developed to overcome insensitivities in seismic and gravity subsurface mapping as part of an effort to identify the location of deeply buried ore deposits, in addition to more broadly understanding mantle temperature and water contents. An understanding of the conductivity of mantle minerals is an essential prerequisite to the full interpretation of magnetotelluric data. Current proton conduction models for simple mineral systems, such as olivine, show large discrepancies. The material used for these determinations, San Carlos peridotite, is not a single mineral phase and may have compositional variations. This could be one of the origins of these discrepancies. To test this hypothesis, a sample of San Carlos olivine was taken and separated out the mineral components using a combination of electrostatic rock disaggregation, magnetic susceptibility as well as manual separation. The separated fractions were characterised using petrography. Impedance data were collected as a function of temperature and pressure in a multi-anvil press from both the separated olivine material and the original mixture. Comparison of these values with literature data has been made.
\end{abstract}




\section{Acknowledgements:}

I wish to acknowledge the extensive and onerous effort that has gone into this work and the team of people who have taken time from their own work to guide, mentor and advise me. These people not only provided me with an amazing amount of academic help but also showed care and compassion during a personal illness suffered during the course of this thesis.

To my supervisors, Associate Professor Simon Clark, Associate Professor Tracy Rushmer, Associate Professor Juan Carlos Afonso, I can never repay the immense amount of time you've given me over the past two years.

Simon, I thank you for the guidance and tasks you set for me during the coursework component of this MRes, I do not think I would have anywhere near the grasp of this subject area I currently have without you challenging me. I wish to thank you also for the useful and informative discussion throughout the course of this research project. We may not have always agreed but they certainly helped me to understand how the project was evolving and how impactful and important all aspects of the project can be with a bit more hard work.

Tracy, I wish to thank you for meeting with me regularly and helping me through the formalities at the beginning of this year. Your insight specifically into the way which a research project is planned and executed gave me a unique perspective in how I would carry out future work. I want to also thank you for giving me so much time and for the last minute edits that helped me make this thesis much more consistent. This was all while acting as an Associate Dean as well as having other students submitting this year.

JC, I want to acknowledge the way you make people think about problems. I truly respect and appreciate the dedication you have to your students and your research. You extended this to me in spite of my project deviating from the original plan, however I still hope to work with you in the future while developing the other aspects of this project. I want to assure you your advice was always helpful and I appreciated you always stopping when you saw me to have a quick chat about my progress. On a personal note, one day I hope to emulate the way you approach science and the passion you have for it, and I can confirm your passion is infectious.

To my unofficial $4^{\text {th }}$ supervisor and probably the person who I bugged the most Dr. George Amulele; I absolutely could not have completed this project without your technical and theoretical expertise. Your handle on the science we do is admirable and I hope to be able to 
live up to the standard you have set. I thank you for the training, especially all the times you had to repeat processes because I wasn't taking notes the first time. Thank you for inspecting all of my cells and telling me how bad they looked, it made me strive to make them perfect. Thank you for allowing my opinions to be heard and discussing this project with me, even during lunch and over a beer on Friday afternoon. Thank you for coming in on a Saturday when I asked for your help. I also wish to acknowledge the time you spent sitting next to me at the Raman and SEM, and the time you spent post analysis to make sure the phases were confirmed. I appreciate the thoughtful edits and comments made on the countless sections I sent you, although I am slightly less appreciative of the amount of times you commented "Really?", "Really?!" or "Dude, Really?!". Also for all the times you've helped me refocus and evaluate the situation for what it is, not what l've blown it up to be. Thank you for the $11^{\text {th }}$ hour edits and sitting with me to discuss and decipher what I actually meant to say. Rest assured you have made me a much better scientist simply by imparting the diligence, expertise, perfectionism, patience and your methodical nature on me. I will carry the lessons you've taught me through life and reference them on more occasions then I care to imagine, I am sure! But most importantly thank you for being a great friend and an even better mentor, I really appreciate it.

To my friends at MQ, specifically the MRES Y2 cohort and the PhD candidates (especially Bruno) thank you for checking in on me, asking how I was going or just saying "let's get a beer". On a much more specific note, to Alexandre, Jo, Natalie, Shirin and Uvana, I could not have made it through this year without your jokes, craziness and just plain amazingness. I will forever remember the times we spent together complaining about how much work we had to do... rather than actually doing it. Congratulations on completing and thanks for being there for me. To Lauren (Millzy) and Michael (Mickey), the adversity and experimental issues you both faced and overcame last year was ridiculously inspiring and I am so proud to know you both. Also in spite of your busy schedules you've both became and have remained one of the best support systems anyone could ask for. Thank you both. Also to Johno, cheers for being a mate!

I also wish to thank the ENTIRE EPS at MQ. You are all such amazing people and incredibly dedicated to your work. Thank you all for the well wishes during my illness and the get well card complete with olivine nose. Special thanks goes to Associate Professors Dorrit Jacob, Norm Pearson, Nathan Daczko and Dr. Heather Handley for being amazing MRes advisors/ mentors. The bi-weekly meetings provided a really good outlet to engage and gauge the 
progress of the project but also helped maintain a social element to the masters. Extra thanks to Norm for the helpful edits and convening the coursework component of this year and challenging me to think about my field in a unique way. To the GAU staff in particular Dave Adams, thank you for the dedication and assistance you provide to all who use the GAU but in particular thank you for setting up and training me on the Raman and SEM. Additionally to Dr. Steve Craven, you are far wiser than you know and your words of wisdom and encouragement throughout the year made this process much more enjoyable. Further to that your assistance and training using the Rock Processing facility made much of this work achievable.

Shout out to my Blacktown (Western Sydney) homies: Shaun, Sarah, Alex, Raf, Tom, David, Mitch, McD, Digi, Jess, Karina, Rach, Jos and Laura, and to Morgan and Mark. Thanks for being great friends throughout the last two years and sticking by me even when I disappeared for months at a time.

To Shaun, my brother from another mother and the best mate you could ask for; Thanks for being with me through the crazy journey that has been my masters but also for the high school years and my undergraduate. All the fun times and crazy shit you've instigated has made my life anything but boring and I am looking forward to the stuff you'll undoubtedly convince me to do after this thesis is done and dusted. As for this year, thanks for sitting by my bedside when I was in ICU and visiting me while I was in hospital as well as once I got home. Also thank you to you and Sarah for allowing me to take part in your wedding this year, it was truly a highlight of my year and provided an awesome break from writing even if it was only two days.

Mum, Dad, Manda, Nat, Zaviea, Nash and Charlotte thank you for being the reason I wake up every day. You are the most loving and supportive family I could ask for. Mum and Dad I can never repay the support you've given me and sacrifices you have made in order for me to complete this masters. Thank you to all my family and their partners for checking in on me and making sure I was okay and not completely stressed out. Also sorry for the short temper, which only grew shorter as we drew closer to the due date (all three of them). To Zaviea, Nash and Charlotte thank you for being my beautiful little cherubs and allowing me to step back from study and enjoy watching you grow up over the past two years. You may not be old enough to understand this but you helped me get through this more than you could ever know. 
Finally I wish to thank all of the Doctors and Nurses at Blacktown Hospital intensive care unit and medical ward 2. The time I spent in your care was made much shorter by the expertise and quick action you took to treat the pneumonia and sepsis I was suffering. I also wish to thank my GP Dr. James Hubbard for his extensive monitoring of my condition throughout the hospitalisation and the care he took after l'd been discharged. 


\section{Statement of originality:}

I certify that, to the best of my knowledge, the work presented herein is the original work of the author and has not been presented or published elsewhere. All published works and work carried out by persons other than the author presented here are appropriately referenced and due respect given to the participants. Further no part of this thesis has been presented, accepted or been published for the award or consideration of a higher degree or diploma at this or any other educational institution.

Signed:

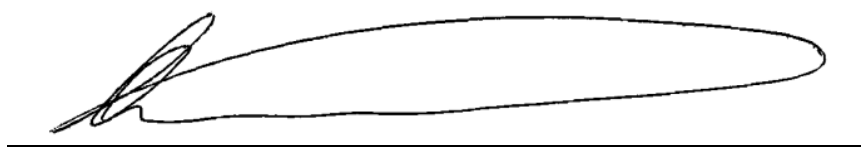

Anthony William Lanati

Author, MRES Candidate

$13 / 11 / 2015$ 


\section{Contents}

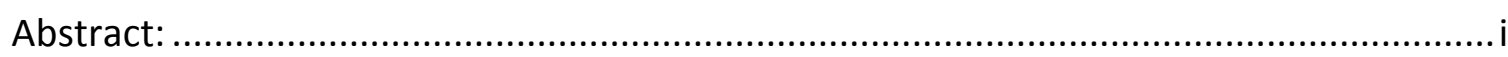

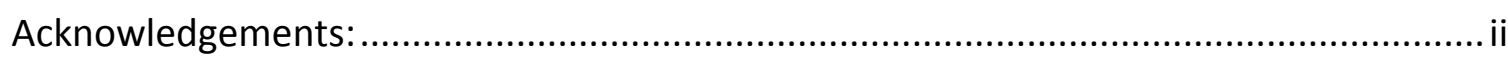

Statement of originality: ...................................................................................... vi

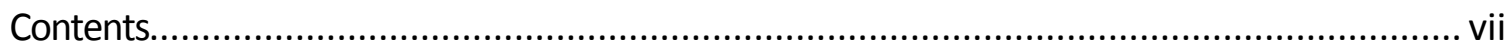

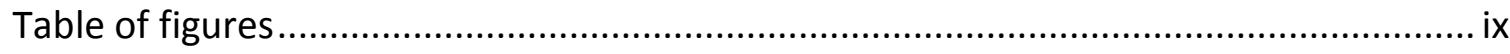

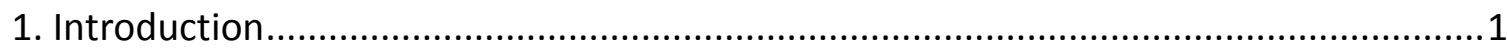

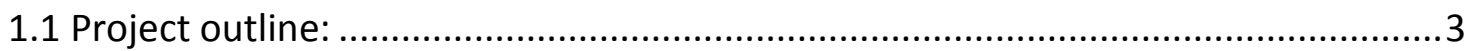

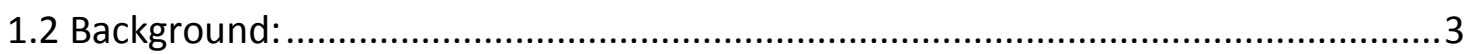

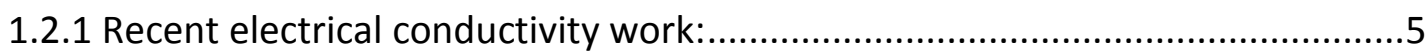

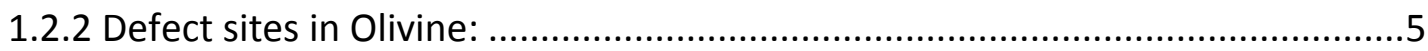

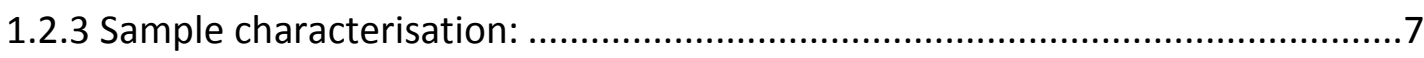

1.2.4 Conductivity mechanism and measurement:..........................................

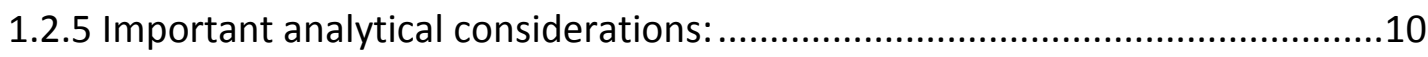

1.2.6 Implications for Magnetotelluric investigations: ......................................13

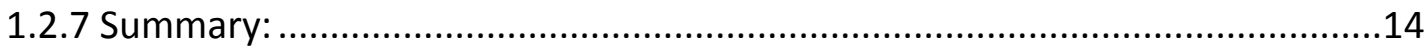

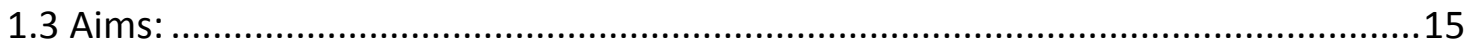

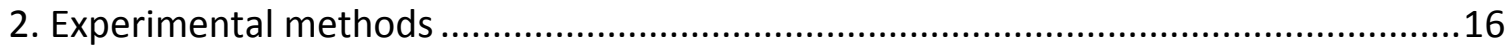

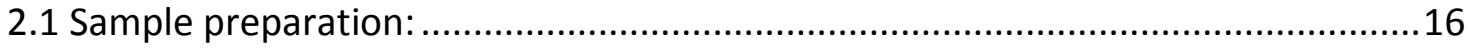

2.1.1 Electrostatic Rock Disaggregation: .........................................................16

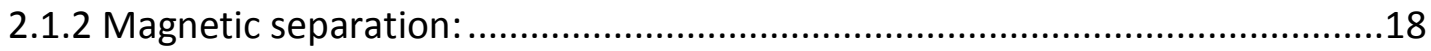

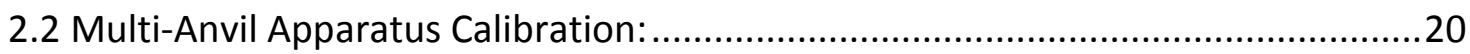

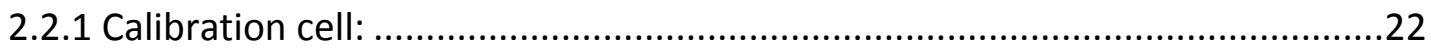

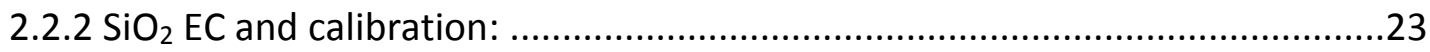

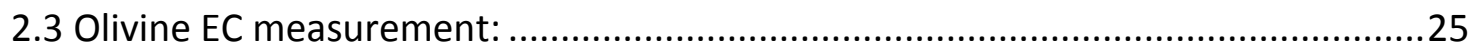

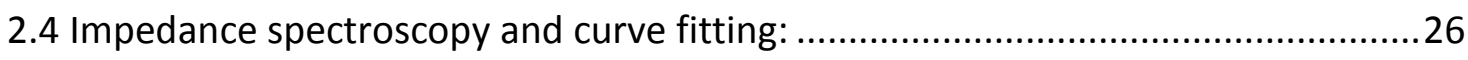

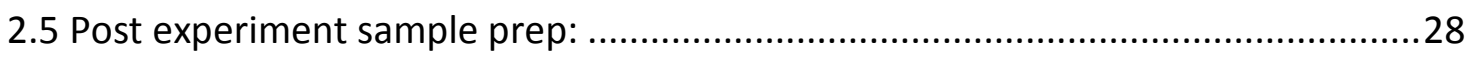

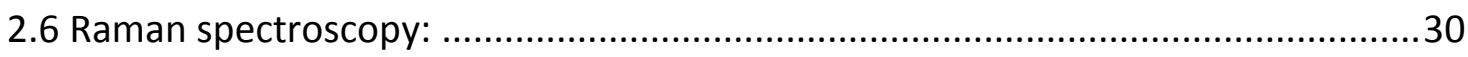




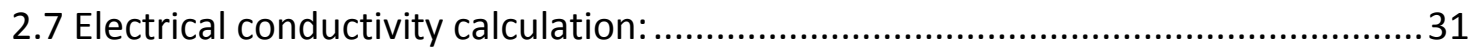

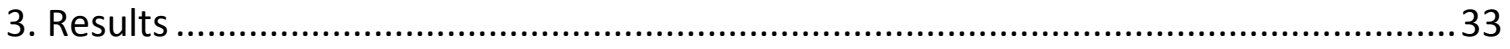

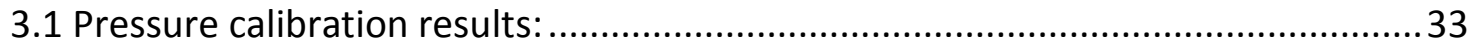

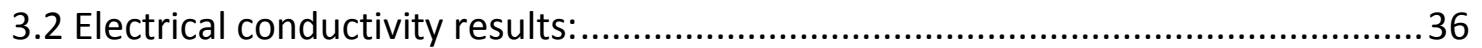

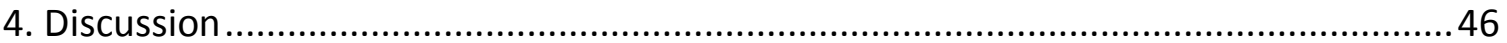

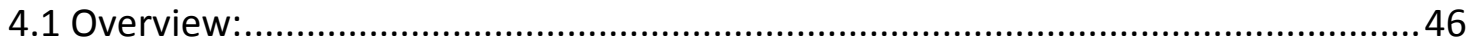

4.2 Experimental results on mineralogically distinct samples: ...............................47

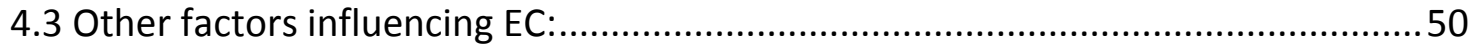

4.4 Powder sample vs. polycrystalline aggregate: .....................................................51

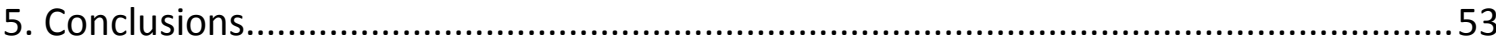

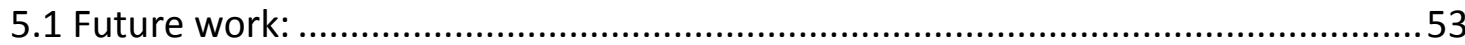

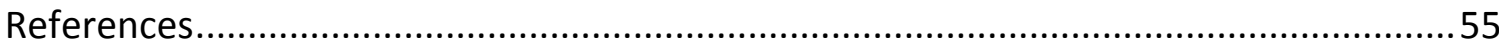

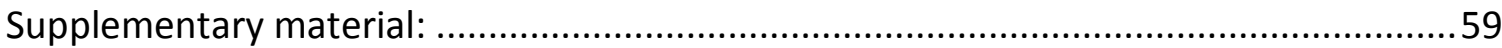




\section{Table of figures}

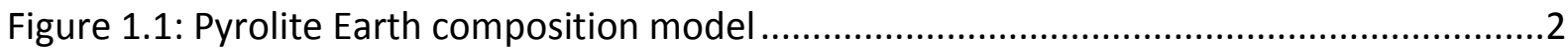

Figure 1.2: Comparisons of electrical conductivity response and models ..............................4

Figure 1.3: FTIR spectra taken from Kovács et al. (2010) ...................................................6

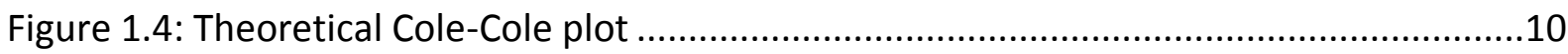

Figure 1.5: Proton conduction contour maps with water content and temperature up to $1,000 \mathrm{ppm}$ and $1,000^{\circ} \mathrm{C}$, respectively

Figure 1.6: Comparison of conductivity models for Karato \& Dai (top row) and Yoshino \&

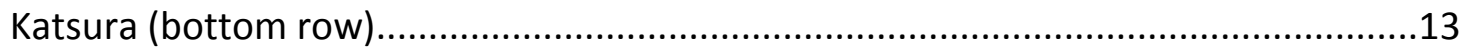

Figure 2.1: SelFrag(

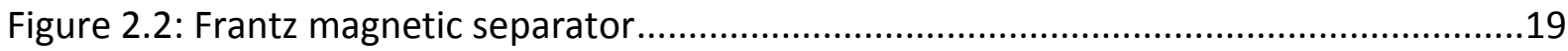

Figure 2.3: 500 ton press with 6-8 Walker type split cylinder multi-anvil............................20

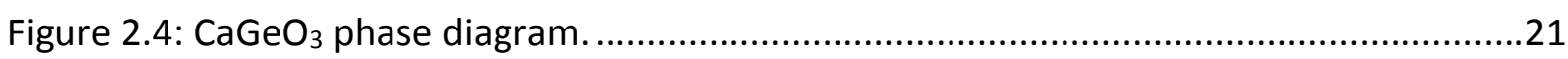

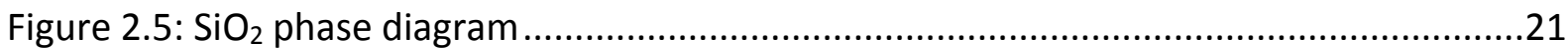

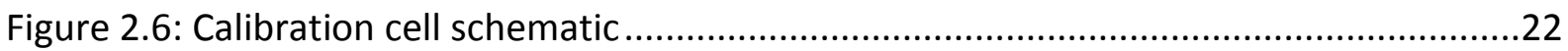

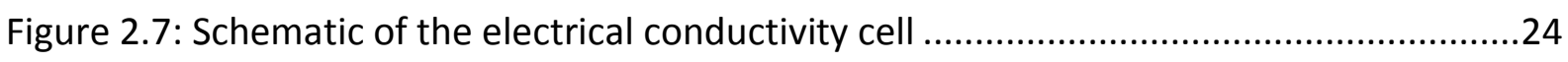

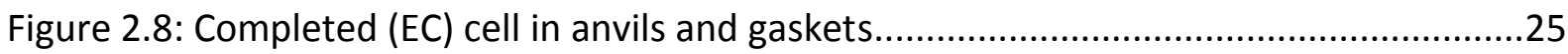

Figure 2.9: Solartron 1260A impedance/ Phase-Gain analyser............................................26

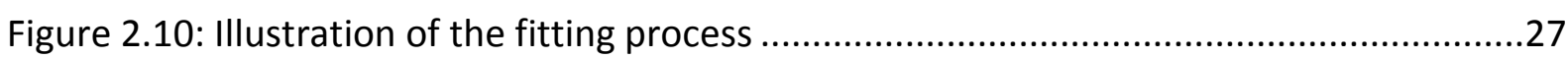

Figure 2.11: Cross-sectional view of EC cell post experiment ............................................29

Figure 2.12: Characteristic Raman spectra for the $\mathrm{CaGeO}_{3}$ polymorph series ........................30

Figure 2.13: Raman spectra for the $\mathrm{SiO}_{2}$ polymorph series ...............................................30

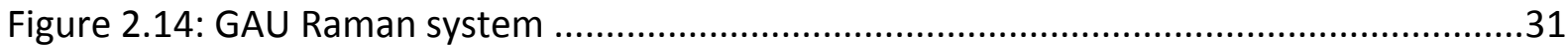

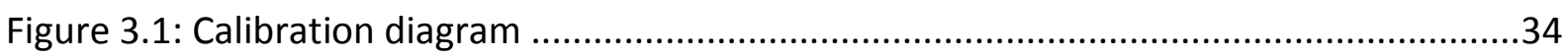

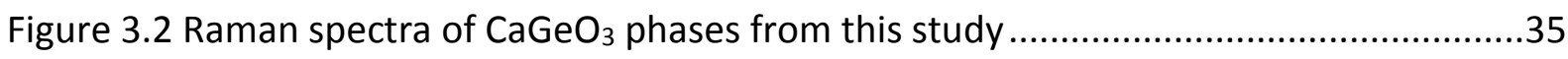

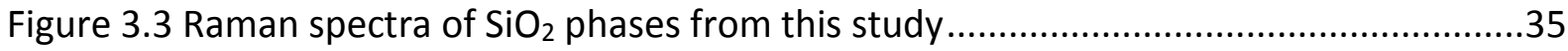

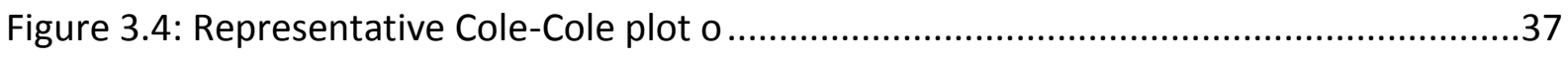

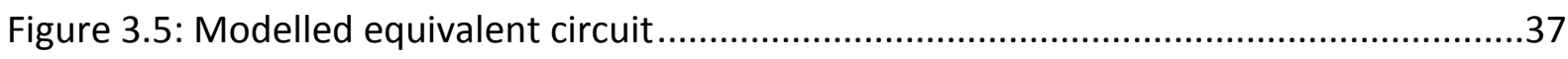

Figure 3.6: Arrhenius electrical conductivity plot for MQ029 .............................................38

Figure 3.7: Arrhenius electrical conductivity plot for MQ034 ............................................40

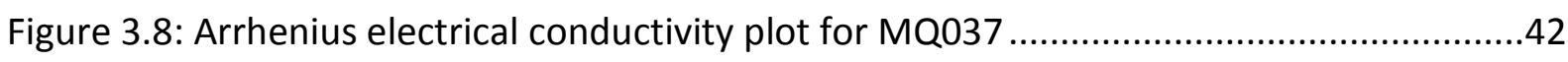

Figure 3.9: Arrhenius electrical conductivity plot for MQ039 ..............................................43 
Figure 3.10: Comparison of literature values with data produced in this study ....................45

S.Figure 1: Comparison of literature values with data produced in this study .....................61

S.Figure 2: Comparison of literature values with data produced in this study .....................62

S.Figure 3: Comparison of literature values with data produced in this study .....................63

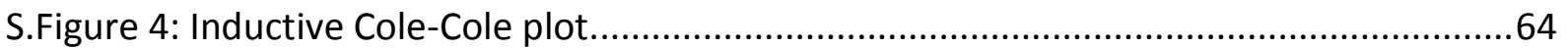




\section{Introduction}

The world's continued reliance on mined resources is adding pressure to the search for ore sources, however we have exploited many of the surface deposits meaning new and diversified techniques are required to maintain adequate resource supply and investigate deeper in to the Earth. The increase of new exploration techniques means geophysical methods, such as magnetotellurics (MT), are becoming widely utilised to detect these hidden ore bodies. MT takes advantage of two naturally occurring processes to provide images of the deep Earth by measuring variations in the Earth's magnetic and electric fields overtime. Firstly, electrical storms in the atmosphere that occur on timescales approximately shorter than 1 second (s) disrupt the magnetic field of the Earth (Selway, 2014; Selway et al., 2014). The second process is the interaction of the ionosphere with the solar wind at periods approximately greater than $1 \mathrm{~s}$ (Selway, 2014; Selway et al., 2014). While many geophysical techniques (such as seismic tomography) are used, MT is becoming especially important in the search for ore bodies and unique features in the Earth. This is because it is an ambient/ passive measurement that requires little manpower as well as providing extensive data on the electrical structure of the Earth. MT relies on stations being placed in the field in arrays to record the electric and magnetic fields of the Earth over time to allow for a wide range of frequencies to be covered. By covering many frequencies (i.e. recording short and long wavelengths) it is possible to see shallow crustal features, such as magma chambers (Ingham et al., 2009) with the high frequency (short wavelength) component. Alternatively MT can be used to investigate very deep (100s of $\mathrm{km}$ ) features, such as the structure of the upper mantle, with the low frequency (i.e. long wavelength) component (Tarits et al., 2004; Ichiki et al., 2006; Meqbel et al., 2014; Vozar et al., 2014; Cherevatova et al., 2015; Kahn et al., 2015; Zhang et al., 2015). In order to see deep features, such as those expected to exist within the mantle, it is necessary to record over long time periods (> 1 month) (Selway, 2014; Selway et al., 2014). However, once the data is collected there is extensive processing to correct it to find the usable components. One correction that is not yet possible is the correction for composition and more importantly water content. Water is a known conductor and therefore any presence of water will change the response and result in inaccurate assumptions and models. In the same way the varying chemical make-up of minerals also distorts the accuracy of any model produced. For this reason a number of labs have looked to simulate real Earth conditions 
utilising common minerals of variable hydration to perform electrical conductivity (EC) measurements. One way of simulating real Earth conditions is to use versatile high pressure and temperature devices known as multi-anvil apparatus (MAA). MAAs rely on a ram, often driven by oil pressure, to apply force to a pressure module, which contains secondary anvils (wedges) that support and close in on eight inner tungsten carbide (WC) anvils. The WC anvils are truncated on one corner, forming a cavity, to enclose an octahedron containing the sample with the truncation of the anvil dictating the achievable pressures. Pressures achievable in the MAA are in excess of $50 \mathrm{GPa}$ allowing investigation from the upper mantle to the deep mantle. The upper mantle is believed to extend from the surface to $\sim 400 \mathrm{~km}$ depth with pressures expected to range from $2 \mathrm{GPa}$ at the base of the lithosphere to $14 \mathrm{GPa}$ at the mantle/ transition zone boundary. It is in this zone where olivine ( $\alpha$-spinel), the stable iron magnesium silicate mineral phase, is located. Olivine is believed to make up $~ 55 \%$ of the pyrolytic upper mantle (Figure 1.1), and is therefore the most abundant mineral. The abundance of olivine within the upper mantle has made this mineral the focus of extensive EC work. The high pressure polymorphs of olivine (wadesleyite/ $\beta$-spinel and ringwoodite $/ \gamma$-spinel) are known to

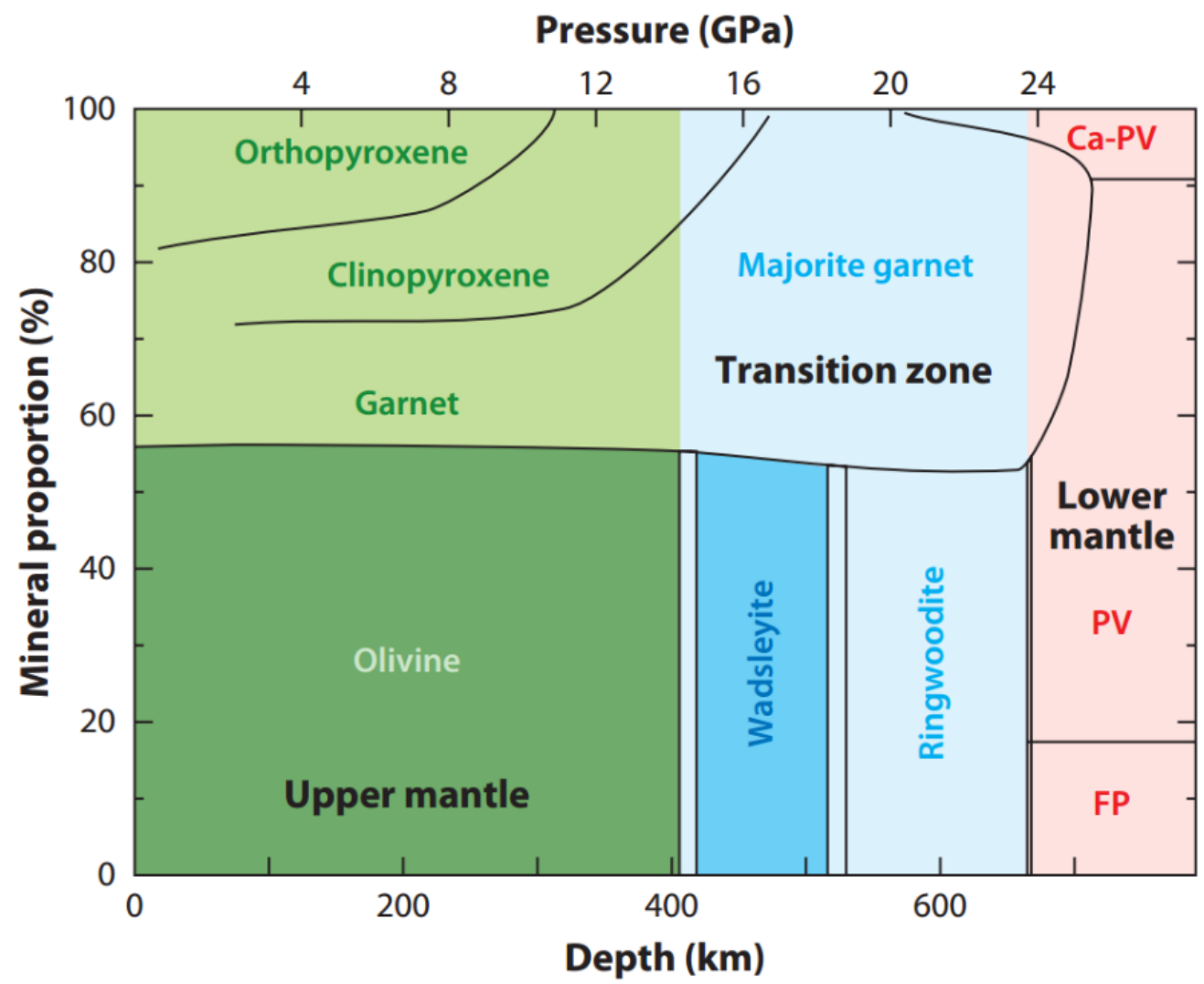

Figure 1.1: Pyrolite Earth composition model. Mineral proportion of pyrolite Earth model showing olivine as the most abundant mineral in the upper mantle. Abbreviations $\mathrm{Ca}-\mathrm{Pv}, \mathrm{Pv}$ and FP represent calcium perovskite, perovskite and ferropericlase respectively (After Yoshino and Katsura, 2013). 
hold within their structures large amounts of water ( 1 - 3 weight $\%$ (wt. \%)), while olivine is considered to be a nominally anhydrous mineral with a maximum water storage capacity of 0.89 wt. \% (Smyth et al., 2006). In order to investigate the role of water content it is essential to first understand the effects of composition on electrical conductivity in olivine and how the presence of water in olivine may alter composition effects, such as charge mobility. This work will focus on the effect of the compositional properties on electrical conductivity.

Hydrous olivine has been studied extensively over the past two decades with EC being the primary investigation tool. However, in spite of the range of work done to understand hydrous olivine and develop an appropriate olivine conduction model there is still disagreement among Earth scientists. The disagreement stems from the models produced by two labs (Wang et al., 2006; Yoshino et al., 2009; Yoshino et al., 2012), that illustrate an order of magnitude difference in EC across water content (Figure 1.2a). The reasons for this will be examined further.

\subsection{Project outline:}

This project forms the initial stage of a broader project in to the effect of water content, oxygen fugacity, temperature and composition on electrical conductivity measurements at pressures similar to those expected within the upper mantle (100-400 km). Furthermore the broader project looks to create an internally consistent database of electrical conductivity measurements at varying pressures and temperatures, as well as facilitating large volume synthesis of polycrystalline samples to investigate diffusion mode and mechanism.

The initial stage of the study presented in this thesis looks to assess the way in which electrical conductivity is affected by the compositional aspects of olivine. Emphasis will be placed on developing a working electrical conductivity cell as well as calibrating the 500 ton MAA at Macquarie University. Finally electrical conductivity measurements will be carried out on two samples generated from the San Carlos peridotite.

\subsection{Background:}

Research in geoscience has seen an increased emphasis on the use of integrated techniques such as magnetotellurics, in addition to the traditional methods of field observations and relationships. In the course of this process the source of water within the Earth has become a major consideration, primarily due to the need to understand the effects of water within the deep Earth, on properties such as melting, rheology and elasticity, and discern the origin of water on Earth both in terms of generation and timing. Early work on 
water in mantle-derived magmas dates back prior to Nicholls and Ringwood, (1973), and references therein, which outlines the generation of melt under saturated conditions within the Benioff zone. Importantly the aforementioned study is perhaps some of the earliest experimental work conducted on a potentially hydrous subcontinental lithospheric mantle. Further, other studies out of Ringwood's lab at the Australian National University from 1960 onwards laid the ground work for much of the current understanding of the mantle, particularly relating to the iron-magnesium silicate mineral; olivine.

Olivine is the ambient pressure and temperature stable phase in the iron-magnesium silicate series that encompasses the high pressure-temperature polymorphs wadsleyite and ringwoodite. The current understanding of this group of minerals and the role that water may play in the molecular structure of each phase ranges from nominally anhydrous (i.e. dry) for

a)

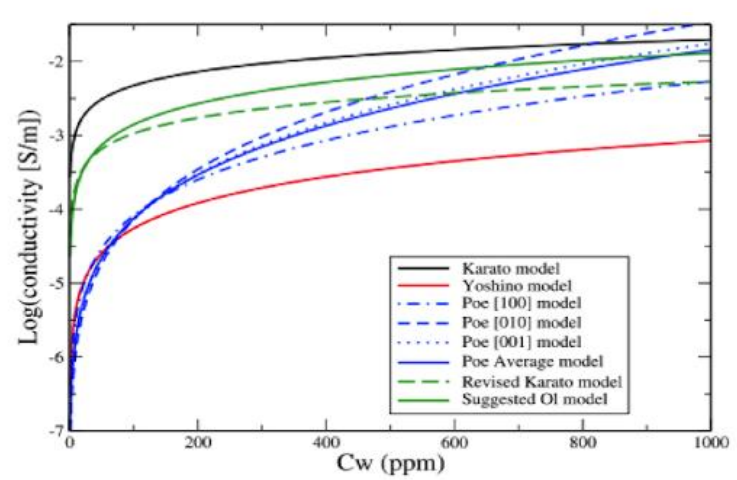

c)

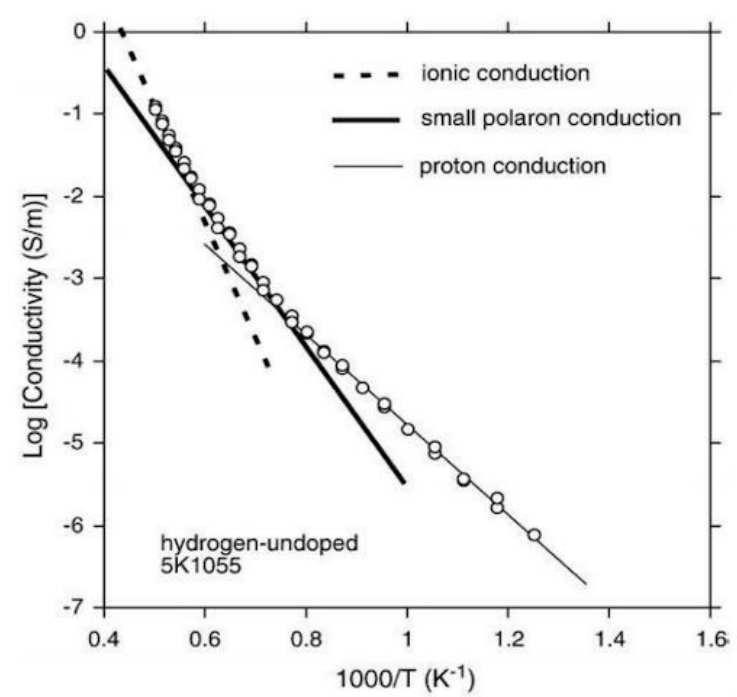

b)

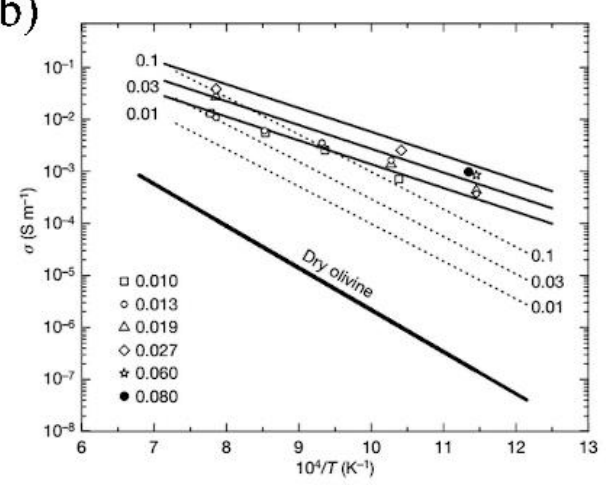

d)

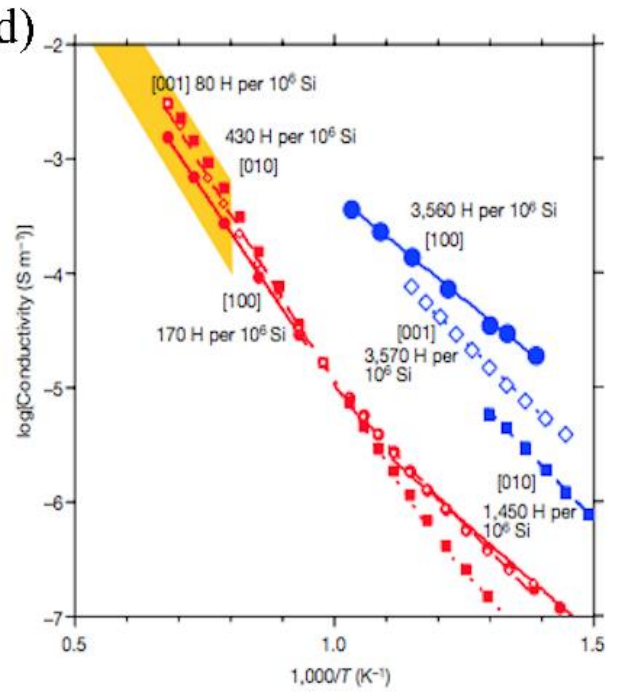

Figure 1.2: Comparisons of electrical conductivity response and models. a) results presented EC response as a function of water content at $800^{\circ} \mathrm{C}$ (from Jones et al., 2012). b) Shows the conductivity vs. temperature with series plotted based on determined water content (wt\%) (from Wang et al., 2006). c) Dry olivine dataset Yoshino et al., (2009), use to show conduction mechanism change, based on activation energy and inflection of EC response. d) Same as b), showing the conductivity vs. temperature with series plotted based on determined water content ( $\mathrm{H}$ per $10^{6} \mathrm{Si}$ ) (from Yoshino et al., 2006). 
olivines to up to $3 \mathrm{wt} \%$ water for ringwoodite. Hydrated olivine as a location for mantle water has predominantly been investigated by three laboratories associated with high-pressure studies. Namely the labs of Karato, (Wang et al., 2006), Yoshino (Yoshino et al., 2009 and Yoshino et al., 2012) and Poe, (Poe et al., 2010). Importantly though, there has been little investigation into the effect of composition, outside of iron content, and the effects that sample preparation may have on electrical conductivity measurements, making an investigation into the componentry of electrical conductivity of olivine a unique and interesting study.

\subsubsection{Recent electrical conductivity work:}

Much of the recent work in electrical conduction has been focused on hydrated olivine samples for the purpose of tracking the source of water within the Earth and using it to enhance geophysical imaging techniques. However, there are drastic discrepancies in the measured electrical conductivities of hydrated olivine, (Figure 1.2a), between the measurements generated at the laboratories listed above as has been reported in Jones et al. (2012). These four papers; (Wang et al., 2006; Poe et al., 2010; Yoshino et al., 2012; Jones et al., 2012); will form the basis of this investigation.

Electrical conductivity can be attributed to one or more models;

1) $\mathrm{H}^{+}$ions carrying the electrical charge, by a process called "proton hopping"

2) The charge moving in between electron vacancies, referred to as "small polaron" conduction or

3) "Ionic conduction", which involves an ion moving between sites via defects in the crystal lattice.

While all of these mechanisms contribute to conductivity, the magnitude of conductivity contribution will greatly vary, depending on the characteristics of the sample, such as, chemistry, grain size and grain boundary composition. In addition to these characteristics, specific conditions during experimentation like temperature, pressure and oxygen fugacity and annealing time also contribute to conductivity.

\subsubsection{Defect sites in Olivine:}

The constituent crystallographic defect sites that water resides at in olivine are primary for an accurate measurement of electrical conductivity in olivine. By understanding the 
mechanism by which these defect sites host water more accurate conductivity models of the Earth's interior are possible.

Olivine has the ability to encompass water at one of the four available locations. Of the four sites the most extensively covered is the $\mathrm{Fe}^{3+}$, (referred to as the trivalent), cation, as it is believed this is the preferential substitution site over $\mathrm{Al}^{3+}$ and $\mathrm{Ti}^{4+}$, (Berry et al., 2007a). The

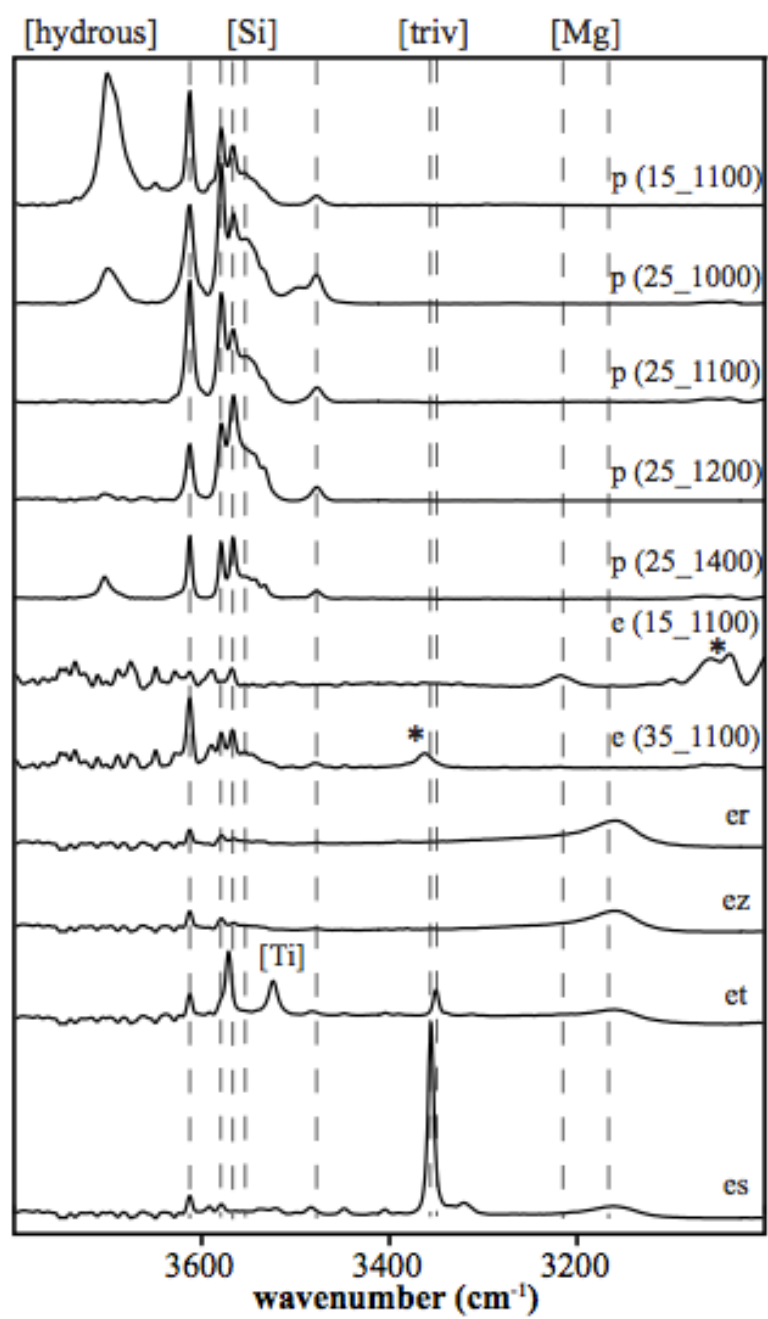

Figure 1.3: FTIR spectra taken from Kovács et al. (2010), showing the peaks identifying the individual sites. Sample names are located along the right of the figure, however, for the purposes of this paper they are not essential to note. Peaks with a wavenumber $>3614$ are considered hydrous serpentinisation and are not included in the measurements of conductivity. The peaks between wavenumber 3613 - 3535 may be considered to have water on the Si site. Trivalent peaks occur only in two of the samples and between wavenumber $3400-3300$. $\mathrm{Mg}$ peaks will occur below 3300 and primarily between wavenumber $3220-3160$. possible remaining locations are those of Ti point defects (within the lattice), and atomic Si or Mg sites with primary investigation of these sites included extensively in Berry et al., (2007a) and Berry et al., (2007b) as well as, to a lesser extent, Kovács et al., (2010).

There is also a distinct variation in the effective diffusion rate with the trivalent and $\mathrm{Mg}$ sites most readily jettisoning waters with Ti diffusion from clinohumite point defects operating an order of magnitude slower (PadónNavarta et al., 2014). Additionally, Padón-Navarta et al., (2014), shows that the Si water site is three orders slower than the $\mathrm{Mg}$ and therefore roughly two orders slower than the $\mathrm{Ti}$ site.

Temperature also appears to be a key control on the diffusion of water on any of the four sites especially when mantle temperatures of around $1000^{\circ} \mathrm{C}$ are reached with diffusion rates of $\mathrm{Si}$ slowing drastically, particularly if $\mathrm{Ti}$ values are low or zero, (Padón-Navarta et al., 2014). Despite slight disagreement with Padón-Navarta et 
al., (2014), Demouchy and Mackwell, (2006) present data suggesting diffusive anisotropy is present and the [001] axis is likely to dewater at a significantly faster rate compared with the [100] and [010].

Therefore it has been suggested that naturally occurring olivine is more likely to have waters encompassing Ti sites in clinohumite point defects, (Berry et al., 2005; Padón-Navarta et al., 2014, and references therein). However, there is also a reasonable possibility that the water sites of the trivalent cation and $\mathrm{Mg}$ site will diffuse water much more readily than the Ti sites. Hence, there is the potential for water to exist at depth in these sites within natural olivine, (Padón-Navarta et al., 2014, and references therein). Thus, there is a reasonable assumption that the likely sites for water in olivine is the trivalent i.e. $\mathrm{Fe}^{3+}$, and $\mathrm{Mg}^{2+}$ site, with the $\mathrm{Mg}^{2+}$ site being the more likely option.

Each of the four locations described above can be tracked using Fourier Transform Infrared, (FT-IR), spectroscopy, (Figure 1.3), as is the case in Berry et al., (2005). Alternatively, the total water content can be determined via the use of Secondary lon Mass Spectrometry (SIMS) (Kovács et al., 2010). The use of FT-IR in water content quantification requires calibration. There are currently three calibrations that are utilized; Paterson (Paterson, 1982), Rossman (Libowitzky and Rossman, 1997) or Bell, (Bell et al., 2003), with the Bell calibration being exclusively developed for crystal anisotropy, (Jones et al., 2012).

\subsubsection{Sample characterisation:}

Characterisation is the process of defining the underlying chemical and physical properties of the polycrystalline olivine samples. This is a key step particularly when working to differentiate between the modes (grain interiors vs. grain boundaries) of conduction. However, the characterisation of San Carlos olivine itself is poorly reported with contributions limited to works by Smyth and Frost, (2002), and Smyth et al., (2006), as well as brief statements in each of the contributions under examination; being, Wang et al, (2006), Poe et al., (2010), Yoshino et al., (2012), and Jones et al., (2012). This limits interpretation of electrical conductivity made by these contributions with the key parameters, being grain size, grain boundary width and pre- and post-experimental water contents, going largely unreported. There are further issues with respect to the characterisation of sample material relating specifically to the use of "clear inclusion free single crystals" (Wang et al., 2006; Yoshino et al., 2006; Yoshino et al., 2009; Yoshino et al., 2012; Dai and Karato, 2014a; Dai and Karato, 2014b). It is well reported that the San Carlos Peridot Mesa, within the San Carlos Volcanics, contains 
two groups of mantle xenoliths (Frey and Prinz, 1978; Galer and O'Nions, 1989; Uchida et al., 2005). Group one xenoliths are reported to be high Mg-olivine peridotites with orthopyroxene, $\mathrm{Cr}$-rich clinopyroxene as well as spinels (predominantly chromite-spinels), with highest modal proportion being olivine and lowest being spinel (Frey and Prinz, 1978; Galer and O'Nions, 1989). While group two xenoliths are far more variable with respect to modal proportion, but may be classified as being Fe, Ti rich clinopyroxene peridotites (Frey and Prinz, 1978). Further group two xenoliths are commonly much richer in large spinels $(<100$ $\mu \mathrm{m})$ as well as titanomagnetitie than group one. (Frey and Prinz, 1978). There is no mention of group one or two San Carlos xenoliths within the conductivity literature therefore it is unclear where the olivine sample originated within the San Carlos volcanic field

While FTIR is used in the characterisation of all samples investigated by the keynote papers, (Wang et al., 2006; Poe et al., 2010; Yoshino et al., 2012; Jones et al., 2012), SIMS is neglected and ideally would be used as part of the experimental procedure for all investigations into hydrous olivine to allow data assurance to the experimental community. This is not practical at this time given the lack of appropriate standards (Turner et al., 2015) as well as the intensive sample preparation and issues of surface water associated with in situ analysis (Kovács et al, 2010). Furthermore there is a distinct lack of standard with respect to SIMS and FTIR that must be developed to allow a measure of consistency across laboratories (Turner et al., 2015)

\subsubsection{Conductivity mechanism and measurement:}

There are multiple mechanisms of conductivity in hydrous olivine being; proton hopping, small polaron and ionic (Figure 1.2c) and each of the keynote papers highlighted here argues a slightly differing model with varying constraints.

The primary mechanisms suggested are proton hoping and small polaron conduction, however, it is considered that ionic conduction is the likely mechanism at high temperatures (Yoshino et al., 2006; Yoshino et al., 2009; Yoshino et al., 2012).

Proton hopping as a mechanism neglects the potential role of oxygen in the conduction with the assumption that the current will follow the path of $\mathrm{H}^{+}$ions. Proton hopping is the favoured mechanism by the Karato model (Wang et al., 2006), with very little consideration of the small polaron method. However, this is in contrast to other work in which it is believed to be primary the mechanism of conduction only below $1300 \mathrm{~K},\left(\sim 1023^{\circ} \mathrm{C}\right)$, (Yoshino et al., 2009; Poe et al., 2010; Yoshino et al., 2012; Jones et al., 2012). This may be due to the limited 
nature of the temperature range examined by Wang et al., (2006), and more recently by Dai and Karato, (2014a).

Small polaron conductivity is reported (Yoshino et al., 2006; Yoshino et al., 2009; Poe et al., 2010; Yoshino et al., 2012; and Jones et al., 2012) as the primary mechanism for anhydrous conduction in olivine and works by the charge moving between empty electron sites, termed in the literature as "electron holes".

Additionally in the context of this paper it is important to highlight that from $1300 \mathrm{~K}-1700$ $\mathrm{K},\left(1023^{\circ} \mathrm{C}-1423^{\circ} \mathrm{C}\right)$, it is perceived that small polaron conduction is the dominant mechanism with a slight period of change over as noted by Poe et al., (2010). In the most basic sense, however, it should be noted that this mechanism is not, as previously stated, covered in the contribution by Wang et al., (2006), due to the temperature range investigated during their experiments. The third mechanism of conduction, ionic conduction, that is considered the dominant mechanism by Yoshino et al., (2009), and Yoshino et al., (2012). Ionic conduction is depicted in Figure 1.2c to be present at high temperature and is accompanied by an activation enthalpy of $>2.0 \mathrm{eV}$. Further, Poe et al., (2010), states that this is unlikely to be the dominant mechanism as it occurs at much higher temperatures, $\left(\sim 2000 \mathrm{~K} / 1727^{\circ} \mathrm{C}\right)$, and up to $10 \mathrm{GPa}$.

Further, this temperature is much higher, $\left(\sim 100^{\circ} \mathrm{C}\right)$, than that expected in the average deep upper mantle or upper transition zone, suggesting that unless there were anomalous zones of high temperature this mechanism would not be present. In order to measure electrical conductivity of silicate minerals impedance spectroscopy must be used. Impedance spectroscopy works by applying an alternating current across the sample over a range of frequencies at a given temperature and pressure and measuring the response. Impedance has a real and imaginary component that are measured in addition to the frequency and plotted on a complex plane (sometimes referred to as a Cole-Cole plot or Nyquist diagram) (Karato and Wang, 2013). Importantly AC power is used in impedance spectroscopy, as opposed to DC, to avoid the current passing into the sample and forming a capacitor. Instead current is supplied through a wire, in the form of a flow/ oscillation of electrons, which pass into and through the sample and are measured by the opposing wires. The impedance can be represented quite by the equation:

$$
Z=\frac{R}{1+i \omega R C}
$$

Where $Z$ is the impedance, $C$ is the capacitor within the system, $i$ is the imaginary component of the complex plane, $\omega$ is the angular frequency and $R$ is the resister. The Cole- 
Cole plot can then be used to determine $R$, the resistance of the sample. This is done by utilising two components of the Cole-Cole plot, specifically the impedance magnitude, $|Z|$, and the phase degrees (angle), $\phi$, (Figure 1.4) that are measured by the impedance spectrometer. Once these values are measured they can be converted to a real $\left(Z_{\text {Real }}\right)$ and imaginary ( $\left.Z_{\text {Imaginary }}\right)$ (S.Table1) using basic trigonometry:

$$
\begin{aligned}
Z_{\text {Real }} & =\cos (\phi)|Z| \\
Z_{\text {Imaginary }} & =-\sin (\phi)|Z|
\end{aligned}
$$

Units for $|Z|$ are ohms and degrees for $\phi$.

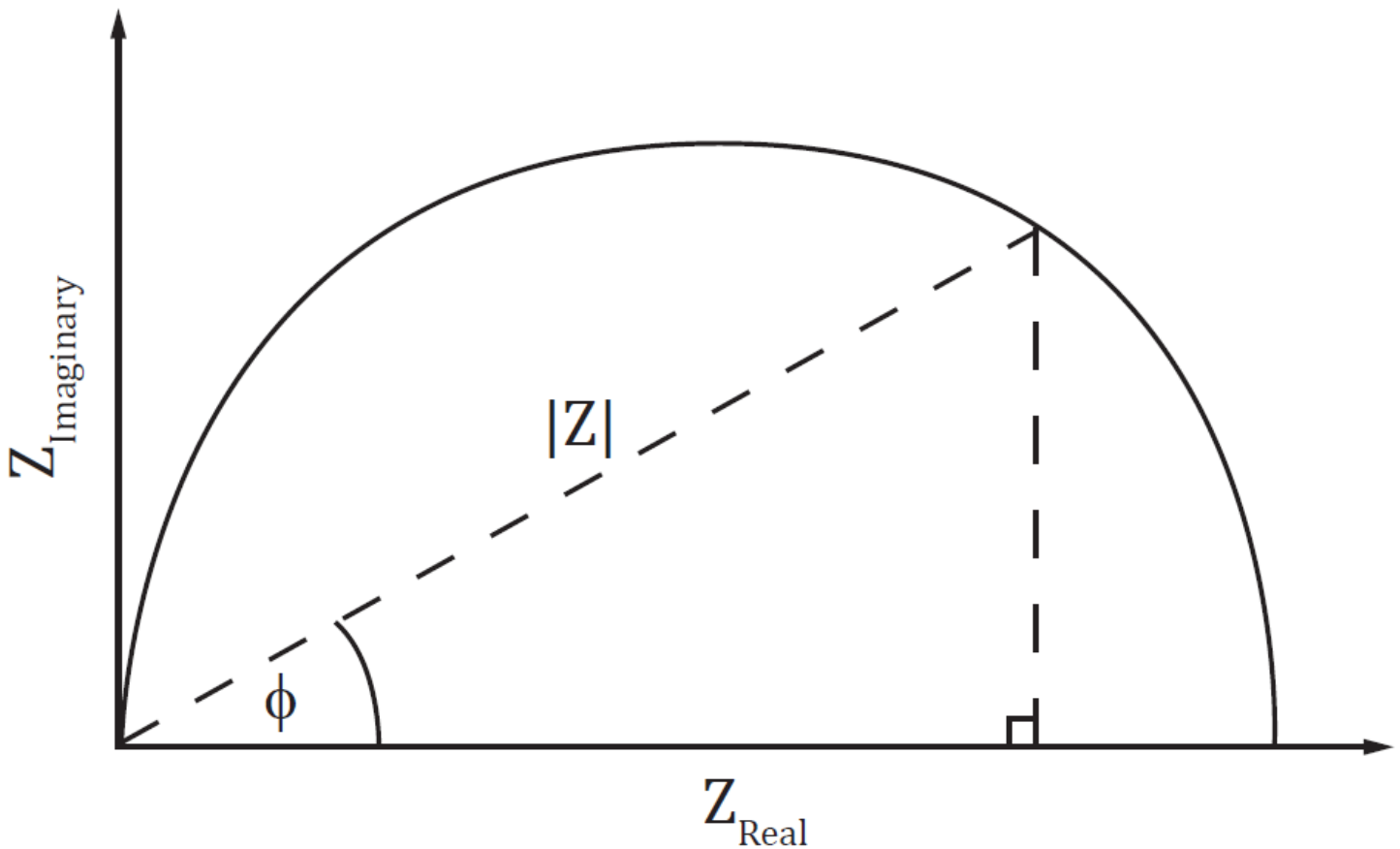

Figure 1.4: Theoretical Cole-Cole plot. As per eqs. 1.2 and 1.3, $|\mathrm{Z}|$ is the impedance magnitude (ohms) and $\phi$ is the phase degrees both of which are used to calculate real $\left(Z_{\text {Real }}\right)$ and imaginary ( $\left.Z_{\text {Imaginary }}\right)$ impedances.

\subsubsection{Important analytical considerations:}

This section draws heavily on the work of Jones et al., (2012).

Yoshino and Karato use two different equations to model proton conduction, $\sigma$ :

$$
\begin{gathered}
\sigma=\sigma_{0} C_{w} \exp \left(\frac{-\left(\Delta H-\alpha C_{w}^{1 / 3}\right)}{R T}\right) \\
\sigma=\sigma_{0} C_{w}^{r} \exp \left(-\frac{\Delta H}{R T}\right)
\end{gathered}
$$

The differences between the two equations are the water content term within the exponent in Yoshino's equation (1.4) and the power, $r$, in the water content term in Karato's 
equation (1.5). $\quad \alpha$ is closely linked with the water content, $(\mathrm{Cw})$, meaning this variable will strongly depend on the characterisation of the sample and an accurate knowledge of the $\mathrm{Cw}$. Additionally in the Yoshino model $\alpha$ is very small hence the effect of $\mathrm{Cw}$ on the magnitude of electrical conductivity is limited, effectively weakening this correlation.

Secondly, as previously mentioned there are three calibrations for water content. The specific calibration chosen will drastically affect the results. In the studies examined here Karato and Yoshino, (Wang et al., 2006; Yoshino et al., 2009; Yoshino et al., 2012), use Paterson's calibration while Poe uses the Bell calibration (Poe et al., 2010). The Bell calibration was developed to include the effect of crystal anisotropy, hence the reason why Poe et al., (2010), chooses this calibration, however, it also assigns the highest values, in some cases by a factor of 3 (Jones et al., 2012). This may explain why there are discrepancies in the measurements between Poe et al., (2010), and the other contributions. It does not, however, explain the order and a half of magnitude difference between the models of Karato and Yoshino, even after the initial revision of the Karato model, (Figure 1.2a).

The third consideration is the water content that is assumed by these contributions. After conversion to parts per million (ppm) Poe has the highest water contents, $360-2,000$ ppm, with Karato's samples ranging from $100-200$ ppm, Yoshino, however, has water contents mostly below 100 ppm, (Jones et al., 2012). As stated above, Yoshino's model utilises a low $\alpha$ to limit the dependence of electrical conductivity on the water content. This suggests that the contributions of Yoshino, namely Yoshino et al., (2009) and Yoshino et al., (2012), have grossly underestimated the true water content and activation energies subsequently suppressing the conductivity model generated.

Finally, there is an implicit analytical concern with respect to the ability of the contributions to thoroughly characterise the samples and understand the water content and therefore the electrical conductivities measured. Particularly the contributions of Wang et al., (2006), Yoshino et al., (2009) and Yoshino et al., (2009), that all use polycrystalline aggregates, this suggests Yoshino's model is not a realistic representation of the true mantle water content or electrical conductivity.

An additional concern to be considered is the role of using xenoliths as mantle proxies given the studies above suggesting diffusion of water from the two primary sites in olivine (Demouchy and Mackwell, 2006). This would therefore bring the methodology of Jones et al., (2012), in to question especially with respect to the use of the Gibeon and Jagersfontein xenoliths as proxies for mantle water. Jones et al., (2012), suggests the actual mantle 
conductivity lies somewhere between the values obtained by Wang et al., 2006 and Poe et al., (2010), (Figure 1.5d), and therefore supports the theory that the conductivity presented by the Yoshino model is simply too low.
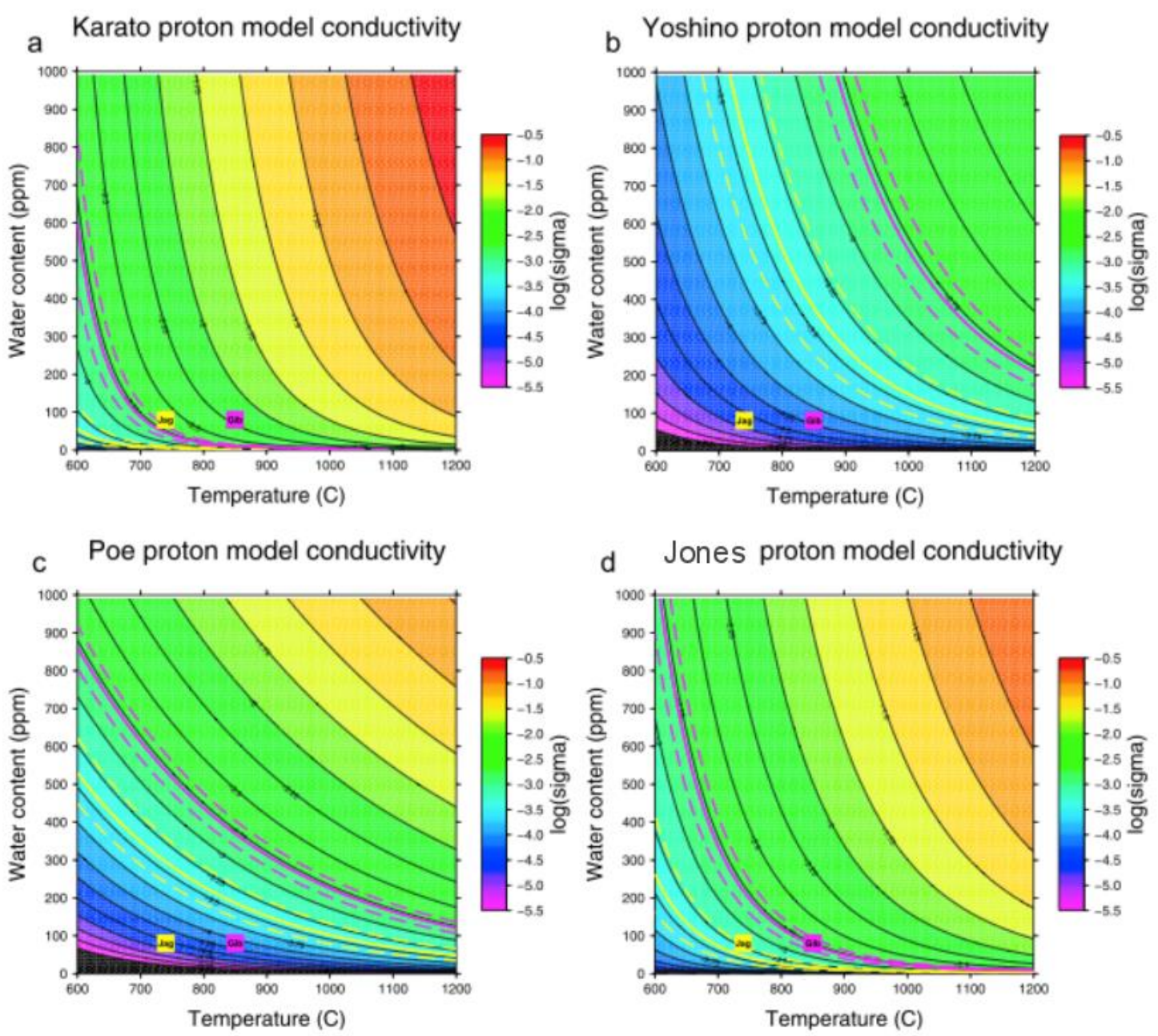

Figure 1.5: Proton conduction contour maps with water content and temperature up to $1,000 \mathrm{ppm}$ and $1,000^{\circ} \mathrm{C}$, respectively. a) Conductivity model suggested by Karato in a revised format from Wang et al., (2006). b) Yoshino conductivity model with contours showing the lower conductivity values presented in Yoshino et al., (2012), and reported in Jones et al., (2012). c) Poe model, (Poe et al., 2010), showing the Fullea et al., (2011), average, showing the mid-range conductivity profiles discussed below. d) Model of Jones et al., (2012), that is the midpoint between the models of Karato and Poe, showing contour gradient similar to Karato with conductivity slightly higher than Poe. Note the yellow and pink blocks represented on each plot are the Jagersfontein and Gibeon xenolith proxies as modelled by Jones et al., (2012). The solid lines in yellow and pink correspond to the xenolith of the same colour and represent the resistivity at $100 \mathrm{~km}$ depth, while the yellow and pink dashed lines represent the one-sigma error of the respective xenoliths. 


\subsubsection{Implications for Magnetotelluric investigations:}

Magnetotellurics (MT) is a passive measurement technique developed post-WWII (Cagniard, 1953) that utilises the Earths electric and magnetic fields to image the subsurface. Much like ambient seismic measurements MT stations are placed within field settings and left to record over long periods of time. However, the rollout of this type of large, continental scale array is expensive and is therefore generally undertaken by government organisations or institutes (See USArray and AusLAMP links in references).

Further, unlike seismic and gravity measurements, MT is much more sensitive to heterogeneities such as fluids, melts and areas of compositional variation as well as being unhindered by depth. These characteristics have made MT a desirable data acquisition technique particularly for mapping lithosphere architecture (Meqbel et al., 2014; Zhang et al.,
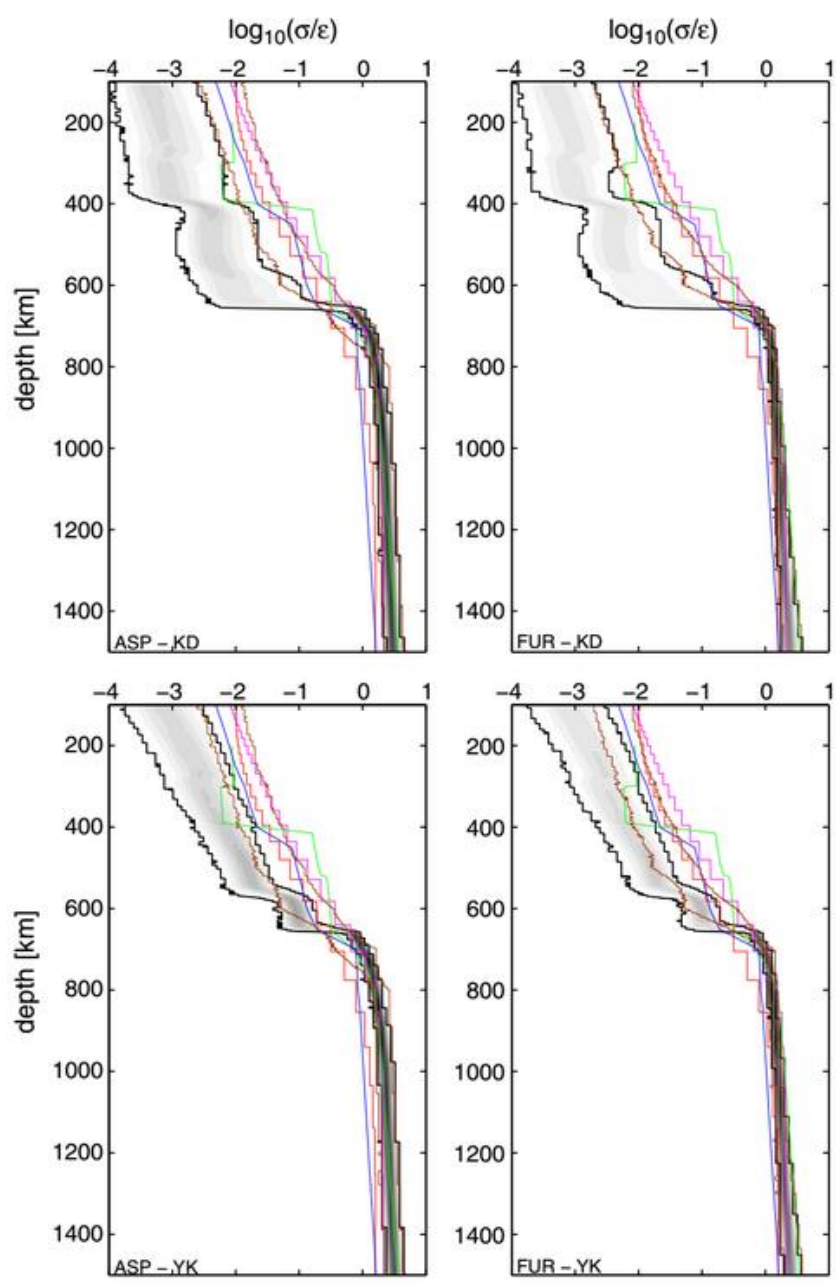

Figure 1.6: Comparison of conductivity models for Karato \& Dai (top row) and Yoshino \& Katsura (bottom row). Composition is fixed as per Table 10 of Kahn and Shankland (2012). Black lines indicate the range of $99 \%$ confidence, with coloured lines representing a number of 1-D models (see Kahn and Shankland, 2012). Contours within range of $99 \%$ certain are separated into 20 equal sized zones of probability density. Darker contour zones are the most probable to encompass the true value, with white contours least probable. Taken from Figure 7 of Kahn and Shankland, (2012). 
2015). The versatility of MT has also meant it can be used for a wide range of applications, not only within hydrocarbon and mineral exploration but also within the volcanology field as a tool to investigate magma build up (Ingham et al., 2009). However, for investigations to be successful there must be adequate understanding of the geology, including thermal, compositional and structural information.

This need for information is best exemplified by Figure 1.6, which shows the variation in conductivity as a function of depth between the labs of Yoshino and Karato (YK and KD datasets respectively). Figure $\mathbf{1 . 6}$ illustrates the immense difference in these two models independent of the other factors mentioned previously, being composition, thermal and structural. This large error, particularly within the upper portion of the mantle is the area of most concern especially given the uncertainty regarding water concentration and conduction mechanism (Kahn and Shankland, 2012). While the exact source of the error has not yet been determined within the experimental community it is the centre of ongoing debate.

\subsubsection{Summary:}

It is clear from the presentation of evidence in this paper that mantle conductivity is poorly understood and will require further work to reconcile the models presented.

The broader project will look to show the importance of understanding the initial sample conditions and choosing an appropriate water content calibration during the sample preparation stage. Further, it will show the need for more thorough understanding of sample source and petrography.

In spite of the issues mentioned previously there is a good understanding of the olivine water sites as well as the modes of conduction within the atomic structure. Also conductivity in hydrated olivine is likely to occur via proton conduction or small polaron conduction given the energy required to initiate ionic conduction. This is not to say that ionic conduction does not play a role, however, it is proposed only to exist within very small regions of the upper mantle where temperatures are above average.

Additionally it has been shown that there is no current model that adequately assesses olivine conductivity especially given the lack of agreement between the labs of Yoshino and Karato. The suggestion by Jones et al., (2012), that Poe's model is too low and Karato's is too high, is questionable as these models are not comparable given the lack of pre-experiment water content analysis by Poe et al., (2010) 
Finally it is also clear from the above contribution that there is a strong influence of temperature and water content on electrical conductivity measurements and mechanism, specifically relating to Figure $\mathbf{1 . 2 .}$

\subsection{Aims:}

In order to adequately assess the suitability and understanding of olivine conduction models this study proposes to fulfil a number of aims throughout the eight month (Masters of Research) duration. The first aim of this study is to recommission the 500 ton walker type MAA in the Macquarie University high-pressure laboratory. In order to undertake this aim this study intends to confirm or re-establish the high temperature pressure calibration of the MAA for the $18 \mathrm{~mm}$ octahedral edge length (OEL) and $11 \mathrm{~mm} \mathrm{WC}$ anvil truncation edge length (TEL). These are the sizes of octahedra and anvils respectively that will be used in the electrical conductivity experiments. As well as this a high temperature pressure calibration using the same assembly (i.e. an electrical conductivity cell) will be established.

The second aim is to look at using electrostatic rock disaggregation (ERD) to generate two samples from San Carlos peridotite, with one being processed using magnetic separation to isolate the olivine mineral, while the other will be placed into experiments largely unaltered. This process will be undertaken with the objective to develop an initial protocol for carrying out this method of mineral separation in the future.

The third aim is to carry out electrical conductivity measurements on the two samples generated using the ERD. This will be carried out after developing a working electrical conductivity cell capable of functioning at pressure in excess of $4 \mathrm{GPa}$ and $1273 \mathrm{~K}$ (i.e. upper mantle conditions). This cell will be developed by undertaking electrical conductivity measurements across the quartz polymorph series. Though in the interests of conciseness this quartz conductivity data will not be presented here.

The final aim is to compare data produced in this thesis with data collected by the major (Karato's and Yoshino's) laboratories. As part of this aim data reported here will be compared with published magnetotellurics data collected at a number of locations globally. 


\section{Experimental methods}

\subsection{Sample preparation:}

Powders were generated from large $(\sim 10 \mathrm{~mm})$ natural polycrystals, sourced from the San Carlos Peridot Mesa within the San Carlos volcanic field of the Apache reservation in south east Arizona, USA. Prior to crushing the natural polycrystals were analysed by reflected light microscopy and determined to have a mineralogy similar to that of the San Carlos Peridot Mesa, indicating a peridotite source. Composition is inferred from mineral abundance with the San Carlos peridotite displaying modal proportion; from most to least abundant, of olivine - orthopyroxene - clinopyroxene - spinels (Frey and Prinz, 1978; Galer and O'nions, 1989). Olivine typically displays Mg\# $>0.85$ and makes up $45-60 \%$ of the samples (Frey and Prinz, 1978; Galer and O’nions, 1989).

\subsubsection{Electrostatic Rock Disaggregation:}

The natural polycrystals were analysed using reflected light microscopy with mineralogy determined to be similar to that described in Frey and Prinz, (1978), for the peridotite xenoliths within the basalts of the San Carlos Peridot Mesa. Once examined under microscope sample was weighed into $200 \mathrm{~g}-400 \mathrm{~g}$ fractions and cleaned using water in preparation for electrostatic rock disaggregation (ERD). Electrostatic rock disaggregation was carried out in the Mineral Processing Unit of the CCFS at Macquarie University's Dept. of Earth and Planetary Sciences using a SelFrag (C electrostatic rock disaggregation unit. ERD takes advantage of the dielectric nature of grain boundaries by pulsing high voltage into the sample via a conductive medium. Once in the sample the current forms an intense, short lived (1-2 $\mu \mathrm{s})$ plasma $\left(>10,000^{\circ} \mathrm{C}\right)$ within the boundary region. The SelFrag@ ERD unit (Figure 2.1a,d) utilises a storage bank (capacitor) that is connected to an electrode. The electrode is placed within the conductive medium (in this case water) and separated from a grounding electrode by a gap of $19 \mathrm{~mm}$ (dependant on sample volume). The sample is placed within a metal vessel lined with an insulative polytetrafluoroethylene (PTFE/Teflon) plastic (Figure 2.1b and 2.1c). The base of the vessel is connected to the grounding electrode, at the base of the sample holder, and connects to a copper grounding coil fitted to the SelFrag( ) unit. This allows current to be recovered and reused. The natural polycrystals were placed within the ERD vessel fitted with a $0.7 \mathrm{~mm}$ sieve and immersed in water (i.e. the conductive medium). The vessel was then 
placed in the ERD unit, the electrode gap was set to $19 \mathrm{~mm}$, pulse frequency was set at $3.0 \mathrm{~Hz}$ and initial voltage was set at $110 \mathrm{~V}$. Voltage was then increased in $10 \mathrm{~V}$ intervals to $150 \mathrm{~V}$ where initial discharges were observed. Samples were inspected prior to each voltage increase with water being dirty water being replaced with clean water to encourage current to pass through the sample, and to limit material around the electrode. Discharges and pulses are counted by the SelFrag( $\$ with discharges indicating the current has passed through the sample and formed a plasma, while pulses indicate a misfire where current has passed around, rather than through, the sample. For each sample batch the number of discharges required for complete disaggregation was roughly equal to the weight of the sample (i.e. $200 \mathrm{~g} \approx 211$ discharges). To achieve 211 discharges 1193 pulses were required indicating the purity of the starting material. As the number of discharges increases so does the volume of sample falling through the sieve and being caught in the sample catcher.

The disaggregated sample was then wet-sieved using progressively finer screes from 800 $\mu \mathrm{m}$ down to $30 \mu \mathrm{m}$, fractions were dried at $393 \mathrm{~K}$ for $1 \mathrm{hr}$ and weighed with a representative batch presented in Table 2.1. Further microscopy was undertaken and the $30-300 \mu \mathrm{m}$

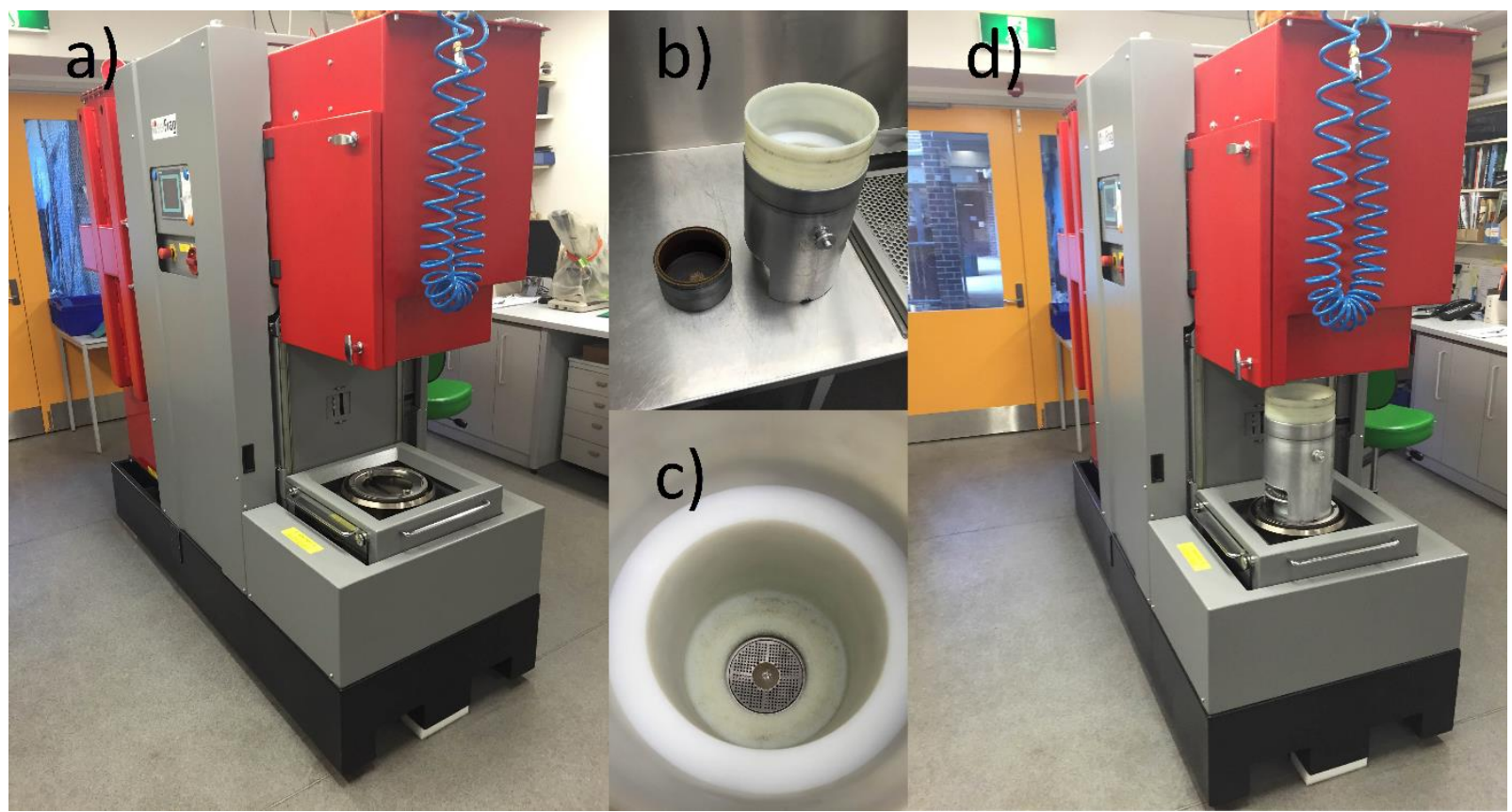

Figure 2.1: SelFrag( $\subseteq$ ERD unit. a) from left to right shows the capacitor (red) and control unit (grey), as well as the vessel platform. b) The sample catcher (left) and the sample vessel. The catcher is secured using two claw supports with the base of the vessel and is sealed by an 0 ring to prevent water draining during electrostatic pulsing. c) Top-view of the sample vessel with the sieve and grounding electrode installed. The lining is Teflon and therefore insulative. Sample is placed onto the metal sieve and arranged so as to not obstruct the electrode in the centre. $d$ ) The vessel is placed onto the platform before being raised to complete the circuit with the electrode and grounding coil that are housed directly above the platform. 
fraction was selected to be milled as a representative natural sample, specifically due to the $600-800 \mu \mathrm{m}$ being the most depleted in spinels and the $300-600 \mu \mathrm{m}$ fraction also being low in spinel. $30-300 \mu \mathrm{m}$ fraction was cleaned by ultrasonic bath in acetone for $\sim 5 \mathrm{~min}$ to remove any residue from processing by ERD. Sample was rinsed with acetone before being placed in an agate mill with five $20 \mathrm{~mm}$ diameter agate balls for $1 \mathrm{hr}$ at $200 \mathrm{rpm}$.

Table 2.1: Representative grain size after sieving and drying from electrostatic rock disaggregation.

\begin{tabular}{lcc}
\hline Sample weight $(\mathrm{g}):$ & 415 & Error: $+/-0.001 \mathrm{~g}$ \\
\hline Grain size $(\mu \mathrm{m})$ & Weight $(\mathrm{g})$ & $\%$ total \\
\hline $\mathbf{8 0 0 +}$ & 228.20 & $54.99 \%$ \\
\hline $\mathbf{6 0 0 - 8 0 0}$ & 33.70 & $8.12 \%$ \\
\hline $\mathbf{3 0 0 - 6 0 0}$ & 82.15 & $19.80 \%$ \\
\hline $\mathbf{0 - 3 0 0 \wedge}$ & 59.61 & $14.36 \%$ \\
\hline Other* & 0.00 & 0.00 \\
\hline Total: & 403.66 & $97.27 \%$ \\
\hline Loss: & 11.34 & $2.73 \%$
\end{tabular}

$\wedge$ All material below $30 \mu \mathrm{m}$ is expected to remain suspended in the water during wet-sieving and is therefore lost as the water is drained prior drying

* Other can be classified as sheet minerals and fine grained particles such as clays visible in the first ERD run. This material was absent in further runs due to extensive cleaning of sample prior to ERD.

\subsubsection{Magnetic separation:}

Once fractions were weighed the $600-800 \mu \mathrm{m}$ range was selected to be separated using a Frantz $@$ magnetic separator. Prior to paramagnetic separation using the Frantz $@$ magnetic separator (Figure 2.2) disaggregated grains were passed over by a stack of 10 high power neodymium magnets ( 5,000 Gauss) to remove ultramagnetic fraction. The ultramagnetic fraction is to be considered the most iron rich spinels with the less ferrous spinels then removed by hand as these minerals were considered to be a major contributor of Fe and would likely interfere with the Frantz@.

The remaining material, assumed to be olivine and pyroxene group minerals based on petrography, was passed through the Frantz @ with continually increasing voltage and current (Table 2.2). Initial mineral separation was at low current to remove any ultramagnetic minerals remaining, with the successive current increase removing the strongest 
paramagnetic minerals. Paramagnetic fractions were stored individually and weighed before being cleaned in acetone and an ultrasonic bath for $\sim 5 \mathrm{~min}$. Cleaned separates were rinsed using new acetone and placed in an agate mill with five $20 \mathrm{~mm}$ diameter agate balls. Acetone was added, the mill was then sealed run $1 \mathrm{hr}$ at $200 \mathrm{rpm}$.

The grain sizes of the powders were also measured using the optical microscope. A small sample of each powder were placed on a glass slide and had a drop of clear oil added to disperse the grains. The size of particles were measured using the calibrated configuration and determined to be homogenous and in the range of $3-10 \mu \mathrm{m}$ in size.

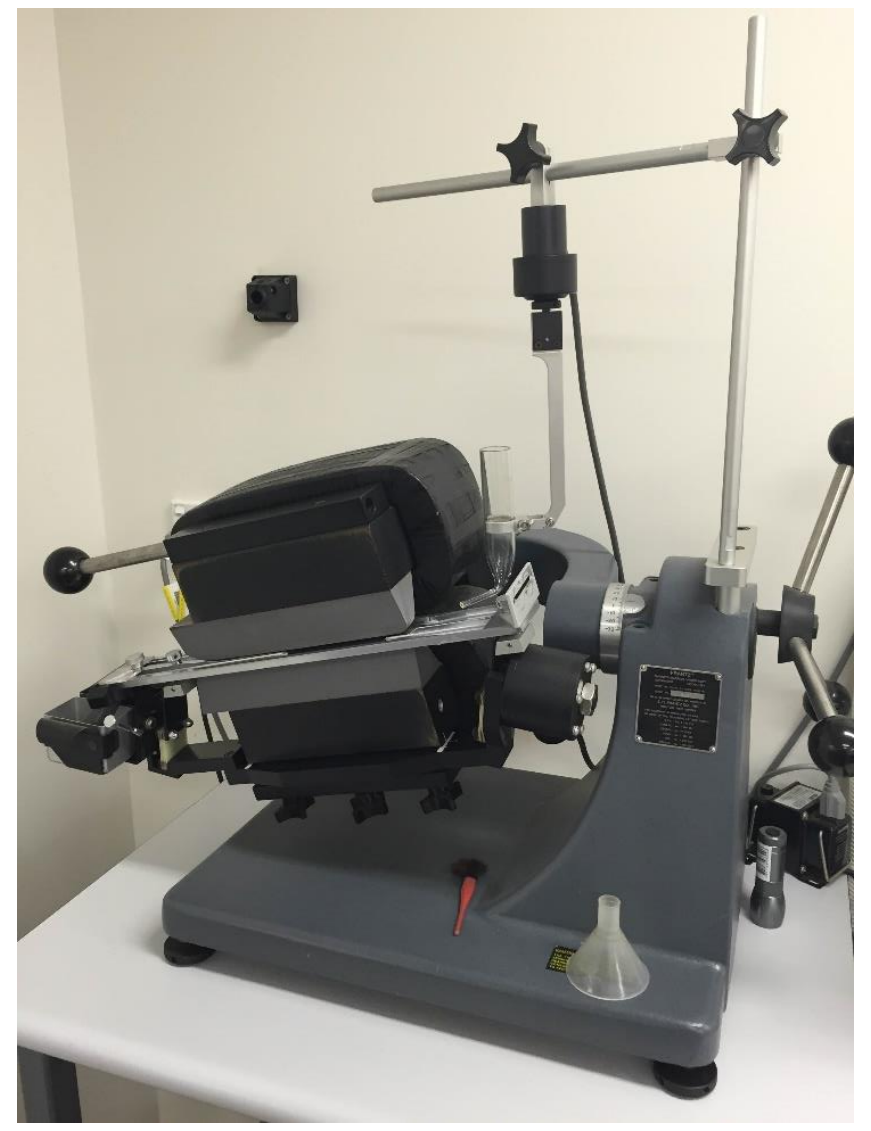

Figure 2.2: Frantz magnetic separator. Sample is placed in the glass feeder and vibrated slightly to encourage grains to fall. These move past the electromagnets above and below the channel and are separated. Nonmagnetic fraction falls to the left with the aid of the $10^{\circ}$ side slope. Magnetic fraction is carried along past the centre divider and is dropped into the magnetics catcher.

Table 2.2: Summary of Magnetic separation runs:

\begin{tabular}{lccccc}
\hline Fraction & $\#$ & Voltage & Current & $\begin{array}{c}\text { Side } \\
\text { slope }\end{array}$ & Forward slope \\
\hline Ultramagnetic & 1 & 4.0 & 0.03 & $10^{\circ}$ & $15^{\circ}$ \\
\hline Paramagnetic & 2 & 20.9 & $0.3^{*}$ & $10^{\circ}$ & $15^{\circ}$ \\
\hline Paramagnetic & 3 & 21.1 & $0.3^{*}$ & $10^{\circ}$ & $15^{\circ}$ \\
\hline Paramagnetic & 4 & 21.4 & $0.3^{*}$ & $10^{\circ}$ & $15^{\circ}$ \\
* The current was unchanged due to the properties of the material that will be \\
discussed in the results section.
\end{tabular}


All powders produced were stored in glass bottles in an oven at $393 \mathrm{~K}$ for a minimum of $12 \mathrm{hrs}$ before use in experiments to ensure unbound water was driven off. This was also to avoid undesired reaction within the sample during experimentation.

\subsection{Multi-Anvil Apparatus Calibration:}

The sample pressure within the Multi-Anvil Apparatus (MAA) is calibrated against the hydraulic oil pressure using a number of fixed point standards. Such standards are the transitions of bismuth that occur at 2.55 (I-III) and 7.7 GPa (III-IV) at ambient temperature. These are observed by conductivity measurements (Rubie, 1999). While these transitions are appropriate for calibrations at ambient temperature, additional calibrations are necessary at high temperatures. This is due to a reduction of sample pressure caused by the relaxation of the confining medium and an increase in pressure due to thermal pressure. These factors therefore make it hard to predict the effect of heating on the internal sample pressure. High temperature calibrations are normally carried out through quench experiments, utilising known and well defined phase transitions of minerals and compounds. To undertake the calibration of this 500-ton Walker type MAA (Figure 2.3) the quartz $\left(\mathrm{SiO}_{2}\right)$ polymorph series and Calcium Germanate $\left(\mathrm{CaGeO}_{3}\right)$ series were used in-line with the previous calibration in 2001 by Bernard J. Wood. As all experiments presented in this study were carried out at high temperature using the 18/11 assembly (18 $\mathrm{mm}$ octahedral edge length (OEL) and $11 \mathrm{~mm}$ WC anvil truncation edge length (TEL)) only the high temperature calibration for this assembly will be reported here.

Initial calibration experiments were carried out using calcium germanate $\left(\mathrm{CaGeO}_{3}\right)$ that has three phases that can be isolated at two transitions points (Figure 2.4). Of these three phases; $\mathrm{CaGeO}_{3}-$

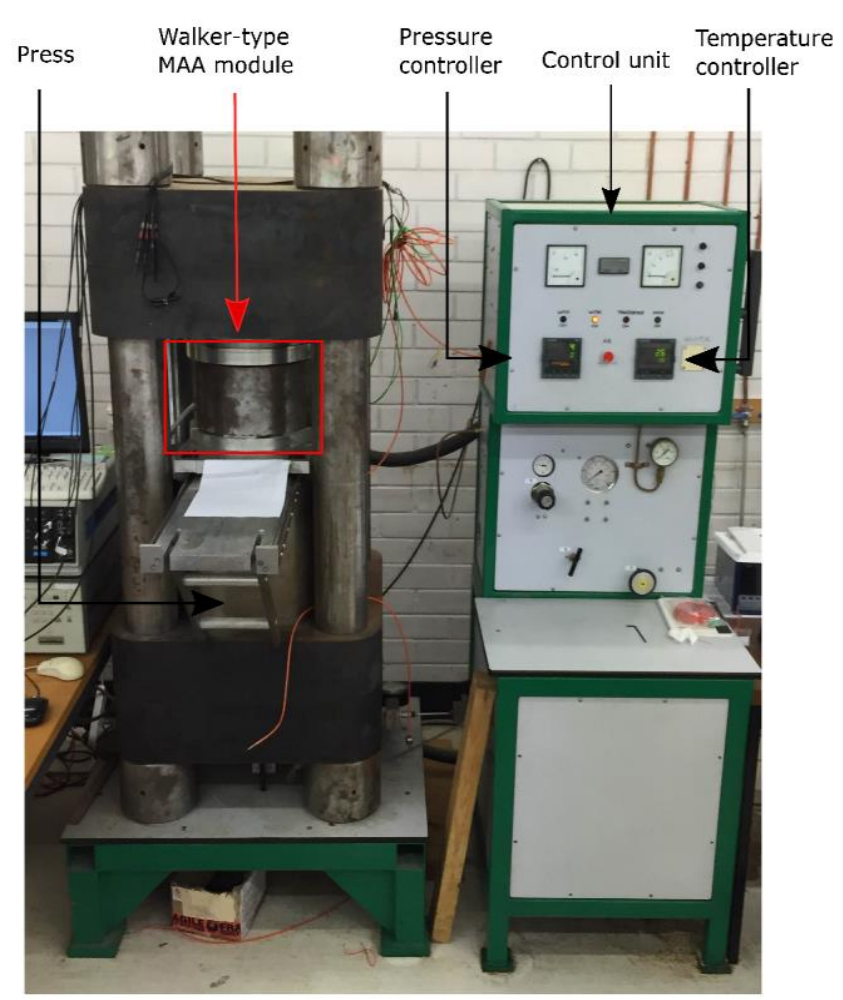

Figure 2.3: 500 ton press with 6-8 Walker type split cylinder multi-anvil. Black arrows show (right to left) the press ram, pressure controller, control unit and temperature controller. Red arrow and box indicate the Walker module. 
wollastonite, $\mathrm{CaGeO}_{3}$-garnet and $\mathrm{CaGeO}_{3}$-perovskite, the garnet to perovskite phase transition at $6.1 \mathrm{GPa}$ was the focus of calibrations. Further calibration experiments were carried out using quartz $\left(\mathrm{SiO}_{2}\right)$. Of the three phases (Figure 2.5) within the quartz system, namely quartz, coesite and stishovite the transition targeted was the coesite to stishovite (Coes-Stis) that occurs at $8.7 \mathrm{GPa}$.

The 6.1 and $8.7 \mathrm{GPa}$ transitions were focused on for a number of reasons. The first being that the previous calibration only included the $\mathrm{CaGeO}_{3}$ system and did not define the maximum sample pressure attainable with the 500 ton press, therefore the coesite-stishovite transition was needed. The second reason related specifically to the previous calibration. In order to confirm the calibration this study merely needed to generate the $\mathrm{CaGeO}_{3}$-garnet-

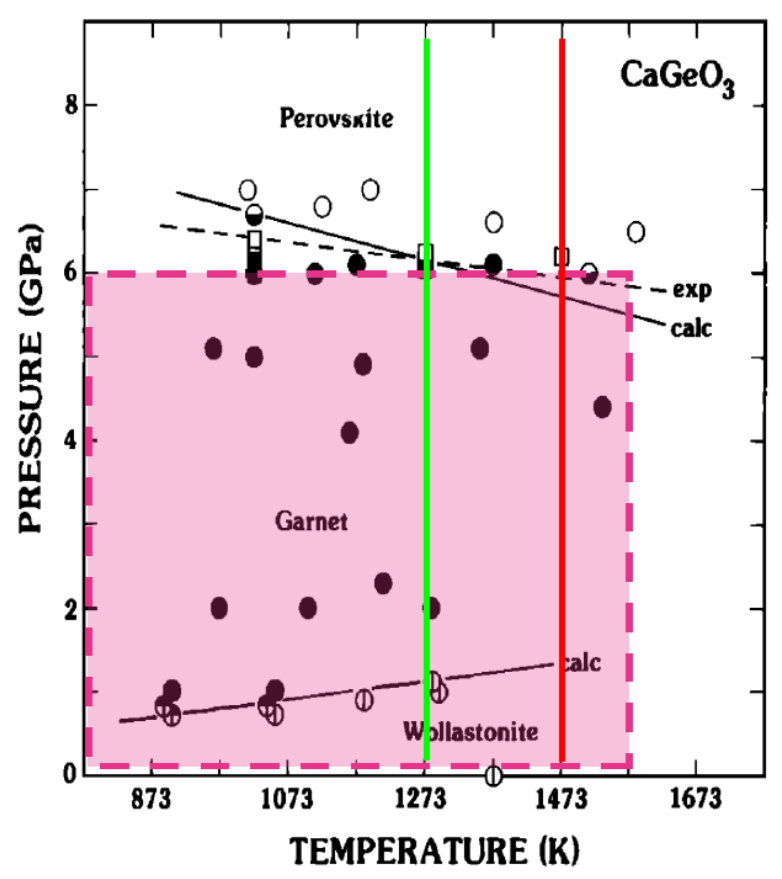

Figure 2.4: $\mathrm{CaGeO}_{3}$ phase diagram. This diagram presents results obtained in Ross et al., (1986) and determines the two transition points of the calcium germanate polymorph series. Light pink shaded area is the area of investigation for conductivity work presented here. Green and red lines dictate the $1000^{\circ} \mathrm{C}$ and $1200^{\circ} \mathrm{C}$ transition paths for $\mathrm{CaGeO}_{3}$ respectively. (after Ross et al., 1986).

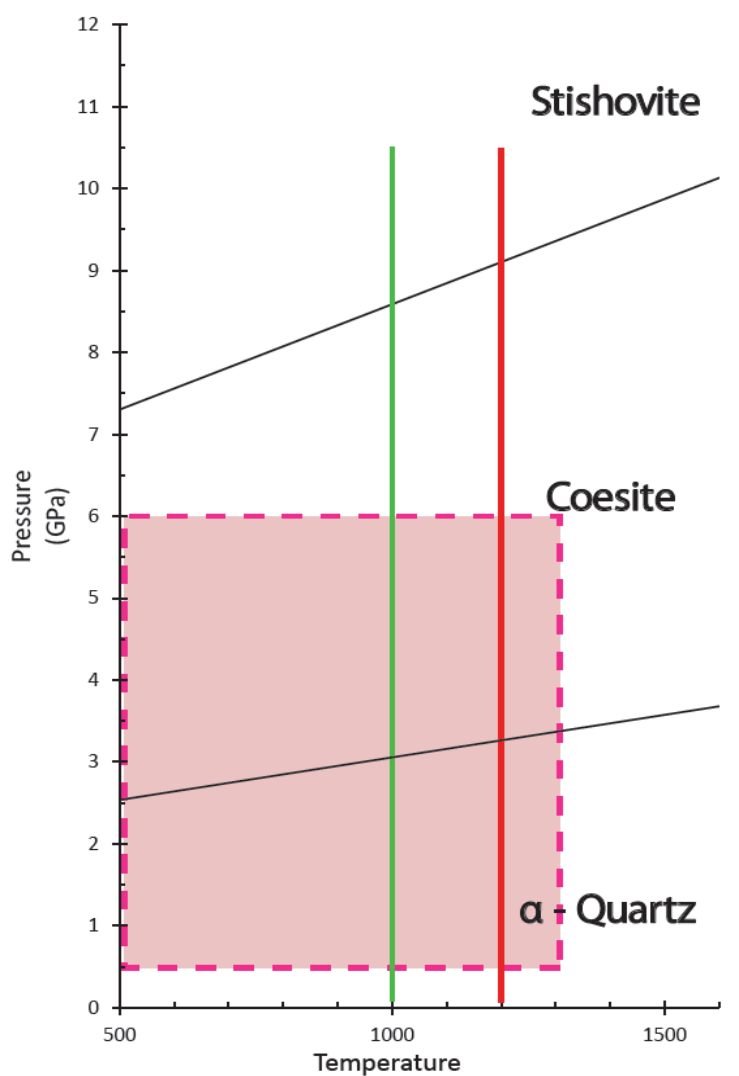

$\left({ }^{\circ} \mathrm{C}\right)$

Figure 2.5: $\mathrm{SiO}_{2}$ phase diagram. Phase as a function of temperature and pressure for the $\mathrm{SiO}_{2}$ (quartz) polymorph series. Light pink shaded area is the area of investigation for conductivity work presented here. Green and red lines dictate the $1000^{\circ} \mathrm{C}$ and $1200^{\circ} \mathrm{C}$ transition paths for $\mathrm{SiO}_{2}$ respectively. Data to form transition boundaries were sourced from Zhang et al., (1996) and references therein. 
perovskite transition at the same pressures. The final reason was that this study initially included a number of experiments undertaken at pressures of $6 \mathrm{GPa}$. However, due to a number of issues to be outlined in section 4, these experiments were not included.

\subsubsection{Calibration cell:}

A schematic of the cell assembly used in the calibration experiments is shown in Figure 2.6. The cell building process involved creating a capsule with dimension of $3 \times 2.5 \mathrm{~mm}$ using a $5 \times 12 \mathrm{~mm}, 50 \mu \mathrm{m}$ thickness, 99\% purity Pt foil (Goodfellows). With the aid of a pin, the Pt capsule was sealed on one end by folding and overlapping sections of the foil. Prior to filling the capsule with sample the capsule as well as the compression pins were cleaned with acetone in an ultrasonic bath for about $5 \mathrm{~min}$. Sample powder was then filled and compressed in the capsule using a specially designed jig to ensure sufficient sample volume. Once the powder was compressed to about $2.5 \mathrm{~mm}$ in length it was sealed by folding the remaining foil and flattened by lightly pressing with a steel pin. Pt was chosen as a lining material for a number of reasons. Firstly, it is a non-reactive metal and would allow a well-controlled sample environment. Secondly, platinum as a material acts as a barrier between the sample and the furnace helping to stop the exchange of volatiles and eliminate issues related to oxygen fugacity. Finally, it has a high thermal conductivity value, meaning the thermocouple placed
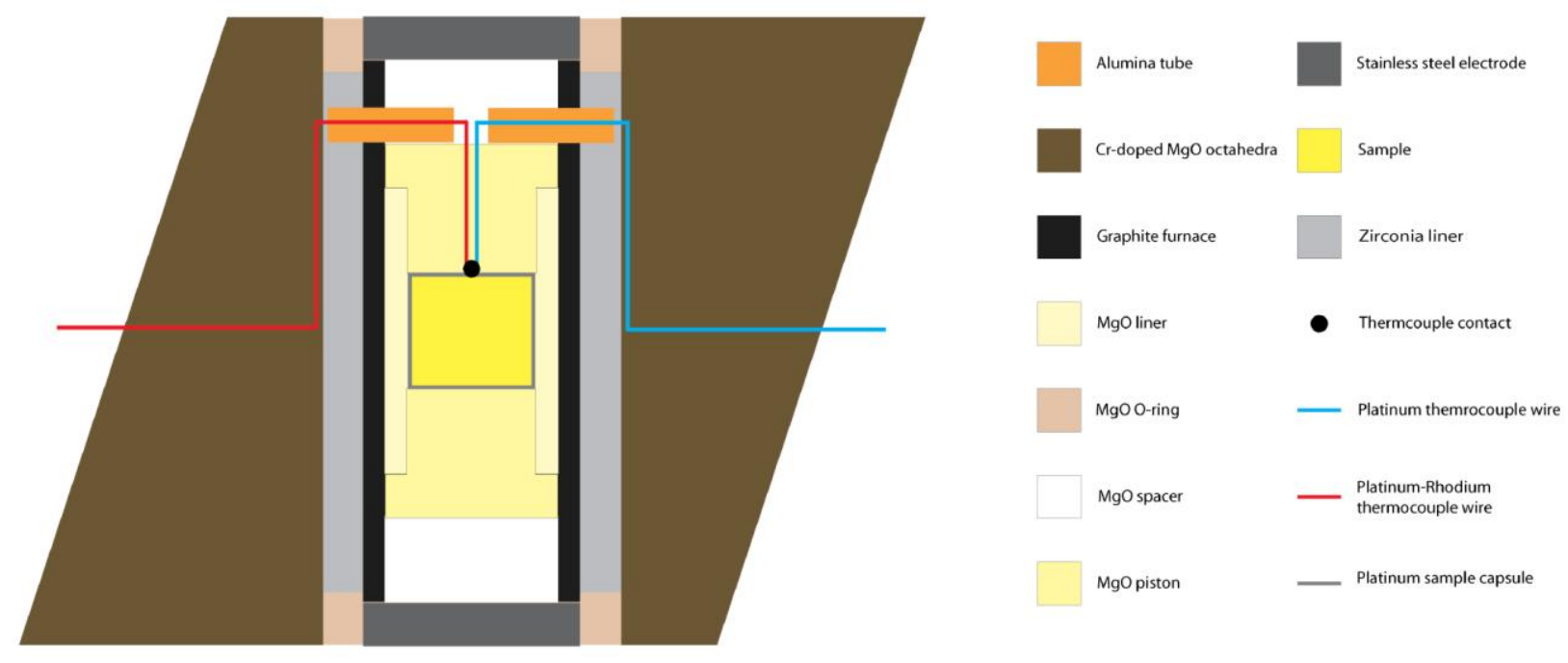

$5 \mathrm{~mm}$

Figure 2.6: Calibration cell schematic showing the configuration used to calibrate the 500-ton walker type MAA. Sample used was $\mathrm{CaGeO}_{3}$. An S-type thermocouple was used and is shown by the blue (Pt) and red (Pt-10\%Rh) wires that contact (black dot) near the exterior of the sample capsule. Thermocouple was isolated from the furnace by the MgO piston and alumina tubing. 
on the outside of the capsule would still be measuring a temperature within the realm of the actual sample.

An $18 \mathrm{~mm}$ truncated edge length (TEL), 5\% $\mathrm{Cr}_{2} \mathrm{O}_{3}$-doped $\mathrm{MgO}$ octahedron were used. Ceramic parts fit in a $7 \mathrm{~mm}$ hole in the octahedra. $\mathrm{ZrO}_{2}$ was used as a thermal insulation liner $(O D=7 \mathrm{~mm})$, graphite as the heating furnace $(O D=5 \mathrm{~mm})$ and an $\mathrm{MgO}$ sleeve $(O D=4 \mathrm{~mm})$ was used to insulate the sample capsule form the furnace. MgO pistons and spacers seal the capsule on both ends, with one piston housing an S-type (300 $\mu \mathrm{m}$ diameter $99.99 \%$ purity Pt and Pt-10\%Rh wires (Omega)) thermocouple (TC). The TC wires are insulated from the furnace using two alumina $\left(\mathrm{Al}_{2} \mathrm{O}_{3}\right)$ tubes sitting in grooves made through the graphite and $\mathrm{ZrO}_{2}$ sleeves. The TC fits within the octahedron in a channel cut parallel to the $\mathrm{ZrO}_{2}$ liner and is filled with a two-part $\mathrm{Al}_{2} \mathrm{O}_{3}$ cement mixture (Resbond (C) 940HT). The MgO spacer on the TC end is notched out to fit around the $\mathrm{Al}_{2} \mathrm{O}_{3}$ sleeves. The cell was sealed by stainless steel electrodes connected to the furnace, and held in place by an $\mathrm{MgO} O$-ring. The $\mathrm{Al}_{2} \mathrm{O}_{3}$ cement was used to fill any loose parts. The assembled cells were then placed into an oven at $393 \mathrm{~K}$ for a minimum of $15 \mathrm{~min}$ to set the cement. Completed cells were placed within eight WC anvils with a TEL of $11 \mathrm{~mm}$ with $3.4 \mathrm{~mm}$ thick pyrophyllite gaskets. Cells were then loaded into the 6-8 walker module and subjected to ram pressures of $200-500$ tons oil pressure and temperatures of $1273-$ $1473 \mathrm{~K}$, with the objective of mapping the garnet to perovskite phase transition in $\mathrm{CaGeO}_{3}$ at $6 \mathrm{GPa}$

\subsection{2 $\mathrm{SiO}_{2} \mathrm{EC}$ and calibration:}

Prior to olivine electrical conductivity measurements, electrical conductivity measurements were carried out on quartz as part of the multi-anvil calibration. Cell dimensions are similar to the cells depicted in Figure $\mathbf{2 . 6}$ to ensure internal consistency of measurements with the obvious exception of the sample chamber (Figure 2.7), and the addition of a second TC to allow electrical conductivity measurements using the impedance spectroscopy method. Quartz powder sample was packed into a capsule, which consisted of an $\mathrm{Al}_{2} \mathrm{O}_{3}$ sleeve with an ID of $1.6 \mathrm{~mm}$ and length of $2.5 \mathrm{~mm}$ that was closed at both ends by two $\mathrm{Ni}$ electrodes of $0.5 \mathrm{~mm}$ in thickness. The $\mathrm{Ni}$ electrodes had previously been oxidised by leaving them in an oven at $393 \mathrm{~K}$ for a minimum of $12 \mathrm{hrs}$. This was in order to prevent current leaking to the $\mathrm{Al}_{2} \mathrm{O}_{3}$ sleeve from the electrodes. The quartz powder was packed into the $\mathrm{Al}_{2} \mathrm{O}_{3}$ sleeve using utensils cleaned with acetone in order to avoid contamination. The powder was compressed using a $1.6 \mathrm{~mm}$ diameter pin. The completed capsules were stored in the oven so 
as to limit uptake of moisture. The TCs were fitted with coils made from the same wire that were $\sim 20 \mathrm{~mm}$ long, prepared by wrapping about 5 inches long of the wire around a $300 \mu \mathrm{m}$ diameter wire. The coils ensured continuity in the electric circuits in the event that the TC broke during the experiment. Two TC grooves were cut in to each end of the octahedron and were closed using the same $\mathrm{Al}_{2} \mathrm{O}_{3}$ cement. Similarly cells were cleaned of excess cement and placed in an oven for a minimum of $15 \mathrm{~min}$ at $393 \mathrm{~K}$ before being loaded.

200 gsm manila paper was glued on the faces of all anvils in order to prevent shorting between anvil and TC wires. Gaskets were marked and drilled with a $1.3 \mathrm{~mm}$ drill to allow the TC wires to transit the gasket Exposed coils were wrapped with PTFE (Teflon) tape and fed through the gaskets prior to being loaded in the MAA (Figure 2.8).

Cells were then loaded in the MAA and compressed to pressures ranging from 50 tons to 450 tons. Temperature was cycled from ambient ( $300 \mathrm{~K})$ to a maximum temperature of 1473 $\mathrm{K}$, with impedance spectroscopy measurements carried out at $100 \mathrm{~K}$ intervals. For each sample a minimum of two EC temperature cycles was taken, with a cycle comprising of an increase of temperature in $100 \mathrm{~K}$ intervals to the maximum temperature and the subsequent decrease in temperature at $100 \mathrm{~K}$ intervals to the minimum temperature. The pressure range was chosen to provide a supplementary calibration of the MAA at a maximum pressure of $8.7 \mathrm{GPa}$ as reported in the literature (Zhang et al., 1996).
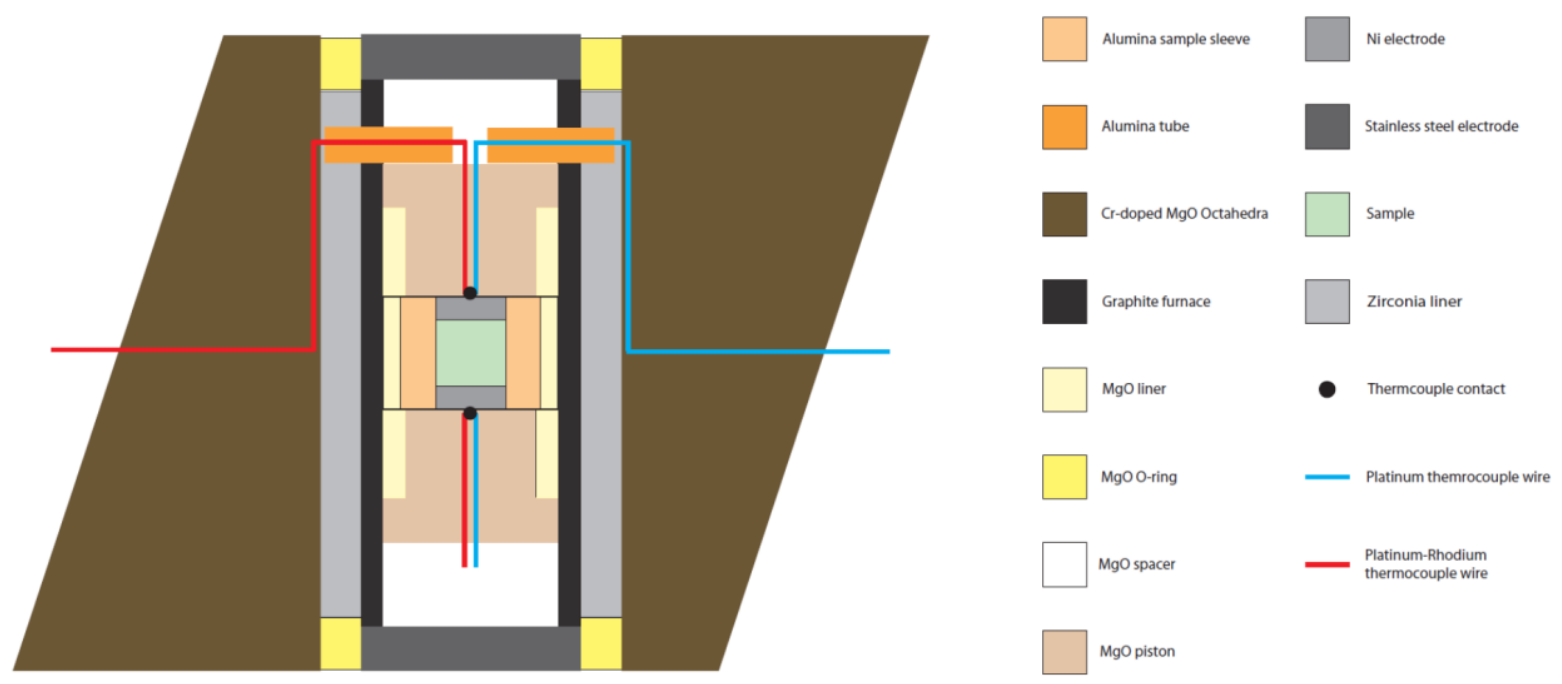

$5 \mathrm{~mm}$

Figure 2.7: Schematic of the electrical conductivity cell used for the HPHT experiments on quartz and olivine runs. Cell design differs with the alteration of the sample cell and also the extra thermocouple. Note: bottom TC would exit perpendicular to cross-section and is therefore only representative. 


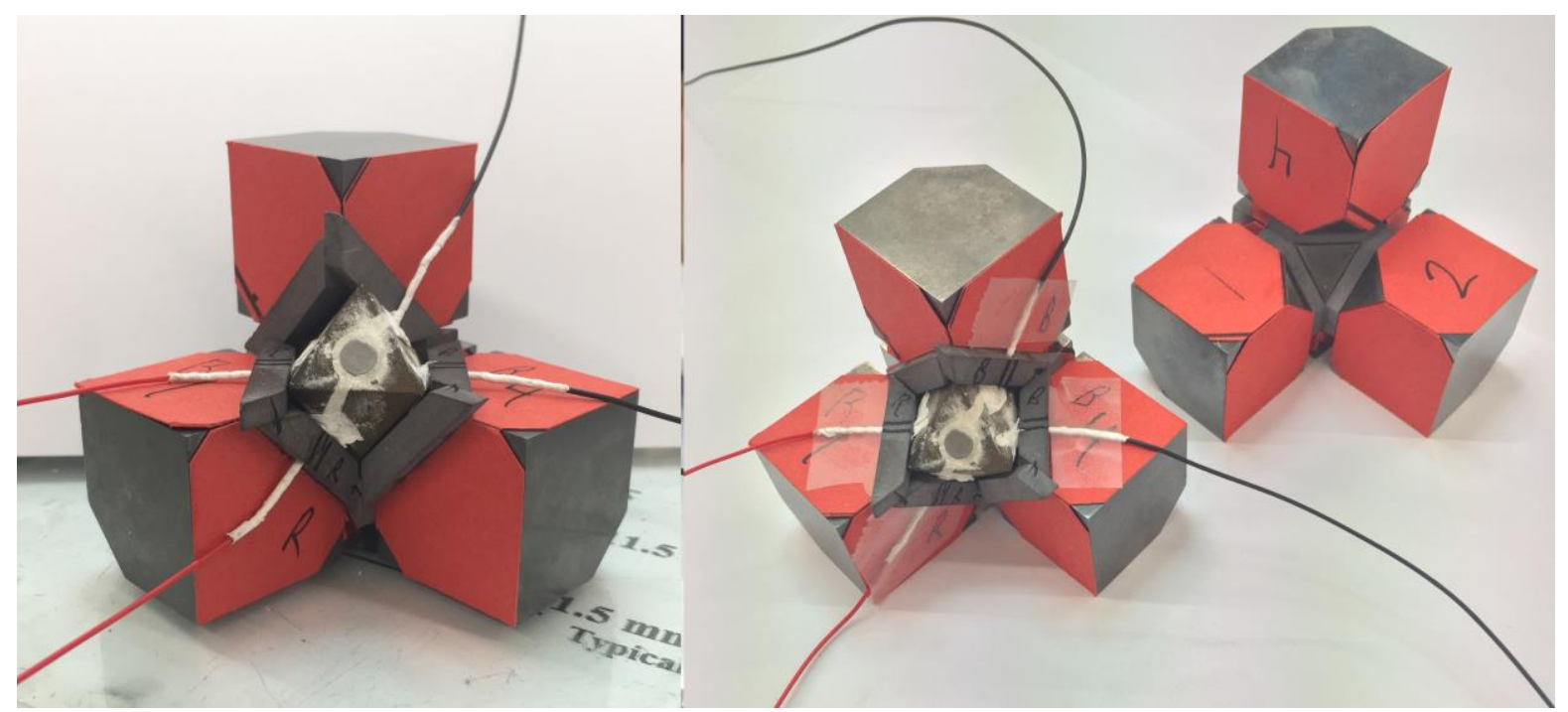

Figure 2.8: Completed (EC) cell in anvils and gaskets. Left: during the fitting process gaskets are fitted and TC transits are marked. The anvil (1 inch)+ in the top of the image was in the process of being marked for the $1.3 \mathrm{~mm}$ hole to accommodate the TC. Right: TCs are fitted secured to manila card using tape to avoid shearing during compression. Importantly this image illustrates the efforts undertaken to ensure isolation of the two circuits within the cell. Isolation is achieved as TCs and coils are encased in PTFE sheathing and PTFE tape. Further contact for heating is made on anvils with no thermocouples.

\subsection{Olivine EC measurement:}

EC of olivine was undertaken using the same cell (Figure 2.7) as that used in the quartz runs with the sample being the only difference. Two olivine samples were studied (Table 2.3). A minimum of two runs were carried out for each sample at different pressures (Table 2.3). Runs ranged from $50-200$ tons $(1-4 \mathrm{GPa})$ and temperatures from $300-1573 \mathrm{~K}$. Like with the quartz sample, a minimum of two EC cycles comprising of an increase and decrease of temperature were completed for each pressure. In some experiments four cycles were achieved. The success, and number of cycles carried out depended heavily on the rough estimation of impedance values in the course of the temperature cycling through the experiment. This is because the sample is believed to change during the experiments based on temperature.

Table 2.3: Summary of high pressure runs on olivine samples.

\begin{tabular}{cccc}
\hline \hline \multirow{2}{*}{ Sample } & \multicolumn{2}{c}{ Pressure } & \multirow{2}{*}{ Experiment } \\
\cline { 2 - 3 } & GPa & Tons & MQ029 \\
\hline San Carlos & 1 & 50 & MQ034 \\
peridotite (SCP) & 4 & 200 & MQ039 \\
\hline Separated San & 1 & 50 & MQ037 \\
Carlos Olivine (SSCO) & 4 & 200 & \\
\hline \hline
\end{tabular}


2.4 Impedance spectroscopy and curve fitting:

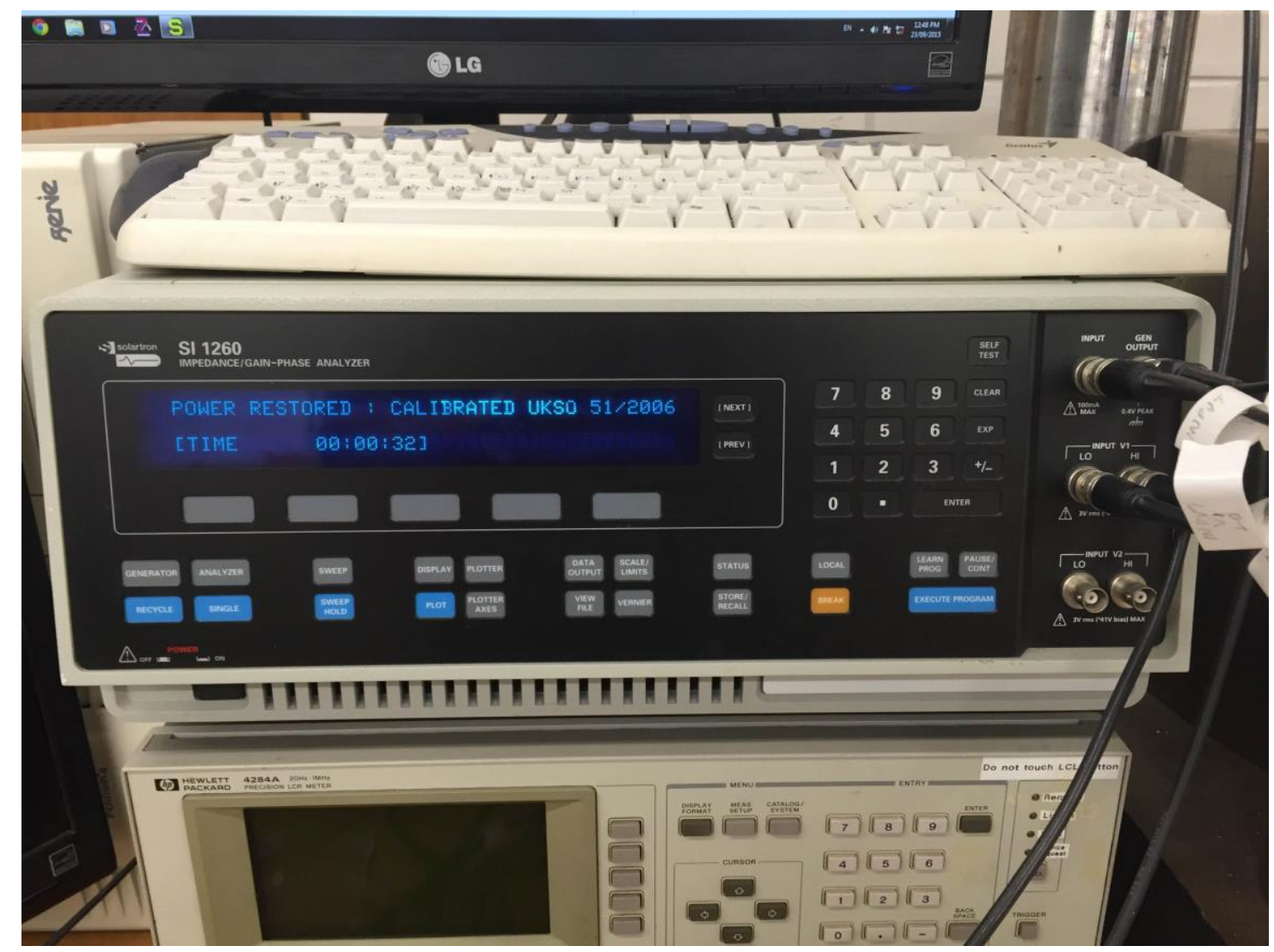

Figure 2.9: Solartron 1260A impedance/ Phase-Gain analyser located in the high-pressure laboratory, Macquarie University. During experimentation the four black leads to the right of this image are connected in sets of two (one upper and one lower) to opposing TC wires to measure impedance across the sample. Frequency range, magnitude and time are displayed on the LED screen during measurement.

Impedance spectroscopy measurements were carried out at temperature intervals of 100 K. Measurement involved connecting one wire of each TC, on opposing ends of the sample, to the inputs of the impedance spectrometer (Figure 2.9). The impedance data was collected using $1 \mathrm{~V} \mathrm{AC}$ across a range of frequencies, which varied based on the number of cycles completed. For the measurements taken during the first temperature increase a frequency range of between $1 \mathrm{MHz}-1 \mathrm{~Hz}$ was used in order to capture the full range of impedances within the sample. The first temperature decreases were generally measured using a frequency range of $1 \mathrm{MHz}-10 \mathrm{~Hz}$, as was the case for the entire second cycle, primarily due to the sample having been annealed at this point in the experiment. For experiments with more than two full cycles frequencies scanned were only changed on individual basis when data were noisy at low frequency. During these times data was collected over a frequency 
range of $1 \mathrm{MHz}-100 \mathrm{~Hz}$, however this was a rare occurrence. All measurements regardless of frequency range involved collecting 10 data points per decade (i.e. 10 data points per $\log _{10}$ frequency), with the exception of initial impedance experiments.

Data was logged by the SMaRTC v.3.3.1 software freely available from Solartron Analytical (CAMTEK), as program specific data files. Upon completion of the experiment the data files were converted to CSV and then Excel format. The impedance magnitude and phase at each frequency was used to calculate the real and imaginary impedances (Figure 1.4). Once impedance values were calculated data were imported into EIS Spectrum Analyser and fitted based on an equivalent circuit that represented the experiment. The fitting process involved removing erroneous data points determined to be noise and initial assignment of maximum resistance values (Figure 2.10).
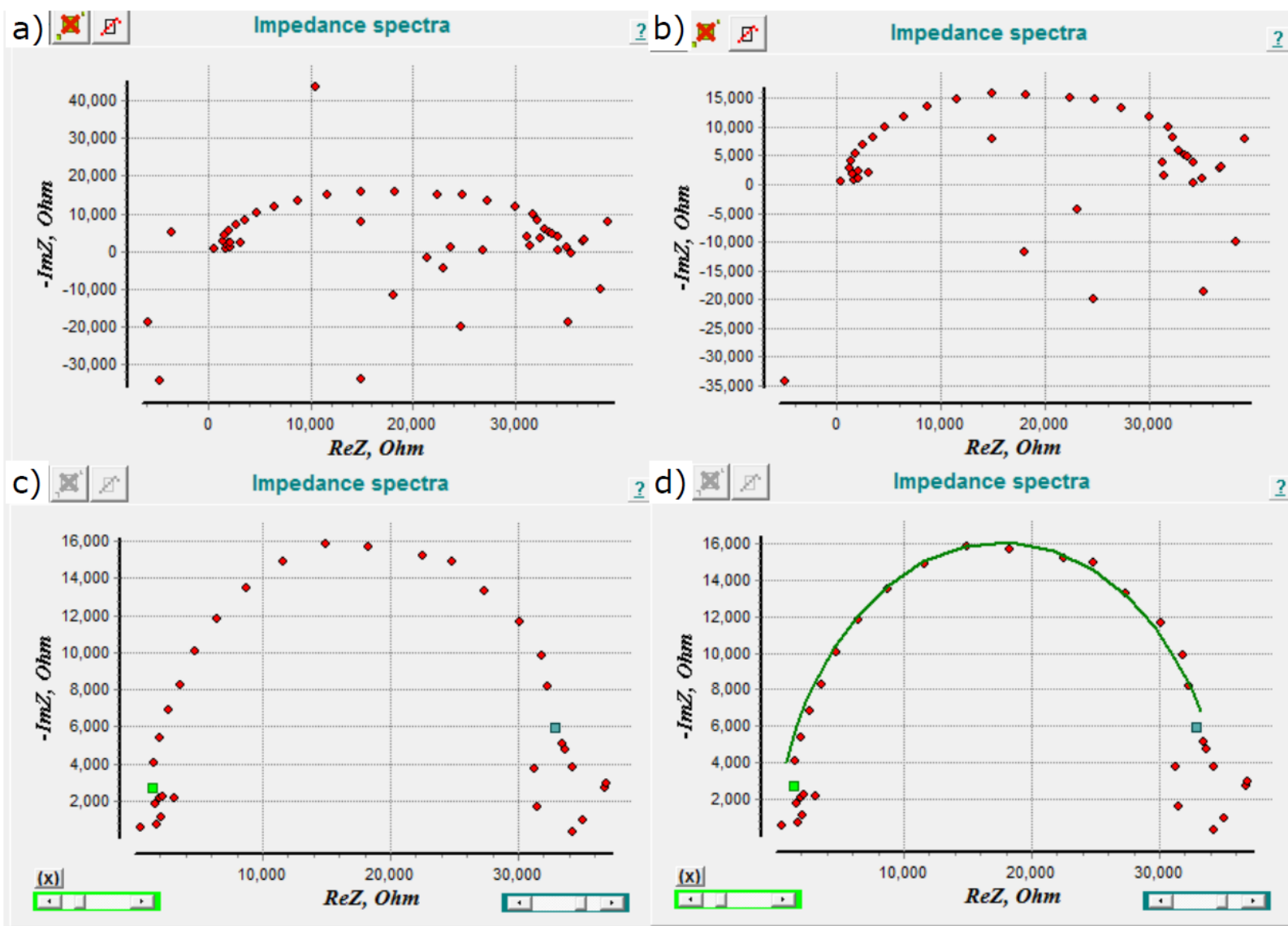

$\stackrel{?}{\text { d) }}$

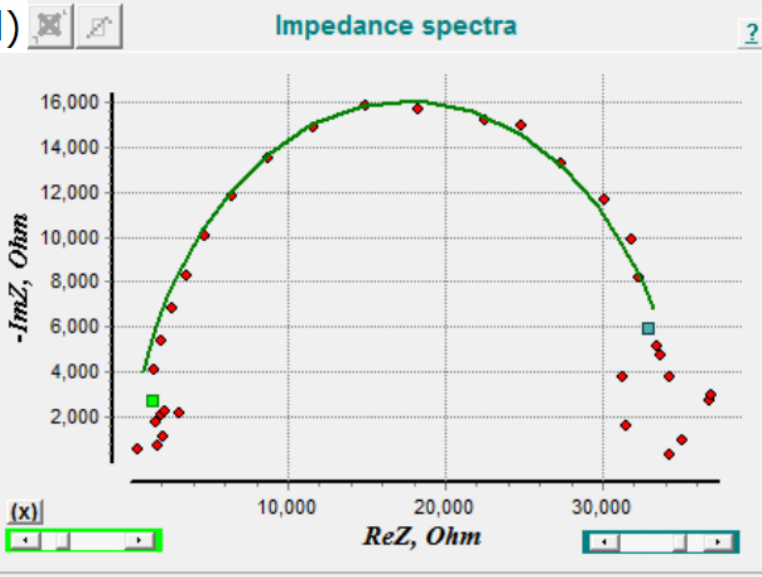

Figure 2.10: Illustration of the fitting process. a) The initial spectral input shows intense negative values in both real and imaginary impedance. b) Removal of points deemed to be erroneous. This section of the fitting process is undertaken with constant cross-referencing between the EIS program and the SMaRT data acquisition software to ensure only erroneous points are removed. c) Shows the spectra to be fitted using the EIS fitting program, with all negative data points removed. Green and Teal boxes are the limits of fitting with data below these boxes not included in the final fit. $d$ ) Fitted spectra showing a reasonable fit with error calculated by the fitting program to be $1.8 \%$. 


\subsection{Post experiment sample prep:}

After experiment anvils were removed individually and contact faces were inspected. In addition to inspecting contact faces for damage, gaskets were inspected for exposed wire or any signs of shorting. Once inspected anvils were placed aside for cleaning and reuse, as well as the cell having gasket fins removed and TCs cut off. Recovered cells were then placed inside 1" epoxy moulds and covered with EpoThin ${ }^{\mathrm{TM}} 2$ (Buehler) two-part epoxy and left to cure for a minimum of $9 \mathrm{hrs}$.

Once cured mounts were marked and cut to create a profile section (Figure 2.11, following page) similar to the schematic presented earlier (Figure 2.6 and 2.7). Cells were cut using a Thermofisher low speed diamond saw with a 4" $x$ 0.012" diamond wheel (South Bay Technology). Polishing was then undertaken using wet/dry abrasive papers increasing in grit from 400 - 2000. EC cells were polished in intervals with electrode diameter measured at each stage with the aim of reaching the cross-section at the centre of the sample. Further polishing was undertaken on samples requiring SEM or EPMA, however these will be discussed in the appropriate section. 


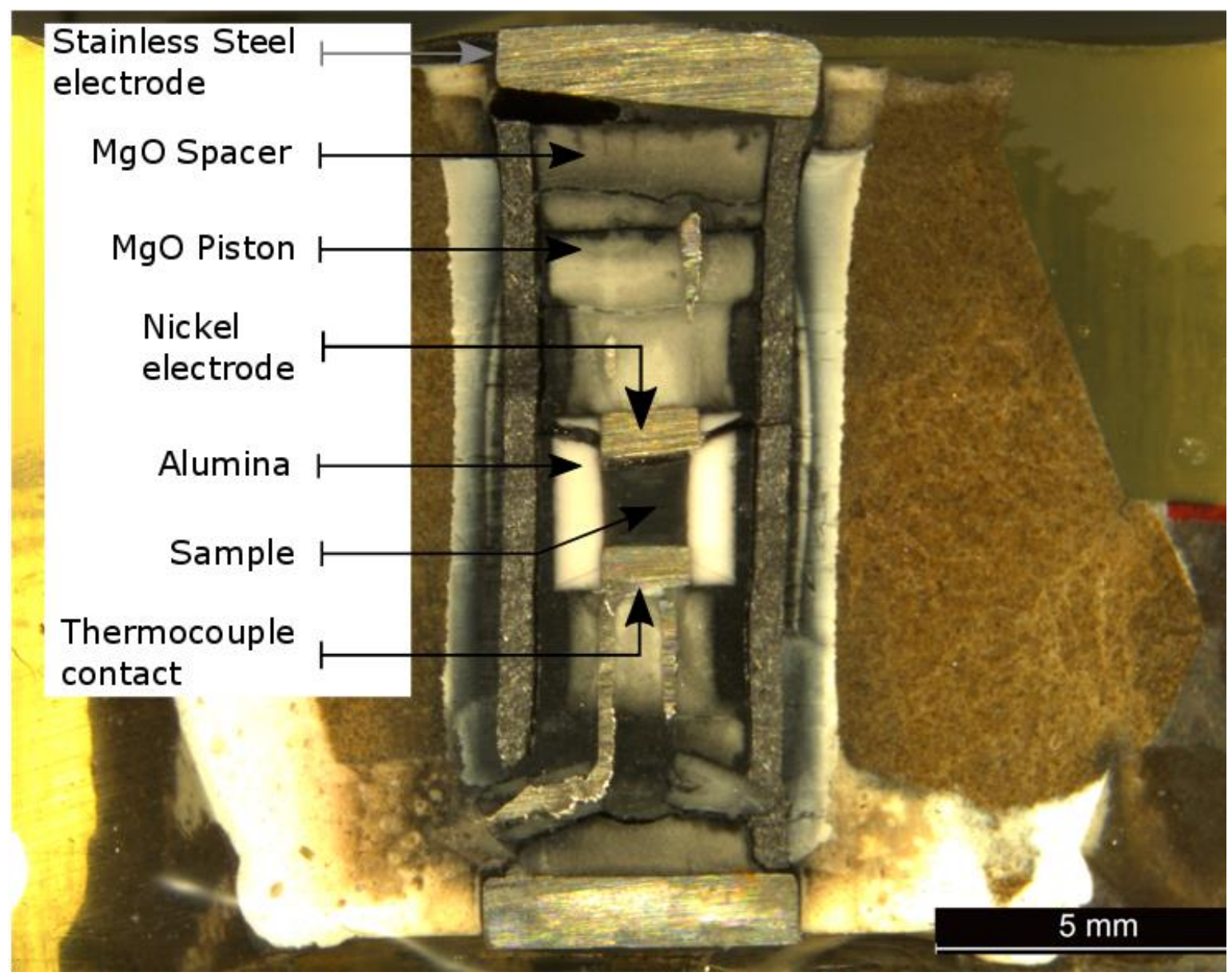

Figure 2.11: Cross-sectional view of EC cell post experiment. Brown matrix is the $5 \% \mathrm{Cr}_{2} \mathrm{O}_{3}$ doped MgO Octahedra, components not labelled include the MgO liner, graphite furnace and $\mathrm{ZrO}_{2}$ liner which are visible left to right from the alumina. White material surrounding stainless steel electrode is the ResbondC $940 \mathrm{HT} \mathrm{Al}_{2} \mathrm{O}_{3}$ cement 


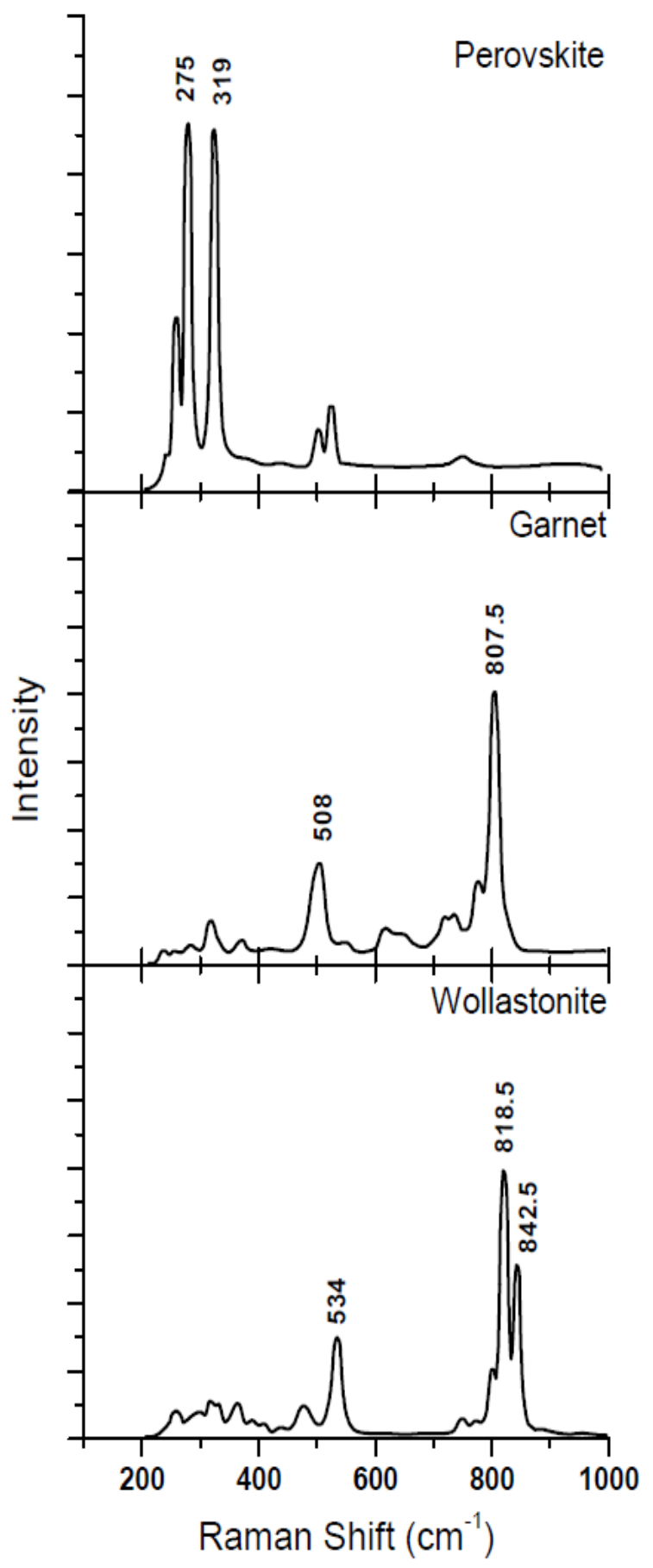

Figure 2.12: Shows the characteristic Raman spectra for the $\mathrm{CaGeO}_{3}$ polymorph series. Plots are labelled with phase: wollastonite, garnet and perovskite. The major peaks occurring at $818.5 \mathrm{~cm}^{-}$ ${ }^{1}$ for wollastonite, $807 \mathrm{~cm}^{-1}$ for garnet and twin peaks of 275 and $319 \mathrm{~cm}^{-1}$ for the perovskite phase. Additional peaks are labelled on the plots accordingly. Data taken from Ross et al., 1986

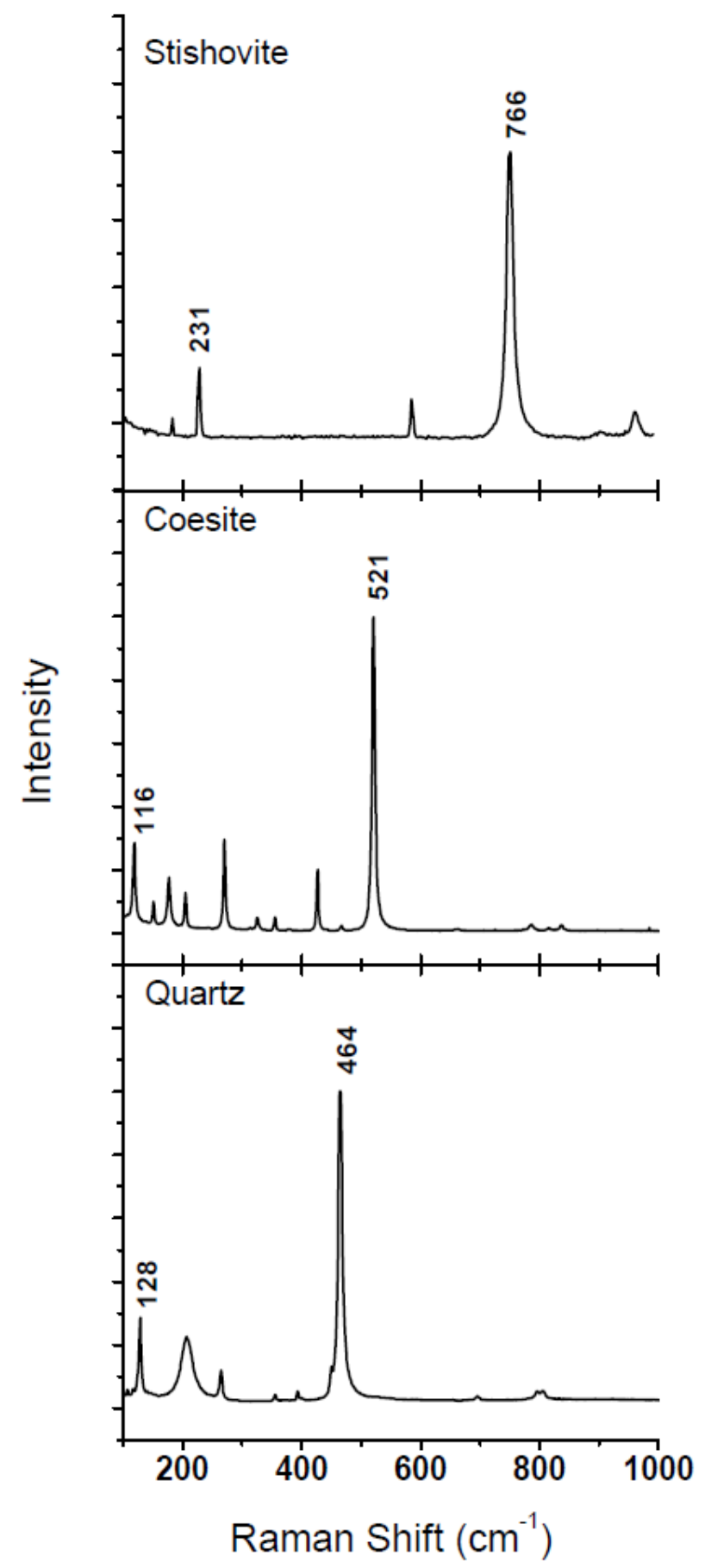

Figure 2.13: Showing Raman spectra for the $\mathrm{SiO}_{2}$ polymorph series. Major peaks are 464, 521 and $766 \mathrm{~cm}^{-1}$ for quartz, coesite and stishovite respectively. Data for this figure was obtained from the Lyon Raman database. 


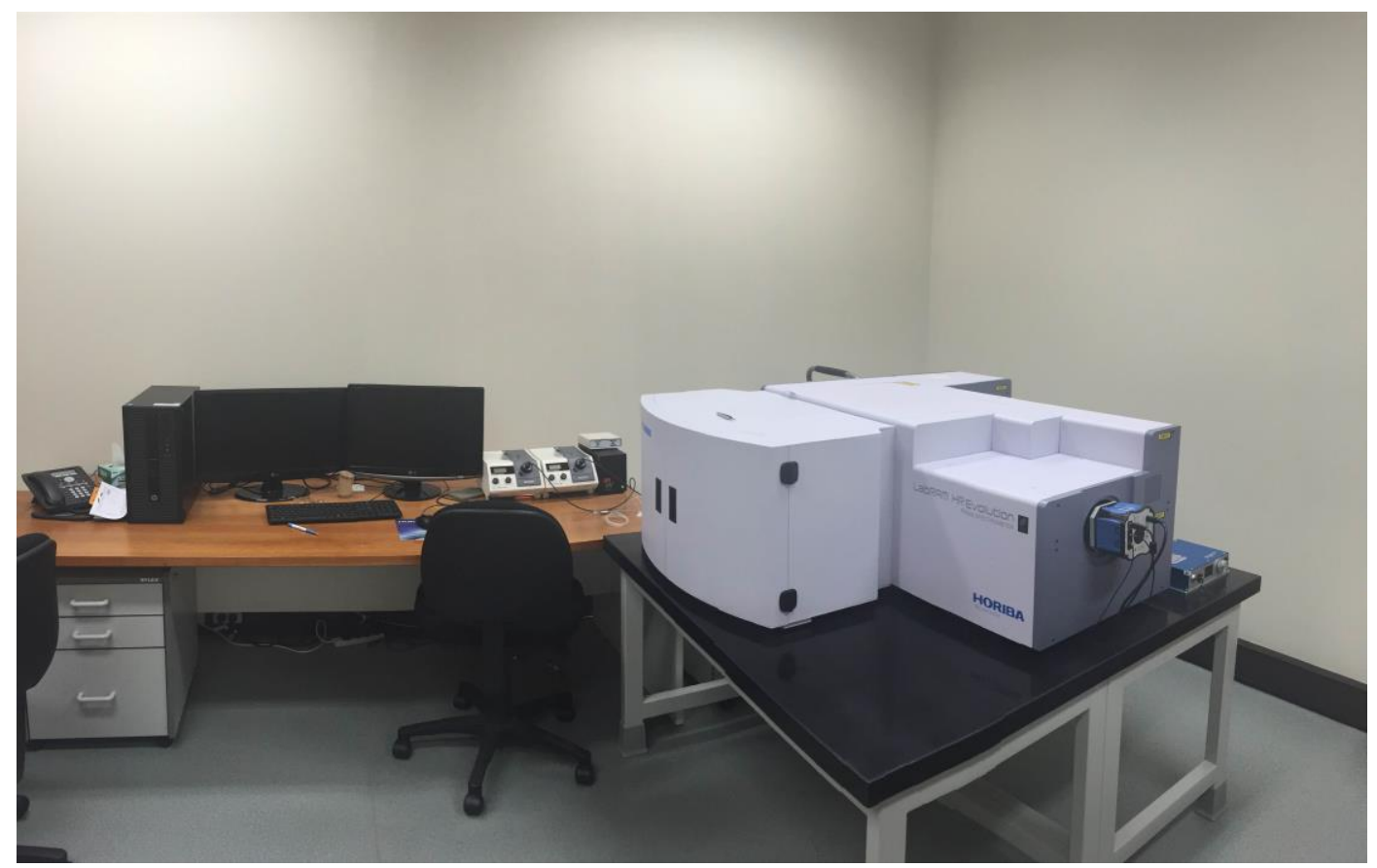

Figure 2.14: GAU Raman system. Showing (left to right) the computers controlling Raman system, the two light intensity control units, the data recorder and the JY Horiba LABRAM HR Evolution confocal laser Raman system.

Raman spectroscopy measurements were carried out on all $\mathrm{CaGeO}_{3}$ (Figure 2.12) and quartz (Figure 2.13) EC calibration runs to determine the phases of the minerals present. Samples were analysed by the JY Horiba LABRAM HR Evolution confocal laser Raman system (Figure 2.14) located in the Geochemical Analysis Unit (GAU), at Macquarie University using both $532 \mathrm{~nm}$ (green) and $633 \mathrm{~nm}$ (red) wavelength lasers. The system was initially checked for calibration using the $512 \mathrm{~cm}^{-1}$ silicon peak. A grating of 1800 grooves/mm was selected for maximum spectral resolution. The wavenumber ranged from $100-1000 \mathrm{~cm}^{-1}$ for $\mathrm{CaGeO}_{3}$ calibrations and $100-800 \mathrm{~cm}^{-1}$ for quartz cells. Spectra were collected over a duration of 20 $-60 \mathrm{~s}$ and averaged over at least 3 accumulations for spectral clarity.

\subsection{Electrical conductivity calculation:}

Electrical conductivity is determined using the simple relation:

$$
R=\frac{\delta l}{A}
$$


Where $R$ is the impedance value determined directly from the Cole-Cole plots. $\delta$ is the resistivity, I the length and $A$ the cross-sectional area of the sample. The conductivity, $\sigma$, given by the inverse of resistivity. Hence the above equation reduces to:

$$
\sigma=\frac{l}{R A}
$$

$A$ is determined by measuring the diameter of the sample while $I$ is determined by measuring the length of the sample between the electrodes. Calibrated images (Figure 2.11) obtained with the Leica optical microscope located in the high-pressure lab are used to determine these measurements. The Arrhenius equation can be used to model the conductivity of the sample:

$$
\sigma=\sigma_{0} e^{-\frac{\Delta H}{R T}}
$$

Where $\sigma$ is the conductivity, $\sigma_{0}$ is the conductivity at extremely high temperature. $\Delta \mathrm{H}$ is the activation enthalpy $\mathrm{R}$, is the universal gas constant and $\mathrm{T}$ is the temperature. Equation 2.3 can be rearranged into a linear expression to give:

$$
\log _{10} \sigma=\log _{10} \sigma_{0}-\frac{\Delta H}{R T} \log _{10} e
$$

By plotting $\log _{10} \sigma$ versus $1 / \mathrm{T}, \Delta \mathrm{H}$ and $\sigma_{0}$ can be determined from the slope and the intercept, respectively. 


\section{Results}

\subsection{Pressure calibration results:}

The MAA was calibrated over a pressure range of $0-9 \mathrm{Gpa}$ and a temperature range of $1173-1473 \mathrm{~K}$ using previously published transitions of $\mathrm{CaGeO}_{3}$ and quartz $\left(\mathrm{SiO}_{2}\right)$. Calibrations were confirmed using Raman spectroscopy with results displayed in Figure $\mathbf{3 . 1}$ and runs summarised in Table 3.1 and 3.2. Characteristic Raman spectra for $\mathrm{CaGeO}_{3}$ and $\mathrm{SiO}_{2}$ are also shown in Figure $\mathbf{3 . 2}$ and 3.3 respectively. Of the 16 calibration runs undertaken three experiments, MQ011, MQ020 and MQ038 were unsuccessful in the sense that upon quenching we did not observe the intended mineral phases. The reason why quartz was observed in the quenched MQ011 is unknown given the ample annealing time. MQ020 and MQ038 were annealed for only a short time, effectively truncating the kinetics of the reaction. This theory is supported by the generation of the stishovite transition in MQ022, which was annealed for $1 \mathrm{hr}$ as opposed to the $15 \mathrm{~min}$ annealing time for MQ020 and MQ038. Importantly there are two runs, MQ003 and MQ004, where we did not observe a phase transition at high pressure despite them being well within the stability field. These may be explained by the metastability of the perovskite phase when exposed to a high heat source, such as a Raman laser used in the phase identification. Similar metastability issues were incurred on MQ002 (Ga-Pv point in Figure 3.1), however, perovskite peaks were detected albeit in low proportion.

Table 3.1: Calcium germanate experiment summary

\begin{tabular}{cccccccc}
\hline \hline \multirow{2}{*}{ Experiment } & & & Temperature & $\begin{array}{c}\text { Annealing } \\
\text { time }\end{array}$ & \multicolumn{2}{c}{$\begin{array}{c}\text { Major } \\
\text { Phase }\end{array}$} & $\begin{array}{c}\text { Minor } \\
\text { Phase }\end{array}$ \\
\cline { 2 - 5 } MQ002 & Tons & Gpa & $\mathrm{K}$ & Hours & & Garnet & Perovskite \\
MQ003 & 500 & 6.1 & 1273 & 2 & & Garnet^ & - \\
MQ004 & 500 & 9.0 & 1323 & 1473 & 2 & Garnet^ & - \\
MQ005 & 500 & 9.0 & 1473 & 2 & & Sample lost* \\
MQ006 & 400 & 8.0 & 1473 & 2 & & Perovskite & Garnet \\
MQ007 & 350 & 7.0 & 1473 & 3 & & Perovskite & - \\
MQ018 & 200 & 4.2 & 1273 & 1 & Garnet & - \\
\hline \hline
\end{tabular}

$\wedge$ Back transformation occurred

* Sample was lost during cutting. 


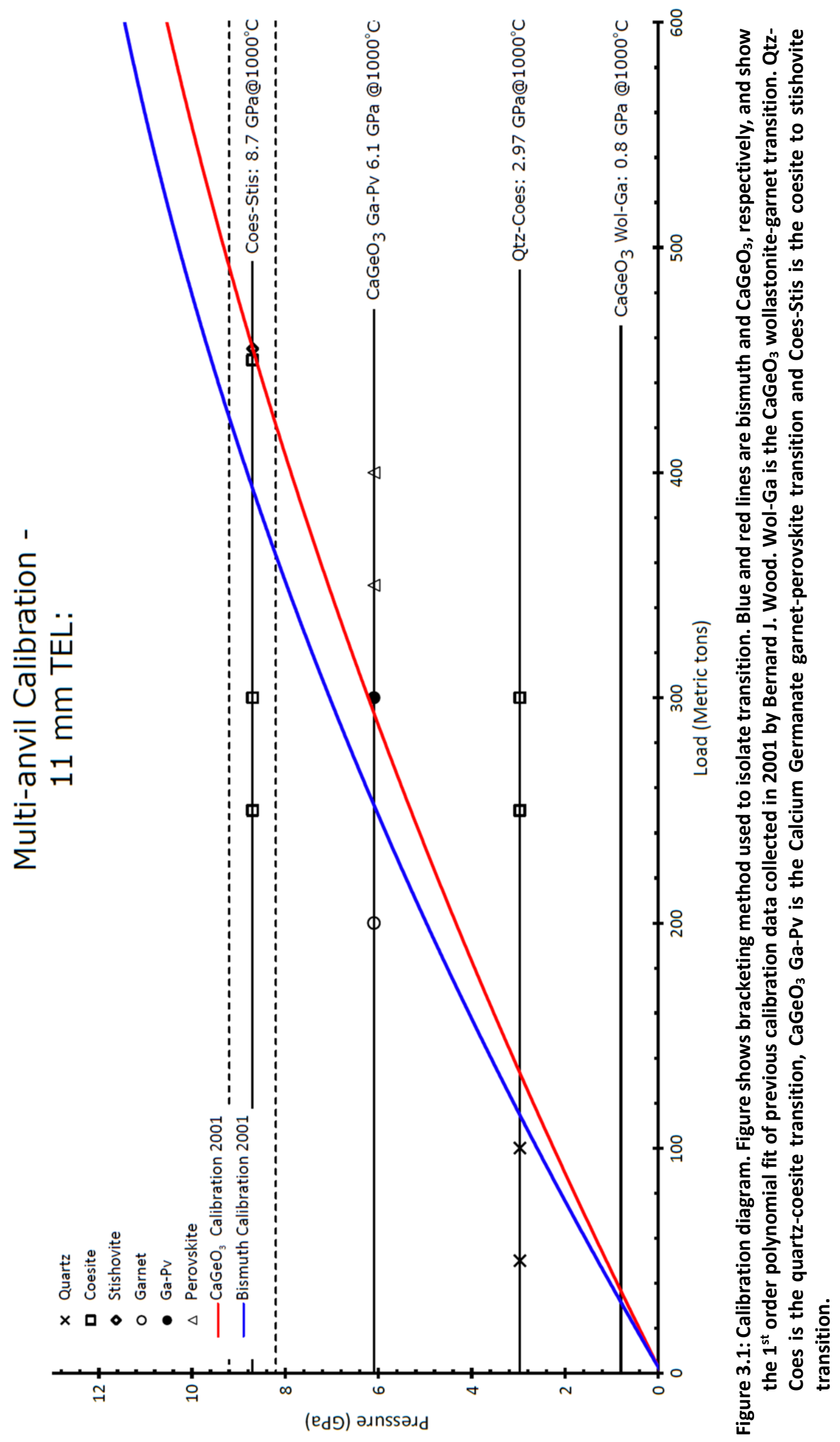




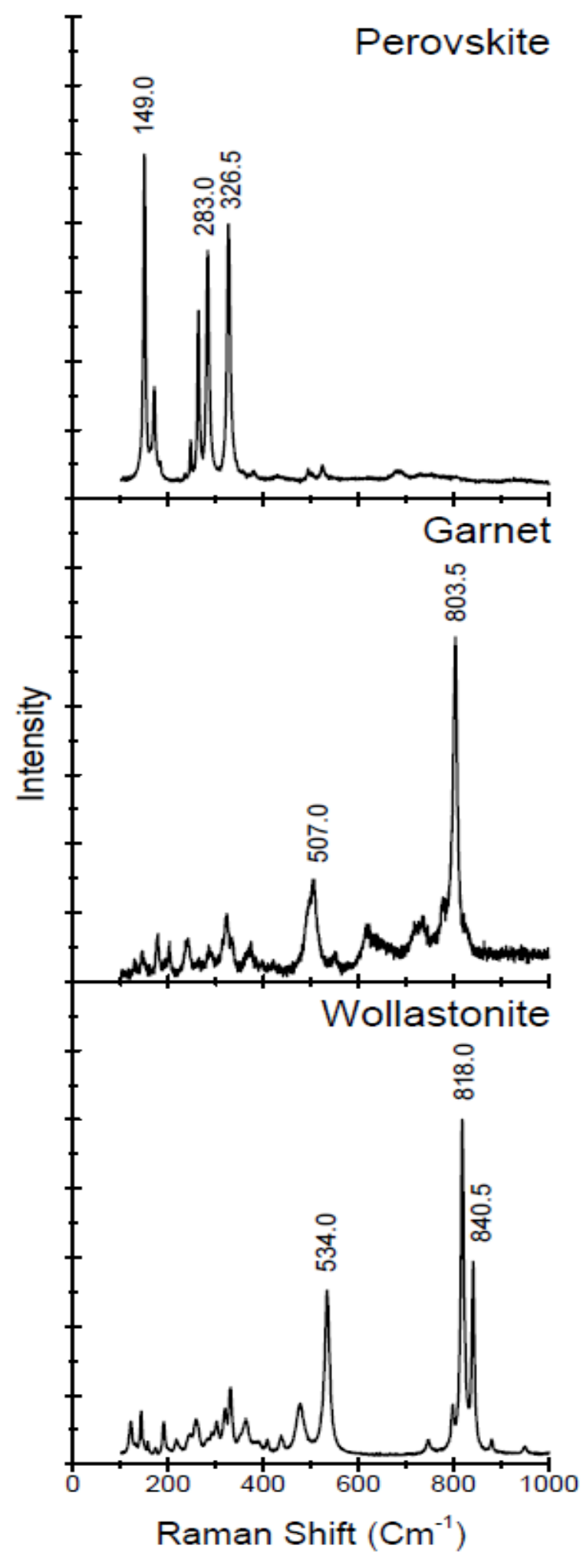

Figure 3.2 Raman spectra of $\mathrm{CaGeO}_{3}$ phases from this study. Wollastonite, Garnet and perovskite phases are indicated on the corresponding graph. Wavenumbers (Raman shift) for each peak are also indicated directly above the corresponding peak.

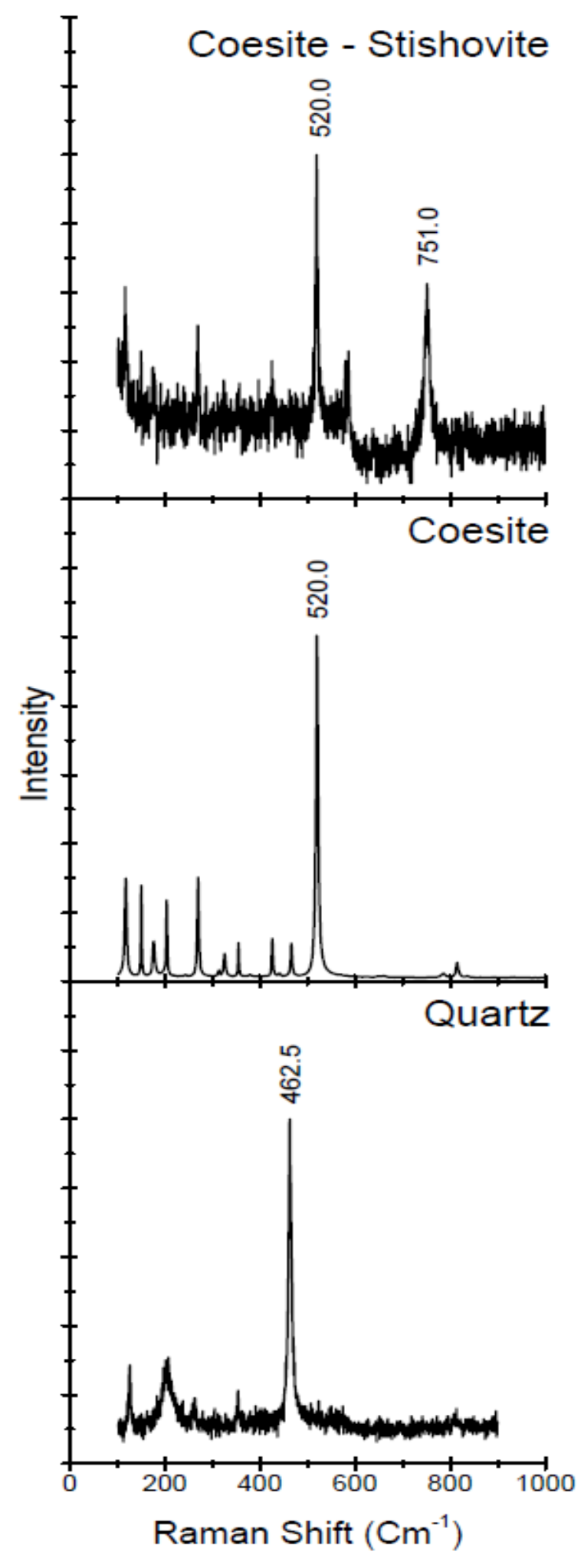

Figure 3.3 Raman spectra of $\mathrm{SiO}_{2}$ phases from this study. Quartz, Coesite phases are indicated on the corresponding graph. As well as a mixed phase of Coesite and Stishovite Wavenumbers (Raman shift) for each peak are also indicated directly above the corresponding peak. 
Table 3.2: Quartz run summary

\begin{tabular}{ccccccc}
\hline \multirow{2}{*}{ Experiment } & \multicolumn{2}{c}{ Pressure } & Temperature & $\begin{array}{c}\text { Annealing } \\
\text { time }\end{array}$ & $\begin{array}{c}\text { Major } \\
\text { Phase }\end{array}$ & $\begin{array}{c}\text { Minor } \\
\text { Phase }\end{array}$ \\
\cline { 2 - 4 } & Tons & Gpa $^{\#}$ & $\mathrm{~K}$ & Hours & & \\
\hline MQ008 & 250 & 5.2 & 1473 & 1 & Coesite & \\
MQ009 & 250 & 5.2 & 1273 & 1 & Coesite & \\
MQ010 & 300 & 6.1 & 1273 & 1 & Coesite & \\
MQ011 & 300 & 6.1 & 1273 & 1 & Quartz* & \\
MQ013 & 100 & 2.4 & 1173 & 1 & Quartz & \\
MQ016 & 50 & 1.4 & 1173 & 0.25 & Quartz & \\
MQ020 & 450 & 8.7 & 1173 & 0.25 & Coesite^ & \\
MQ022 & 450 & 8.7 & 1173 & 1 & Stishovite & Coesite \\
MQ038 & 450 & 8.7 & 1273 & 0.25 & Coesite^ & \\
\hline
\end{tabular}

\# Pressure was calculated from the confirmed phases that form the basis of curves presented in figure 3.1.

* MQ011 was annealed at $673 \mathrm{~K}$ as opposed to the $873 \mathrm{~K}$ of MQ010. Therefore, no transition was seen.

$\boldsymbol{\wedge}$ The short annealing time is suggested as the cause of the failed transitions.

3.2 Electrical conductivity results:

Table 3.3: Summary of Conductivity runs

\begin{tabular}{ccccccc}
\hline \hline \multirow{2}{*}{ Experiment } & \multirow{2}{*}{ Sample } & \multicolumn{2}{c}{ Pressure } & \multicolumn{2}{c}{ Temperature range $(\mathrm{K})$} & \multirow{2}{*}{ Cycles } \\
\cline { 3 - 6 } & & Tons & GPa & Min & Max & \\
\hline MQ029 & SCP & 50 & 1.1 & 300 & 1473 & 4 \\
MQ034 & SCP & 200 & 4.4 & 300 & 1273 & 3 \\
MQ037 & SSCO & 200 & 4.4 & 300 & 1273 & 2 \\
MQ039 & SSCO & 50 & 1.1 & 300 & 1273 & 2 \\
\hline \hline
\end{tabular}

EC runs utilising SSCO (Separated San Carlos Olivine) and SCP (San Carlos Peridotite) are summarised in Table 3.3. Each experiment comprised a minimum of two temperature cycles (sweeps) as per the method outlined previously. The impedance values of each sample, 


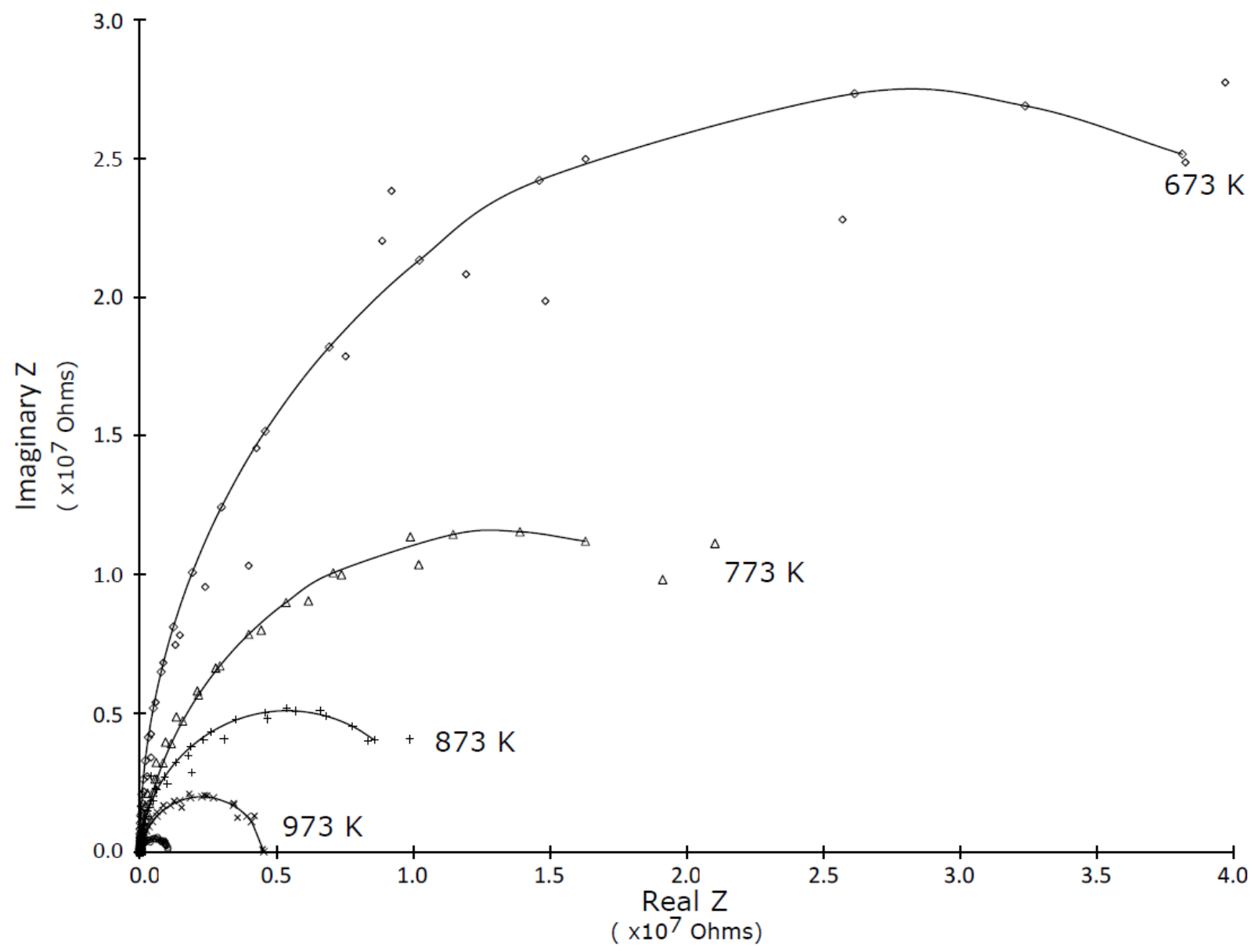

Figure 3.4: Representative Cole-Cole plot show impedance as a function of temperature. This particular spectrum was taken during the first temperature increase of MQ037. Importantly, although plotted, given the magnitude with which impedance changes with increasing temperature 1173 and $1273 \mathrm{~K}$ are not visible. Data series are labelled as per the legend with temperatures for each curve from $673-973 \mathrm{~K}$ also displayed on graph. Impedance of the 1073 $\mathrm{K}$ measurement is shown in the lower left of the plot area beneath the curve of the $973 \mathrm{~K}$ measurement.

calculated from the phase angle and magnitude, decreased dramatically with increasing temperature (Figure 3.4). Further, impedances taken at low temperature $(<973 \mathrm{~K})$ did not

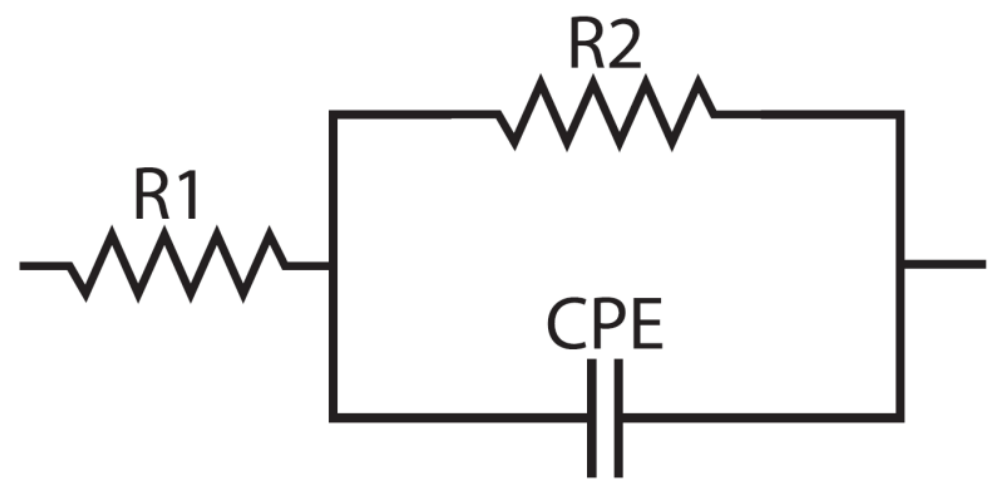

Figure 3.5: Modelled equivalent circuit. R1 is the first resistor feeding into a second resistor

(R2) in parallel with a capacitive element, in this case a constant phase element (CPE). 
generate a full semi-circle, with the occasional exception of the first increase in temperature, leading to high error of up to $15 \%$ while mean error was $5 \%$.

Impedances were calculated via an equivalent circuit, modelling as per the methods section. Conductivity and activation enthalpy were then calculated as per eq. 2.2 and eq. 2.4, respectively. Figure $\mathbf{3 . 5}$ shows the equivalent circuit used in the impedance modelling. This circuit was chosen as it best describes the plots shown in Figure 3.4. The choice of a constant phase element (CPE) in place of a classical capacitor was to allow more freedom in fitting as a CPE is often used to model impure samples (i.e. fits elongated semi-circles well).

Experiment MQ029 was carried out at $1.1 \mathrm{GPa}$ over a temperature range from ambient to $1473 \mathrm{~K}$ on sample SCP. $\log _{10}$ conductivity ranged from -5.78 to $0.35 \mathrm{~s} / \mathrm{m}$ and $\sigma_{0}$ ranged from -1.31 to $3.08 \mathrm{~s} / \mathrm{m}$ over four sweeps (Figure 3.6 \& Table 3.4). The first increase is characterised by conductivities of $-5.78 \mathrm{~S} / \mathrm{m}$ at $373 \mathrm{~K}$ increasing to $-2.09 \mathrm{~S} / \mathrm{m}$ at $973 \mathrm{~K}$. $\sigma_{0}$ was $-1.31 \mathrm{~S} / \mathrm{m}$ with a change in activation enthalpy occurring between 673 and $773 \mathrm{~K}$. Overall activation enthalpy of this increase was calculated to be $0.33 \mathrm{eV}$. Temperature decrease 1 began with an initial temperature decrease to $873 \mathrm{~K}$ where a $\log _{10}$ conductivity of $-1.74 \mathrm{~S} / \mathrm{m}$ was recorded, higher

MQ029 - $1.1 \mathrm{GPa}$

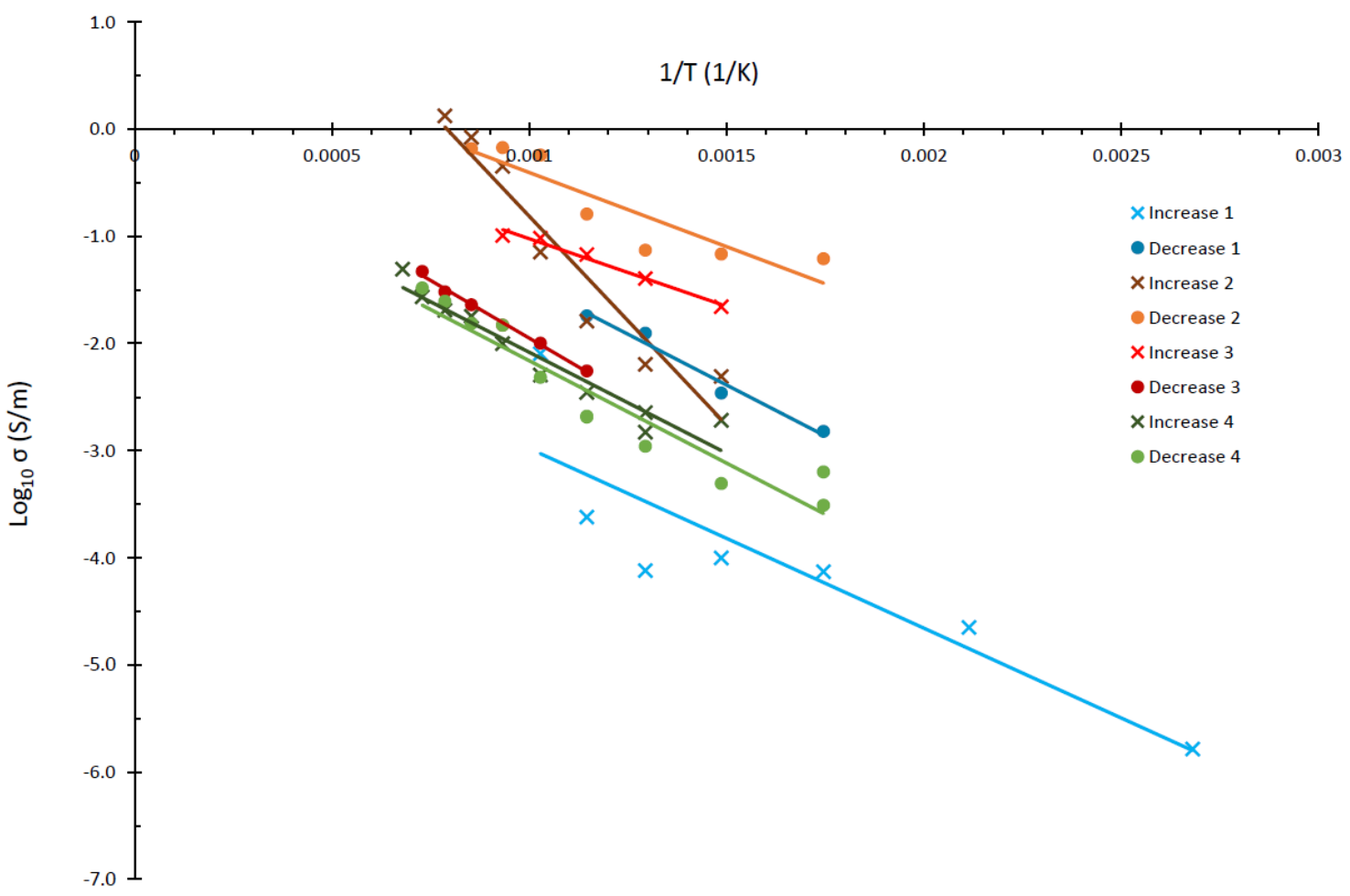

Figure 3.6: Arrhenius electrical conductivity plot for MQ029. Conductivity of MQ029 (SCP) over four temperature sweeps at 1.1 GPa. Sweeps are isolated by colour with increase and decreases indicated by the crosses and circle symbols respectively. 
Table 3.4: MQ029 (SCP) conductivity summary

\begin{tabular}{|c|c|c|c|c|c|c|}
\hline \multirow[t]{2}{*}{ Cycle segment } & \multicolumn{2}{|c|}{ Temperature (K) } & \multicolumn{2}{|c|}{$\begin{array}{l}\log _{10} \sigma \\
(\mathrm{S} / \mathrm{m}) \\
\end{array}$} & \multirow{2}{*}{$\begin{array}{c}\log _{10} \sigma_{0} \\
(\mathrm{~S} / \mathrm{m})\end{array}$} & \multirow{3}{*}{$\begin{array}{c}\Delta \mathrm{H} \\
(\mathrm{eV})\end{array}$} \\
\hline & $T \min$. & T max. & $\sigma \min _{T}$ & $\sigma \max _{T}$ & & \\
\hline Av. Error: & 25 & 25 & $5 \%$ & $5 \%$ & $5 \%$ & \\
\hline Increase 1 & 373 & 973 & -5.78 & -2.09 & -1.31 & 0.33 \\
\hline Decrease 1 & 573 & 873 & -2.82 & -1.74 & 0.32 & 0.38 \\
\hline Increase 2 & 673 & 1273 & -2.31 & 0.13 & 3.08 & 0.77 \\
\hline Decrease 2 & 573 & 1173 & -1.21 & -0.18 & 2.56 & 0.57 \\
\hline Increase 3 & 673 & 1473 & -1.66 & -1.11 & 0.24 & 0.25 \\
\hline Decrease 3 & 573 & 1373 & -2.82 & -1.33 & 0.20 & 0.43 \\
\hline Increase 4 & 673 & 1473 & -2.72 & -1.31 & 0.09 & 0.44 \\
\hline Decrease 4 & 573 & 1373 & -3.20 & -1.48 & 0.38 & 0.51 \\
\hline
\end{tabular}

than the preceding increase at the same temperature. This trend of higher conductivity was maintained to $573 \mathrm{~K}$ where $\log _{10} \sigma$ was $-2.82 \mathrm{~S} / \mathrm{m}$. Activation enthalpy on this portion of the first cycle was slightly higher at $0.38 \mathrm{eV}$ as was $\sigma_{0}$ at $+0.32 \mathrm{~S} / \mathrm{m}$.

The second temperature increase recorded $\log _{10} \sigma$ at $673 \mathrm{~K}$ of $-2.31 \mathrm{~s} / \mathrm{m}$ increasing to $+0.13 \mathrm{~S} / \mathrm{m}$ at $1273 \mathrm{~K}$ with $\sigma_{0}$ of $+3.08 \mathrm{~S} / \mathrm{m}$. Activation enthalpy for this increase was the highest of the experiment (when all points are included) at $0.77 \mathrm{eV}$. At $1173 \mathrm{~K} \log _{10}$ conductivity of the second decrease was $-0.18 \mathrm{~S} / \mathrm{m}$ decreasing along a subdued slope to $-1.21 \mathrm{~S} / \mathrm{m}$ at $573 \mathrm{~K}$ to provide a $\sigma_{0}$ of $+2.56 \mathrm{~S} / \mathrm{m}$ and activation enthalpy of $0.57 \mathrm{eV}$. Increase 3 displayed log conductivities of -1.66 to $-1.11 \mathrm{~S} / \mathrm{m}$ at $673 \mathrm{~K}$ and $1473 \mathrm{~K}$ respectively. Activation enthalpy for this increase was $0.25 \mathrm{eV}$ with $\sigma_{0}=+0.24 \mathrm{~S} / \mathrm{m}$. Third decrease cycle began with the initial decrease in temperature of $100 \mathrm{~K}$ to $1373 \mathrm{~K}$ where $\log _{10} \sigma$ was $-1.33 \mathrm{~S} / \mathrm{m}$ decreasing to -2.82 $\mathrm{S} / \mathrm{m}$ at $573 \mathrm{~K}$. Activation enthalpy and $\sigma_{0}$ were calculated at $0.43 \mathrm{eV}$ and $+0.20 \mathrm{~S} / \mathrm{m}$ respectively. The final sweep of MQ029 comprising increase and decrease 4 is comprised of $\log _{10}$ conductivity of $-2.72 \mathrm{~S} / \mathrm{m}$ at $673 \mathrm{~K}$ increasing to $-1.31 \mathrm{~S} / \mathrm{m}$ at $1473 \mathrm{~K}$ for the increase component. $\log _{10}$ conductivity of the decrease was $-1.49 \mathrm{~S} / \mathrm{m}$ and $-3.20 \mathrm{~S} / \mathrm{m}$ at $1373 \mathrm{~K}$ and $573 \mathrm{~K}$ respectively. Increase 4 , displayed an activation enthalpy of $0.44 \mathrm{eV}$ and $\sigma_{0}$ of $-0.09 \mathrm{~S} / \mathrm{m}$ while the decrease component showed a slight increase in activation enthalpy $(0.51 \mathrm{eV})$ and $\sigma_{0}(0.38 \mathrm{~S} / \mathrm{m})$.

MQ034, also run using sample SCP, comprised three temperature sweeps and was carried out at $4.4 \mathrm{Gpa}$ and temperature ranged from ambient to $1273 \mathrm{~K}$ with $\log _{10}$ conductivity ranging from -5.9 to a maximum of -2.0 and $\sigma_{0}=-2.1$ to $0.98 \mathrm{~S} / \mathrm{m}$ (Figure 3.7 and Table 3.5). The first 
Table 3.5: MQ034 (SCP) conductivity summary

\begin{tabular}{|c|c|c|c|c|c|c|}
\hline \multirow[t]{2}{*}{ Cycle segment } & \multicolumn{2}{|c|}{ Temperature (K) } & \multicolumn{2}{|c|}{$\begin{array}{l}\log _{10} \sigma \\
(\mathrm{S} / \mathrm{m}) \\
\end{array}$} & \multirow{2}{*}{$\begin{array}{c}\log _{10} \sigma_{0} \\
(\mathrm{~S} / \mathrm{m})\end{array}$} & \multirow{2}{*}{$\begin{array}{c}\Delta \mathrm{H} \\
(\mathrm{eV})\end{array}$} \\
\hline & $T \min$. & T max. & $\sigma \min _{T}$ & $\sigma \max _{T}$ & & \\
\hline Av. Error: & 25 & 25 & $5 \%$ & $5 \%$ & $5 \%$ & \\
\hline Increase 1 & 373 & 973 & -5.92 & -2.53 & 0.29 & 0.67 \\
\hline Decrease 1 & 573 & 873 & -2.97 & -2.61 & -2.11 & 0.10 \\
\hline Increase 2 & 673 & 1173 & -2.88 & $-1.97^{*}$ & -0.21 & 0.45 \\
\hline Decrease 2 & 573 & 1173 & -3.47 & -2.39 & -0.61 & 0.44 \\
\hline Increase 3 & 373 & 1273 & -3.53 & -2.14 & -0.28 & 0.50 \\
\hline Decrease 3 & 673 & 1173 & -2.34 & $-5.19 *$ & 0.98 & 0.86 \\
\hline
\end{tabular}

* Measurement taken at 1273 and 573 on the $2^{\text {nd }}$ increase and $3^{\text {rd }}$ decrease respectively did not yield a conductivity and thus are excluded.

temperature increases comprised heating from ambient $(300 \mathrm{~K})$ to $373 \mathrm{~K}$ for the first measurement, which recorded a $\log _{10}$ conductivity of $-5.92 \mathrm{~S} / \mathrm{m}$ and rose to a maximum of $2.53 \mathrm{~S} / \mathrm{m}$ at $1073 \mathrm{~K}$. Activation enthalpy for this portion of the cycle was $0.67 \mathrm{eV}$, while $\sigma_{0}=$ $+0.29 \mathrm{~S} / \mathrm{m}$. The decreasing component of the first cycle emulated the decrease cycle from

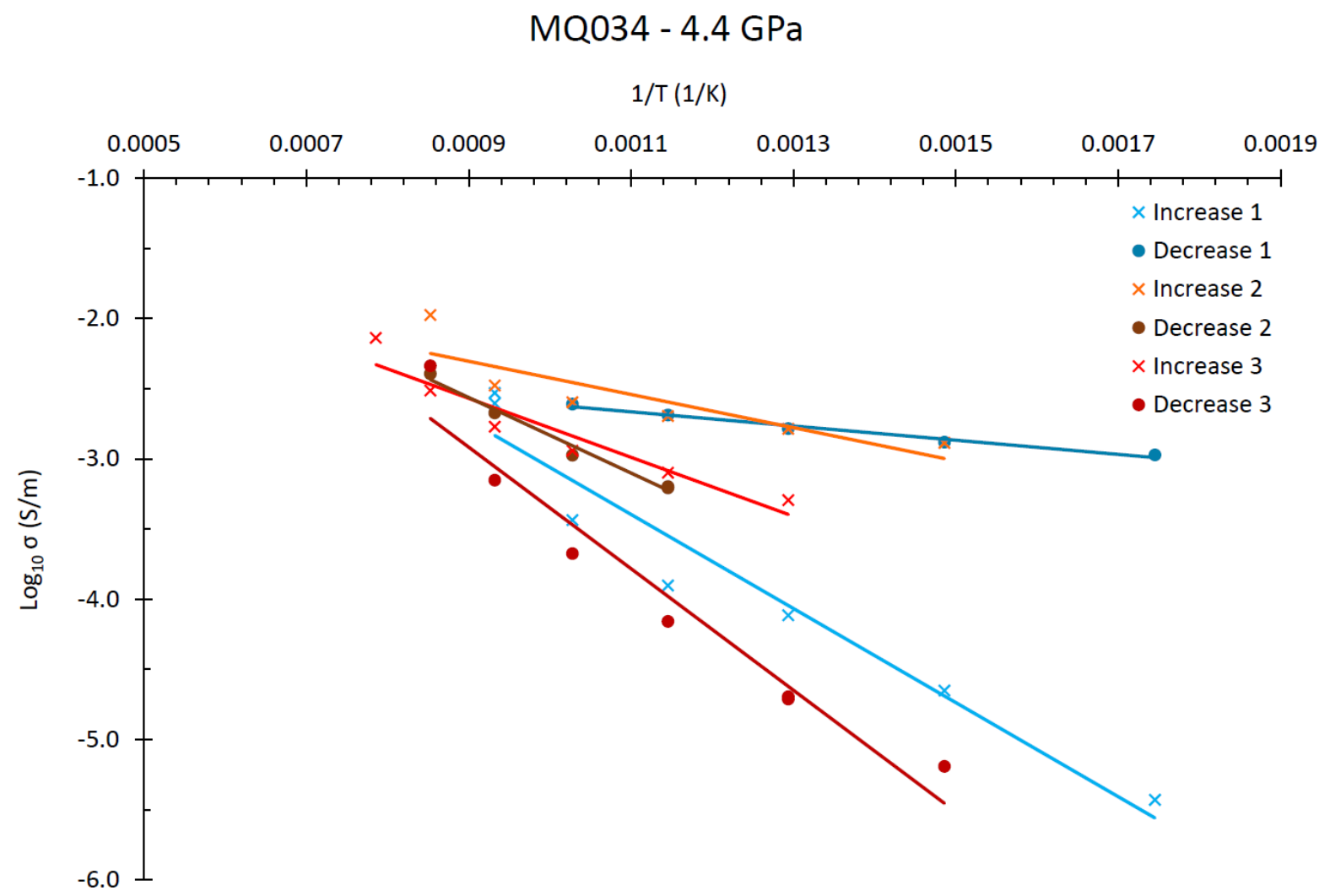

Figure 3.7: Arrhenius electrical conductivity plot for MQ034. Conductivity of MQ034 (SCP) over three temperature sweeps at $4.4 \mathrm{GPa}$. Sweeps are isolated by colour with increase and decreases indicated by the crosses and circle symbols respectively. 
MQ029, showing a subdued slope leading to an activation enthalpy of $0.10 \mathrm{eV}$. $\log _{10} \sigma$ was $2.61 \mathrm{~S} / \mathrm{m}$ at $973 \mathrm{~K}$ and decreased to $-2.97 \mathrm{~S} / \mathrm{m}$ at $573 \mathrm{~K}$, while $\sigma_{0}=-2.11 \mathrm{~S} / \mathrm{m}$. Increase 2 exhibits the highest $\log _{10}$ conductivity of $-1.97 \mathrm{~S} / \mathrm{m}$ at $1173 \mathrm{~K}$ while low temperature $(573 \mathrm{~K}) \log _{10}$ conductivity was $-2.88 \mathrm{~S} / \mathrm{m}$. $\sigma_{0}$ was $-0.21 \mathrm{~S} / \mathrm{m}$ with an activation enthalpy of $0.45 \mathrm{eV}$. Importantly this increase incorporated a maximum temperature of $1273 \mathrm{~K}$, however, data was not able to be fit as the spectral resolution was poor. The second decrease portion of the experiment produced $\sigma_{0}$ of $-0.61 \mathrm{~S} / \mathrm{m}$ while $\log _{10}$ conductivity ranged from $-2.39 \mathrm{~S} / \mathrm{m}$ to -3.47 $\mathrm{S} / \mathrm{m}$ at $1173 \mathrm{~K}$ and $573 \mathrm{~K}$ respectively. Activation enthalpy stayed stable at $0.44 \mathrm{eV}$ suggesting a normalisation of the system. Increase 3 shows initial $\log _{10} \sigma$ of $-3.53 \mathrm{~S} / \mathrm{m}$ at low temperature $(373 \mathrm{~K}$ ) increasing to $-2.14 \mathrm{~S} / \mathrm{m}$ at a maximum of $1273 \mathrm{~K}$ with activation enthalpy of $0.50 \mathrm{eV}$ and $\sigma_{0}$ of $-0.28 \mathrm{~S} / \mathrm{m}$. The final decrease of MQ034 was decrease 3 that exhibits a $\sigma_{0}=+0.98$, $\log _{10}$ conductivity of $-2.34 \mathrm{~S} / \mathrm{m}$ at $1173 \mathrm{~K}$ initially decreasing to $-5.19 \mathrm{~S} / \mathrm{m}$ at $573 \mathrm{~K}$ with an activation enthalpy of $0.86 \mathrm{eV}$. It should also be noted that due to the range of frequencies scanned and spectral resolution being poor at low temperature, impedance measurements at $573 \mathrm{~K}$ for this decrease did not produce a reliable impedance value.

Experiment MQ037 was the first experiment on the SSCO sample and was run at 4.4 GPa. Two temperature sweeps were undertaken and the range was the same as MQ034 (300 $1273 \mathrm{~K}$ ) with conductivity values ranging from -5.6 to $-1.3 \mathrm{~S} / \mathrm{m}$ for $\sigma_{0}$ of -1.37 to $1.97 \mathrm{~S} / \mathrm{m}$ (Figure 3.8 and Table 3.6). The first temperature increases comprised measurement of $\log _{10}$ conductivity of $-5.65 \mathrm{~S} / \mathrm{m}$ at $373 \mathrm{~K}$ and rose to a maximum of $-2.11 \mathrm{~S} / \mathrm{m}$ at $1173 \mathrm{~K}$. Activation enthalpy for this portion of the cycle was $1.06 \mathrm{eV}$, while $\sigma_{0}=+1.97 \mathrm{~S} / \mathrm{m}$. The decreasing component of the first cycle emulated the decrease cycle from Experiments MQ029 and MQ034, showing a subdued slope leading to an activation enthalpy of $0.23 \mathrm{eV}$. $\log _{10} \sigma$ was $2.45 \mathrm{~S} / \mathrm{m}$ at $1073 \mathrm{~K}$ and decreased to $-3.40 \mathrm{~S} / \mathrm{m}$ at $573 \mathrm{~K}$, while $\sigma_{0}$ was $-1.37 \mathrm{~S} / \mathrm{m}$. Increase 2 displays $\log _{10}$ conductivity of $-1.19 \mathrm{~S} / \mathrm{m}$ at $1273 \mathrm{~K}$ while low temperature (673 K) $\log _{10}$

Table 3.6: MQ037 (SSCO) conductivity summary

\begin{tabular}{|c|c|c|c|c|c|c|}
\hline \multirow[t]{2}{*}{ Cycle segment } & \multicolumn{2}{|c|}{ Temperature (K) } & \multicolumn{2}{|c|}{$\begin{array}{r}\mathrm{og}_{10 \sigma} \\
(\mathrm{S} / \mathrm{m}) \\
\end{array}$} & \multirow{2}{*}{$\begin{array}{c}\log _{10} \sigma_{0} \\
(\mathrm{~S} / \mathrm{m})\end{array}$} & \multirow{2}{*}{$\begin{array}{c}\Delta \mathrm{H} \\
(\mathrm{eV})\end{array}$} \\
\hline & $\mathrm{T} \min$. & T max. & $\sigma \min _{T}$ & $\sigma \max _{T}$ & & \\
\hline Av. Error: & 25 & 25 & $5 \%$ & $5 \%$ & $5 \%$ & \\
\hline Increase 1 & 573 & 1173 & -5.65 & -2.11 & 1.97 & 1.06 \\
\hline Decrease 1 & 573 & 1073 & -3.40 & -2.45 & -1.37 & 0.23 \\
\hline Increase 2 & 673 & 1273 & -4.22 & -1.19 & 1.25 & 0.72 \\
\hline Decrease 2 & 573 & 1173 & -2.41 & -1.33 & 0.37 & 0.40 \\
\hline
\end{tabular}




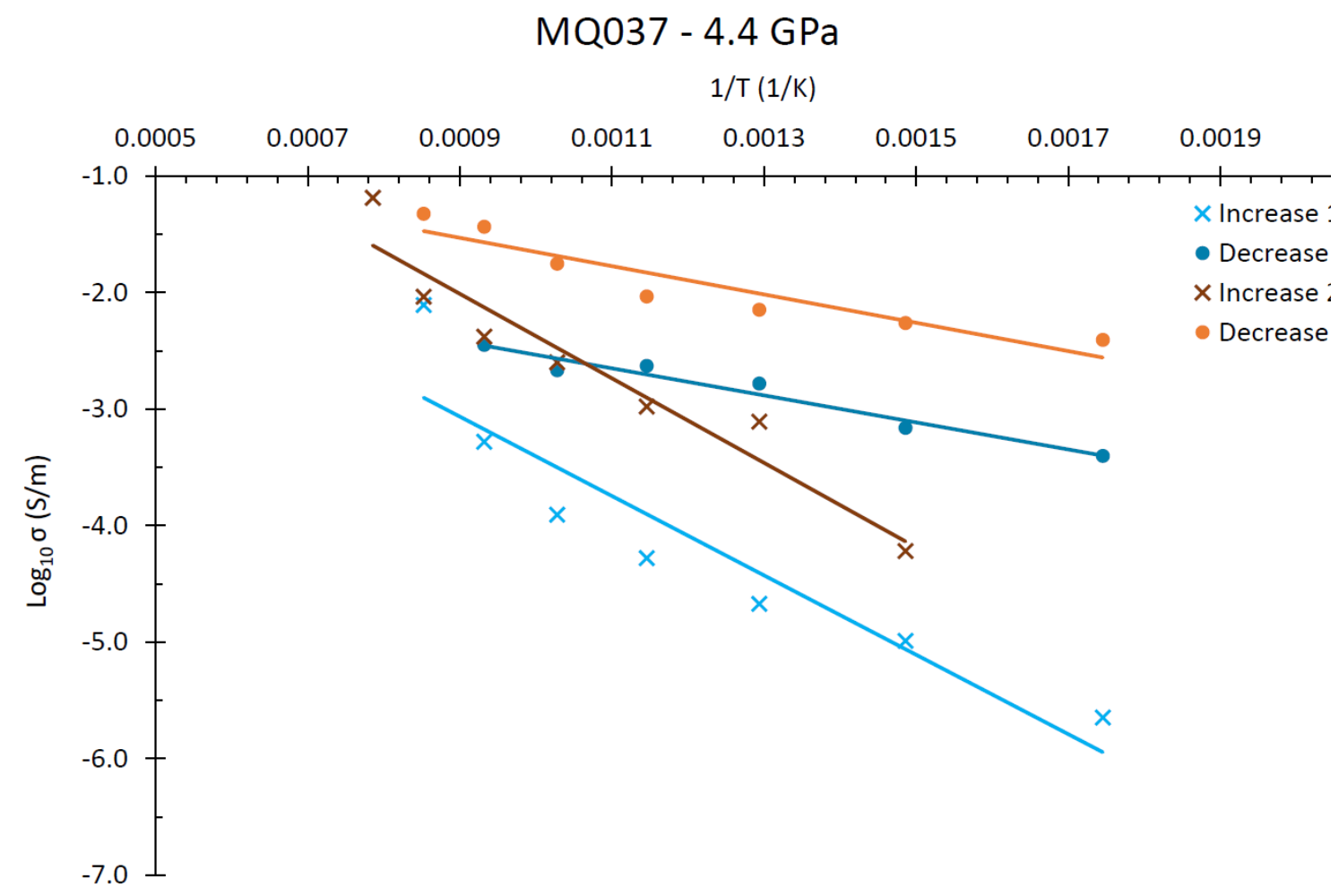

Figure 3.8: Arrhenius electrical conductivity plot for MQ037. Conductivity of MQ037 (SSCO) over two temperature sweeps at $4.4 \mathrm{GPa}$. Sweeps are isolated by colour with increase and decreases indicated by the crosses and circle symbols respectively.

conductivity was $-4.22 \mathrm{~S} / \mathrm{m} . \sigma_{0}=1.25 \mathrm{~S} / \mathrm{m}$ with an activation enthalpy of $0.72 \mathrm{eV}$. The second decrease portion of the experiment produced $\log _{10}$ conductivity ranged of $-1.32 \mathrm{~S} / \mathrm{m}$ to -2.41 $\mathrm{S} / \mathrm{m}$ at $1173 \mathrm{~K}$ and $573 \mathrm{~K}$ respectively. Activation enthalpy decreased to $0.40 \mathrm{eV}$ and $\sigma_{0}$ of 0.37 $\mathrm{S} / \mathrm{m}$.

Experiment MQ039 was run at $1.1 \mathrm{GPa}$ on sample SSCO from ambient temperature to $1273 \mathrm{~K}$. $\log _{10}$ conductivity values for MQ039 ranged from -5.7 to $-1.6 \mathrm{~S} / \mathrm{m}$ and $\sigma_{0}$ of -1.18 to $2.84 \mathrm{~S} / \mathrm{m}$ over two temperature sweeps (Figure 3.9). First temperature increase displays an

Table 3.7: MQ039 (SSCO) conductivity summary

\begin{tabular}{|c|c|c|c|c|c|c|}
\hline \multirow[t]{2}{*}{ Cycle segment } & \multicolumn{2}{|c|}{ Temperature (K) } & \multicolumn{2}{|c|}{$\begin{array}{c}\log _{10} \sigma \\
(\mathrm{S} / \mathrm{m})\end{array}$} & \multirow{2}{*}{$\begin{array}{c}\log _{10} \sigma_{0} \\
(\mathrm{~S} / \mathrm{m})\end{array}$} & \multirow{2}{*}{$\begin{array}{c}\Delta \mathrm{H} \\
(\mathrm{eV})\end{array}$} \\
\hline & $T \min$. & T max. & $\sigma \min _{T}$ & $\sigma \max _{T}$ & & \\
\hline Av. Error: & 25 & 25 & $5 \%$ & $5 \%$ & $5 \%$ & \\
\hline Increase 1 & 373 & 1073 & -5.12 & -2.01 & -1.18 & 0.32 \\
\hline Decrease 1 & 473 & 973 & -4.20 & -2.30 & -0.88 & 0.32 \\
\hline Increase 2 & 573 & 1273 & -4.09 & -1.62 & 1.39 & 0.79 \\
\hline Decrease 2 & 473 & 1173 & -5.71 & -1.76 & 2.84 & 1.03 \\
\hline
\end{tabular}


initial activation enthalpy for MQ039 that has been calculated to be $0.32 \mathrm{eV}$ (Table 3.7) while $\log _{10} \sigma$ at $373 \mathrm{~K}$ was determined to be $-5.12 \mathrm{~S} / \mathrm{m}$ and increased to $-2.00 \mathrm{~S} / \mathrm{m}$ at $1073 \mathrm{~K}$. $\sigma_{0}$ for this first increase was $-1.18 \mathrm{~S} / \mathrm{m}$. The initial temperature decrease for this experiment ranged from $-2.30 \mathrm{~S} / \mathrm{m}$ to $-4.20 \mathrm{~S} / \mathrm{m}$ at $973 \mathrm{~K}$ and $473 \mathrm{~K}$ respectively. $\Sigma_{0}=-0.88$ and activation enthalpy was calculated to be $0.32 \mathrm{eV}$ as it was for the first increase. The second increase in temperature displayed a $\log _{10}$ conductivity of $-4.09 \mathrm{~S} / \mathrm{m}$ at $573 \mathrm{~K}$ to $-1.62 \mathrm{~S} / \mathrm{m}$ at $1273 \mathrm{~K}$ with an activation enthalpy of $0.79 \mathrm{eV}$ and $\sigma_{0}$ of $1.39 \mathrm{~S} / \mathrm{m}$. The second and final decrease shows a $\log _{10} \sigma$ of $1.76 \mathrm{~S} / \mathrm{m}$ at $1173 \mathrm{~K}$ and decreases to $-5.71 \mathrm{~S} / \mathrm{m}$ at $473 \mathrm{~K}, \sigma_{0}=+2.84 \mathrm{~S} / \mathrm{m}$ with an activation enthalpy of $1.03 \mathrm{eV}$.

\section{MQ039 - $1.1 \mathrm{Gpa}$}

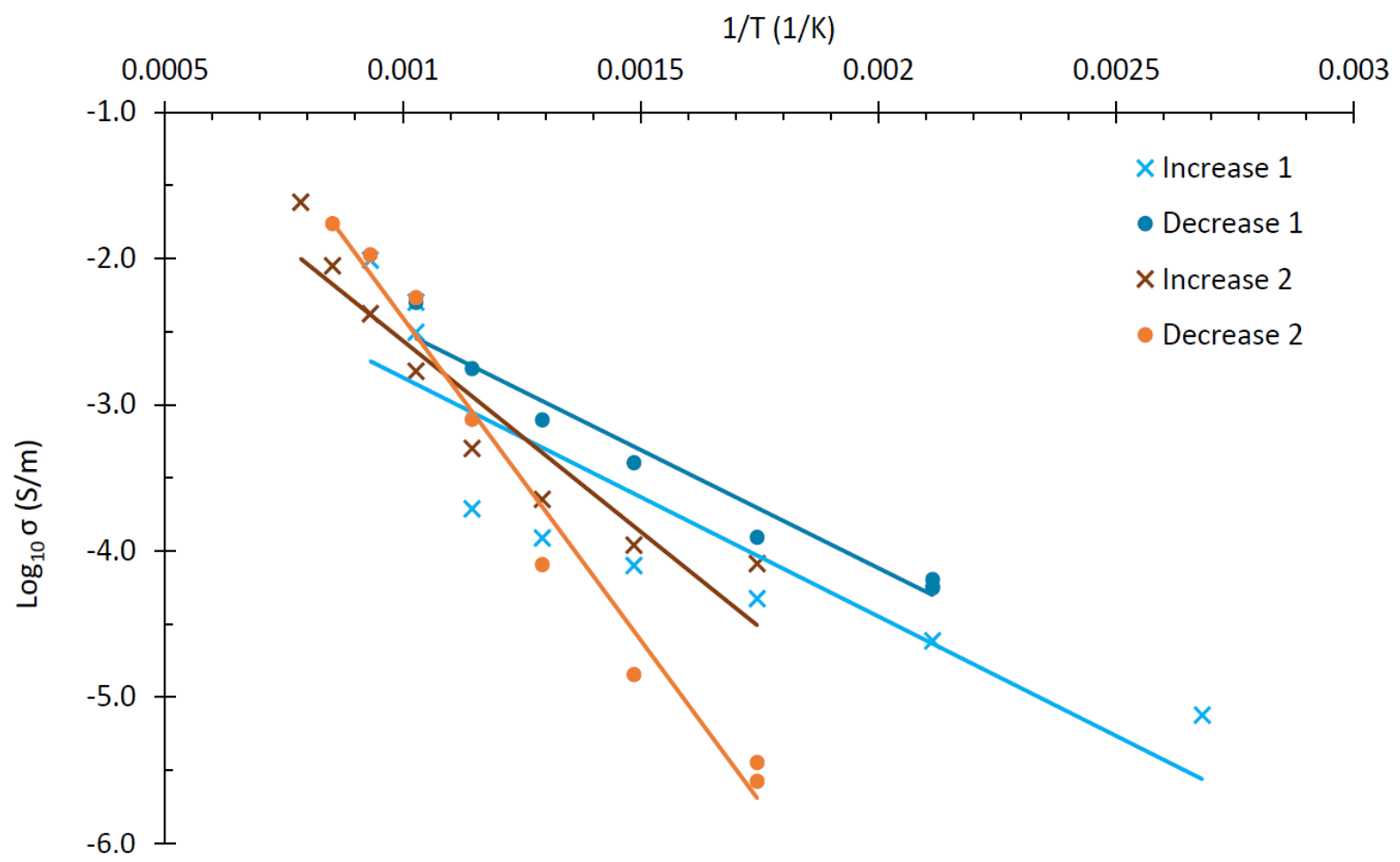

Figure 3.9: Arrhenius electrical conductivity plot for MQ039. Conductivity of MQ039 (SSCO) over two temperature sweeps at 1.1 GPa. Sweeps are isolated by colour with increase and decreases indicated by the crosses and circle symbols respectively. 
Table 3.8: Table of literature values presented in Figure 3.10.

\begin{tabular}{|c|c|c|c|c|c|}
\hline Study: & $\begin{array}{l}\text { Water content } \\
\text { (wt. \%) }\end{array}$ & $\begin{array}{c}\text { Pressure } \\
(\mathrm{GPa})\end{array}$ & $\begin{array}{l}\text { Max Temp. } \\
\text { (K) }\end{array}$ & $\begin{array}{l}\log _{10} \sigma_{0} \\
(\mathrm{~S} / \mathrm{m})\end{array}$ & $\begin{array}{l}\Delta \mathrm{H} \\
(\mathrm{eV})\end{array}$ \\
\hline Wang et al., 2006. & Dry & 10 & 1273 & 2.4 & 1.60 \\
\hline \multirow{6}{*}{ Yoshino et al., 2009. ${ }^{a}$} & \multirow{3}{*}{$\begin{array}{c}\text { Dry } \\
(0.008 \text { wt. \%) }\end{array}$} & \multirow{6}{*}{10} & $1400^{c}$ & 0.83 & 1.11 \\
\hline & & & $1750^{c}$ & 3.34 & 1.70 \\
\hline & & & $2000^{c}$ & 4.73 & 2.25 \\
\hline & 0.040 wt. $\%$ & & 800 & 0.91 & 0.88 \\
\hline & 0.066 wt. \% & & 1000 & 0.93 & 0.87 \\
\hline & 0.189 wt. \% & & 850 & 1.29 & 0.85 \\
\hline Poe et al., 2010. & $1903 \mathrm{ppm}^{\mathrm{d}}$ & 8 & 600 & 1.61 & 0.85 \\
\hline This study, MQ029 (I2) & $\mathrm{TBD}^{\mathrm{e}}$ & 1.1 & 1273 & 3.08 & 0.77 \\
\hline This study, MQ034 (I2) & $\mathrm{TBD}^{\mathrm{e}}$ & 4.4 & 1173 & -1.24 & 0.45 \\
\hline This study, MQ037 (12) & $\mathrm{TBD}^{\mathrm{e}}$ & 4.4 & 1273 & 1.25 & 0.72 \\
\hline This study, MQ039 (12) & $\mathrm{TBD}^{\mathrm{e}}$ & 1.1 & 1273 & 0.05 & 0.79 \\
\hline
\end{tabular}

a : Values presented here and in figure $\mathbf{3 . 1 0}$ form the basis of the conductivity approximation presented in Yoshino et al., (2009).

b : Dry refers to 0 wt. \% unless indicated otherwise. Contribution of Poe et al., (2010) report water as ppm (Mg).

c: Using one sample Yoshino et al., (2009) to defined the bounds of proton, small polaron and ionic conduction at 1400, 1750 and $>2000 \mathrm{~K}$ respectively. This is shown in Fig. 6 of Yoshino et al., (2009) or Figure 1.2c here.

d: reported in ppm as this result is not directly comparable

e: Reader is directed to section $\mathbf{5 . 1}$ where water characterisation plans are discussed 


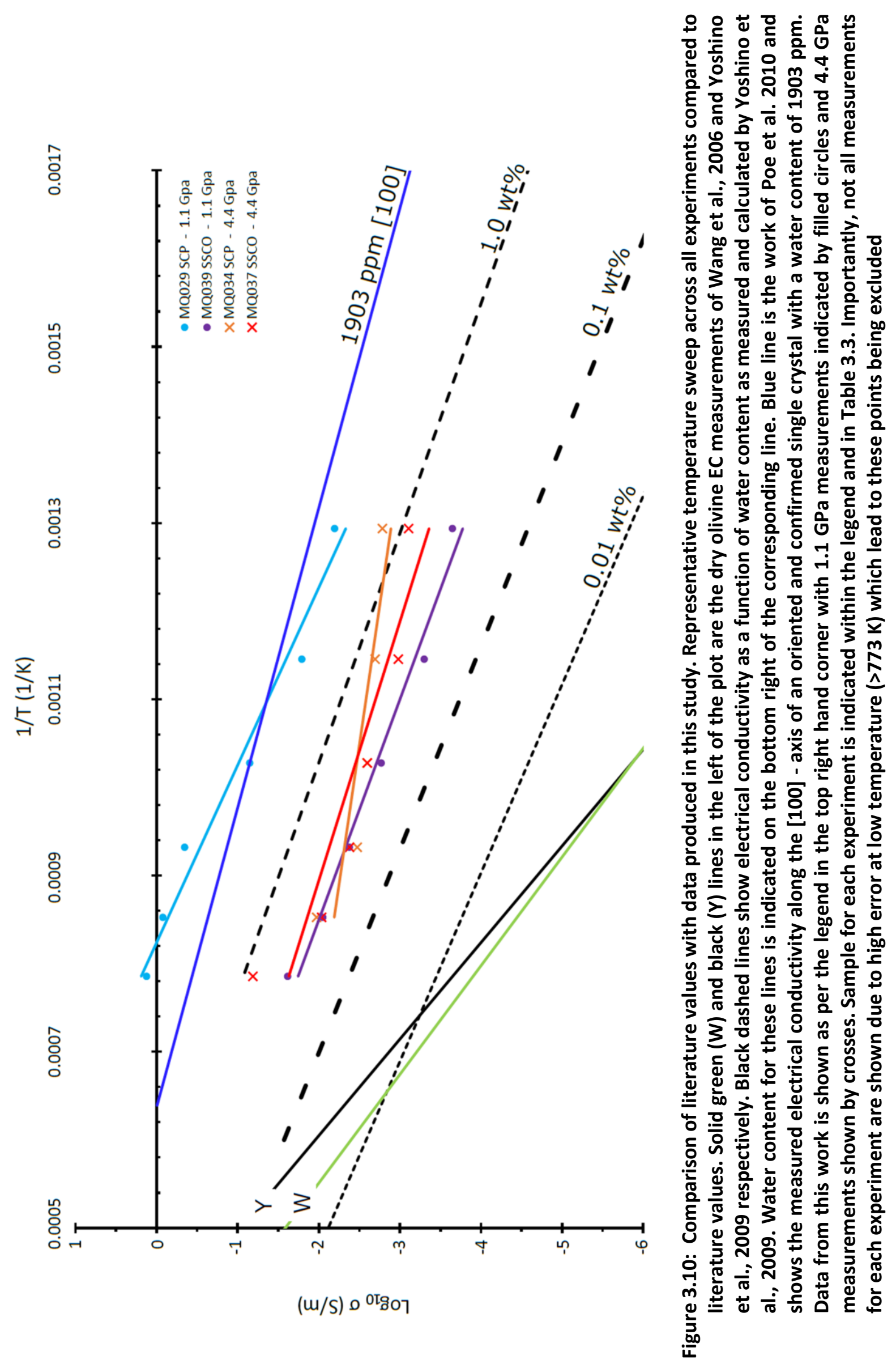




\section{Discussion}

\subsection{Overview:}

Resistivities utilised in electrical conductivity calculations were generated using equivalent circuit modelling utilising the circuit presented in Figure 3.5. This circuit was chosen to fit the data generated in this study for two primary reasons. The first reason is this particular circuit is consistent with similar works (Roberts and Tyburczy, 1991; Roberts and Tyburczy, 1993; Yoshino, 2010; Karato and Wang, 2013). The second reason was specifically related to the sample characteristics and data fit. By utilising a constant phase element in place of a traditional capacitor the impedance of the sample achieved much lower errors and this may be due to the samples being considered imperfect capacitors (Karato and Wang, 2013). From the experiments carried out four graphs were created for the conductivities. The purpose of these graphs was to allow comparison between samples and comparison with literature data as shown in Table 3.8. A representation of these graphs is given in Figure 3.10. Conductivities of the second temperature increase across all four experiments were chosen for this comparison. Further it also illustrates the difference in conductivity and activation enthalpy across starting material. These differences are of high importance to the way in which these electrical conductivity measurements are understood. Specifically because these signatures are plotted within the same region as the hydrous data of Yoshino et al., 2009. There are a number of possible scenarios to explain this including real-time hydration, furnace dehydration or take up of water by hydrous phases (spinel and pyroxene group). In addition to these sample specific scenarios there are a number of other external explanations, which may include surface water contamination and contamination during separation or milling. All of these will be discussed below. In addition, the potential influences on the activation enthalpy will be discussed as well as the complications caused by starting with powder. Finally, a brief discussion of how these values may be used in geophysical modelling will be presented.

To start with, it is first appropriate to discuss why the second temperature sweep, shown in Figure 3.10, is a representative illustration of the electrical conductivities for each sample. During each experiment, there were a number of stability issues as observed from the variations of the impedances across temperatures. This is evident from the differences observed in the activation enthalpies of each sweep across experiments (Table 3.3 - 3.7). With the exception of experiment MQ034, $\Delta \mathrm{H}$ is seen to increase or remain close to a constant 
value for the second temperature increase. This is in contrast to the other sweeps. Temperature increase 1 , temperature decrease 1, and temperature decrease 2 all display inconsistency in $\Delta \mathrm{H}$ across experiments. While it would be useful to select only points from each experiment that display the most appropriate $\Delta \mathrm{H}$ for the sample type, it would impart a substantial bias on the analysis and implications of this work. For example, if the activation enthalpy of the $3^{\text {rd }}$ temperature increase or decrease were deemed to be characteristic of the activation enthalpy of that sample, it cannot be compared with experiments that have not had a third cycle carried out. The reader is directed to the supplementary material to view the other three plots that are presented together with literature data.

\subsection{Experimental results on mineralogically distinct samples:}

This study has focused predominantly on the variation in electrical conductivity between two samples that are mineralogically different. While the methods and experimentation presented here are scientifically sound, a number of analysis techniques are still needed to provide context for this work. Therefore, the comparison and following discussion below between this study and others is speculative, as there are limited means by which to confirm these comparisons, given the time frame of this work. The reader is directed to the future work section that outlines these techniques and work that follows the conclusions. Before moving on it also appropriate to remind the reader that the two samples referenced above are described as the San Carlos Peridotite (SCP) and the Separated San Carlos Olivine (SSCO). Both samples were sourced from the San Carlos Peridot Mesa within the San Carlos volcanic field located in the San Carlos Apache reservation of south-east Arizona, USA. The SCP sample can be defined by the presence of chromium-rich spinels, titanomagnetite and both orthopyroxene and clinopyroxene in addition to olivine (Frey and Prinz, 1978; Galer and O'nions, 1989). Composition is inferred from mineral abundance with the SCP displaying modal proportion from most to least abundant of olivine > orthopyroxene $>$ clinopyroxene $>$ spinels (Frey and Prinz, 1978; Galer and O'nions, 1989). Olivine typically displays Mg\# >85 and makes up $45-60 \%$ of the samples (Frey and Prinz, 1978; Galer and O'nions, 1989). The SSCO sample was sourced from the same batch of material as the SCP with additional processing such as ERD and magnetic and manual separation (see methods section). 
From Figure $\mathbf{3 . 1 0}$ it can be seen that the data from this study falls within Yoshino's data, whose samples have a water content range of $0.1 \mathrm{wt}$. \% - $1 \mathrm{wt}$. \%. Also the activation enthalpies calculated are similar to those determined by Yoshino. This is with noticeable exception of experiments MQ034 and MQ029. As presented in Figure 3.10 \& Table 3.10, MQ029, shows an activation enthalpy of $0.77 \mathrm{eV}$ and was carried out on the SCP sample. This was one of the two measurements undertaken at $1.1 \mathrm{GPa}$, the other being MQ039. MQ039 shows an activation enthalpy of $0.52 \mathrm{eV}$ for the SSCO sample. Experiments are also compared with literature data obtained from dry samples. The dry samples have much higher activation enthalpies of $1.10 \mathrm{eV}, 1.77 \mathrm{eV}$ and $1.60 \mathrm{eV}$ for the Yoshino (excluding $2000 \mathrm{~K}$ ) and Wang samples respectively. Note that due to the proposed Yoshino model, two activation enthalpies are presented for the dry samples, which correspond to low and high temperature (i.e. proton and small polaron conduction) respectively. The activation enthalpy of the hydrous runs by Yoshino et al., (2009) $(0.80-0.90 \mathrm{eV})$ are close to the activation enthalpies from experiments MQ039 and MQ037 both of which were carried out on SSCO. Looking at the activation enthalpies from the second temperature decrease of experiment MQ039 (Table 3.7) an activation enthalpy of $0.90 \mathrm{eV}$ was obtained, suggesting that proton conduction may be the dominant mechanism. It may also suggest that the dominant conduction mechanism is likely to change to polaron conduction if the experiment were to be taken to a higher temperature (Yoshino and Katsura, 2013). Further, when the 1 GPa experiments are compared with the hydrous data of Yoshinos laboratory, it can be noted that the conductivity magnitude is similar to the SSCO MQ039 experiment. It is therefore suggested that the SSCO sample is the most analogous to the composition of the literature data. However, it is also suspected that there has been considerable hydration during experiment due mainly to the low enthalpy displayed across both samples, as well as the increased conductivity magnitude when compared with dry data.

In-situ hydration is possible via a number of mechanisms. Primarily impurities such as hydrous phases (spinel and clay minerals) within the starting powder would be presumed to be the source. As established within sections 1 and 2 of this thesis the San Carlos peridot as a source material is mineralogically diverse with pyroxene, spinel and some clay minerals. It is these external phases that may introduce hydrous contamination and/or impurities that may contribute to conductivity. This hydration may be amplified by the increase in pyroxene group minerals which are known to contain more water within their structure than olivine. The implication for this would be that water more readily diffuses into pyroxene than into olivine. 48 
However, it is not uncommon for graphite furnaces to dehydrate during experimentation (Holyoke, 2000). This is most readily observed with a slight increase in the efficiency of the furnace at temperature over $773 \mathrm{~K}$. Though furnace dehydration, as a hydration mechanism, would not be an efficient process. There is no clear remedy to furnace dehydration as the furnaces cannot be stored in ovens like powders and componentry, although, ambient temperature desiccators may reduce water content. There is one major complication with this theory, which is that from Figure 3.6 and 3.7 EC values of subsequent increase and decrease cycles (i.e. cycles three and four) are seen to be markedly lower than those present during initial cycles. This points to a rapid dehydration that is to be expected from hydrous samples, which further limits the comparability of this study with others as precise water content, even with post experiment FT-IR spectroscopy analysis, are likely unobtainable.

In addition to this it was discovered during the sample preparation that many of the separated grains were susceptible to superparamagnetism. Superparamagnetism is the generation of magnetism by an opposing field (Butler, 2004). This was seen during magnetic separation and is evidence of the presence of spinel minerals within the separated grains. While the field does degrade with time, magnetic remanence and retention time is a function of field strength and particle size (Butler, 2004). This explains why no increase of voltage was necessary during magnetic separation as the remanent field allowed potentially less magnetic grains with large spinel inclusions to move to the magnetic fraction. This suggest that the SSCO sample could be slightly contaminated when compared to samples from other laboratories and may have higher iron content than expected. Further it also provides an additional post experiment objective; to investigate and quantify the possible contaminants as well as provide insights as to why our data exhibits similar conductivity magnitudes as the wet data of Yoshino.

As for the SCP sample the two runs were MQ029 and MQ034 at 1.1 and $4.4 \mathrm{GPa}$ respectively. MQ029 was discussed above however MQ034 has been intentionally neglected. The reason for this is that the activation enthalpy and therefore the $\sigma_{0}$ is much lower than expected for this sample given the estimated high iron content. This may be due to various reasons, with the most probable being what can be described as kinetic interference. Kinetic interference in this instance specifically refers to the reactions and grain growth occurring within the sample during the experiment. In an idealised (i.e. pure olivine) system, this grain growth takes many hours (20 - 200 hours) to grow sufficiently large grains similar to the average grain size expected in the mantle (Karato 1989). Although, the SCP system is not 
idealised and, potentially not dry. The presence of water would speed up the kinetics dramatically (Karato, 1989) which may be exacerbated by the presence of alternate phases. In particular there is the presence of the iron rich spinel mineral believed to be magnetite and pyroxene group minerals in the SCP sample. These phases may have caused an increased rate of kinetic reaction resulting in an interference seen in the activation enthalpy and $\sigma_{0}$ values. Importantly from Table 3.5, it is clear that as the experiment progressed the activation enthalpy stabilised, with temperature decreases two and three showing activation enthalpies much more consistent with literature values of 0.53 and $0.86 \mathrm{eV}$ respectively.

\subsection{Other factors influencing EC:}

A key determination in the understanding of EC measurements is the way in which the data from any one study can be compared to other experimental work. For example, there are a number of points within the data acquisition and processing processes where human judgement may impart a bias on to the data. Specifically within the data fitting process, as highlighted within the methods section, a number of points must be removed to allow adequate and accurate impedance values that are then presented on plots such as Figure 3.4. It would be remise not to point out the potential bias this process imposes on data, further at low temperature impedance can often vary greatly leading to larger errors (up to $10 \%$ difference in resistance value of the sample). Furthermore much of the previous work, with respect, neglects external verification of water content with more than one technique (i.e. using FT-IR as well as nano-SIMS).

There is a lack of internal consistency in measurements between labs often switching between nickel (Ni) and molybdenum (Mo) electrodes within the cell design to act as solid state oxygen fugacity buffers. The main advantage of using molybdenum ( $\left.\mathrm{Mo}-\mathrm{MoO}_{2}\right)$ electrodes as an oxygen fugacity buffer is that it is more representative of the lower mantle (Yoshino, 2010; Karato and Wang, 2013). Although, laboratories often use different electrodes depending on the experiment undertaken making comparison difficult. In olivine, the Mo$\mathrm{MoO}_{2}$ buffer produces higher conductivities than $\mathrm{Ni}-\mathrm{NiO}$ buffer at any given temperature, (Dai et al., 2010). Furthermore, it is uncommon to undertake calibrations using an electrical conductivity cell and by changing the assembly parts within an experiment (e.g. platinum to alumina sample capsule) the error in measuring pressure may increase due material properties. In part, this thesis aimed to create a calibration method using both conventional 
(platinum capsules) and electrical conductivity (alumina capsule) cells, to ensure a proper calibration.

\subsection{Powder sample vs. polycrystalline aggregate:}

A further discussion point is how a powdered starting sample compares with a presynthesised polycrystalline aggregate. It was initially thought during the experiments that the negative impedance curves (supplementary material) observed were a result of utilising powdered samples as a starting media. This was not the case, instead this was a result of inductive behaviour within the sample. This behaviour is only observed in the first temperature increases in some of the experiments prior to hydration/dehydration and activation of the oxygen fugacity buffer (Wang and Karato, 2013). This was a major step forward in experimentation during this project as it suggested that the system was buffered. This also shows, as previously discussed, that the powders used here where likely not dry. This is one of many complications that arise from a powdered sample and in many regards will shape the experiments moving forward in the next phase of this project. Large polycrystalline samples will be grown in large volume synthesis runs using a 25/19 octahedra prior to electrical conductivity measurements. This will have a distinct advantage of producing excess material, which will be used for geochemical analysis. The large volume synthesis allows sample volume of up to $300 \mathrm{~mm}^{3}$ to be produced, as compared to only $21 \mathrm{~mm}^{3}$ in an 18/11 assembly identical to the one used for the calcium germanate (platinum capsule) calibrations presented above. Extra sample would mean that conductivity experiments can run concurrent with analytical geochemistry work and therefore would allow a greater level of data consistency. In part this consistency would also be a product of the homogenous nature of the large volume samples which unlike for powders will not segregate based on density if stored for long periods.

Finally from a number of studies the average log conductivity of Earth's upper mantle can be estimated at between -1.75 to $-2.3 \mathrm{~S} / \mathrm{m}$ (Xu et al., 2000; Tarits et al., 2004; Yoshino and Katsura, 2013). These numbers are an average of a number of literature values. As outlined in the introduction, magnetotelluric response varies geographically, as well as a function of depth and therefore no one value is appropriate for the entire Earth. Geographically, for a depth range of $200 \mathrm{~km}$ depth (approximately $4 \mathrm{GPa}$ ), conductivity ranges from -2.0 to $-2.3 \mathrm{log}$ 
$\mathrm{S} / \mathrm{m}$ beneath Australia (Kahn et al.,2015), to -2.5 to $-2.75 \log \mathrm{S} / \mathrm{m}$ beneath the Northern Pacific (Kuvshinov et al., 2005).

When comparing this study with the data presented above it can be said that there is poor agreement between data sets. At $1473-1673 \mathrm{~K}$ (an acceptable range for $200 \mathrm{~km}$ depth), the conductivities measured in this study are between -1.25 and $-1.39 \mathrm{~S} / \mathrm{m}$ for the separated (SSCO) sample and 0.21 to $-2 \mathrm{~S} / \mathrm{m}$ for the SCP sample, as per the data in Figure 3.10. However, more work is needed on other mantle minerals to allow proper comparison. 


\section{Conclusions}

This study has presented a range of data as part of a preliminary study into the electrical conductivity of the San Carlos Olivine and San Carlos Peridotite. Referring back to the aims set out in section 1.3, it can be seen that all of the aims have been fulfilled.

The first aim of this study was to re-calibrate or re-establish the previous calibration of the 500 ton Walker type multi-anvil apparatus located at Macquarie University for the $18 / 11$ cell assembly, which was achieved utilising the calcium germanate polymorph series and the $\mathrm{SiO}_{2}$ polymorph series. Further this study also aimed to calibrate the maximum attainable pressure in the $18 / 11$ assembly. This was also achieved by the generation of the transition from coesite to stishovite at $8.7 \mathrm{GPa}$ and 450 tons. From this the polynomial generated to fit the calcium germanate and quartz polymorphs was to describe the increase in sample pressure as a function of ram pressure was used to determine at maximum pressure at 500 tons of 9.6 GPa.

The second aim of this study was predominantly based in technical development and was to develop an electrical conductivity $18 / 11$ size cell that is capable of measurements at high pressures and temperature. The cell developed here will serve to form the basis of future conductivity measurement carried out from ambient to the maximum pressure of 9.6 GPa.

The final aim was to generate two samples from the San Carlos peridotite, one pure olivine and the other natural, and carry out electrical conductivity measurements at temperatures and pressures similar to those of the lower crust and upper mantle. As evidenced from the results and discussion this aim has been fulfilled with a number of high pressure and temperature experiments being carried out. Further to this aim this study has shown that not only are these measurements possible using the system available, but it is capable of producing data similar to published values.

\subsection{Future work:}

The work presented in this thesis is the culmination of eight months of research to partially fulfil the requirements for a Masters of research degree. This study has demonstrated the complicated nature of the experimental work required to undertake electrical conductivity measurements at real Earth conditions. It must be acknowledged that this study still requires extensive work in order to allow meaningful and accurate conclusions to be made. 
The first step in contextualising the data presented previously is to employ a range of analytical techniques to quantify various aspects of the samples used. Primarily, compositional analysis of the samples that have been presented in this work, using the Electron Microprobe, will be necessary. Further X-ray diffraction on the starting powders will have to be carried out and modal composition calculated. Further, FT-IR spectroscopy needs to be carried out to determine the water content of the post-experiment samples. FT-IR of the starting powders will also need to be carried out. Typically pellets with dimensions $\sim 10 \mathrm{~mm}$ diameter and $\sim 0.2$ $\mathrm{mm}$ thick are made by cold pressing the sample with $\mathrm{KBr}$ (potassium bromide). If FT-IR shows that water is present the samples may be analysed using nano-SIMS (secondary-ion mass spectrometry), however this is not of highest priority.

The final analytical technique that will be employed on these samples will be scanning electron microscope (SEM). SEM will be used to measure grain size, determine the presence of the nickel oxide to confirm buffering as well as potentially determining crystallographic orientation (using a fitted EBSD detector). SEM will also be used to make compositional maps of the samples as well as assess mineral relationships (for the SCP sample), if present.

This project acts as a pilot study for further work with the desire to resolve or at the very least clear the confusion and lack of consensus within the experimental community on mantle water and magnetotelluric signature. As such this work has been a learning process and will be used to better focus future studies. In order to make significant progress is it planned that large volume synthesis and geochemical analysis will form the basis of future experiments. Large volume synthesis will be used to generate samples for multiple runs at a time and facilitate thorough compositional analysis both pre and post experiments. Further, given the apparent lack of consistency with respect to sample source it is proposed that future work will include geochemical analysis of the peridot mesa from many sample locations that will be sourced via field mapping. Also a close relationship with the sources of the gem quality peridots will be necessary. Finally, electrical conductivity measurements on pyroxene group minerals and garnets (as per the pyrolite Earth model) will be carried out so as to constrain magnetotelluric models that rely so heavily on this work. 


\section{References}

BELL, D. R., ROSSMAN, G. R., MALDENER, J., ENDISCH, D. \& RAUCH, F. 2003. Hydroxide in olivine: A quantitative determination of the absolute amount and calibration of the IR spectrum. Journal of Geophysical Research: Solid Earth, 108, 2105.

BERRY, A. J., HERMANN, J., O'NEILL, H. S. C. \& FORAN, G. J. 2005. Fingerprinting the water site in mantle olivine. Geology, 33, 869-872.

BERRY, A. J., O'NEILL, H. S. C., HERMANN, J. \& SCOTT, D. R. 2007a. The infrared signature of water associated with trivalent cations in olivine. Earth and Planetary Science Letters, 261, 134142.

BERRY, A. J., WALKER, A. M., HERMANN, J., O'NEILL, H. S. C., FORAN, G. J. \& GALE, J. D. 2007b. Titanium substitution mechanisms in forsterite. Chemical Geology, 242, 176-186.

BUTLER, R. F. 2004. Paleomagnetism: Magnetic domains to geologic terranes. Chapter 3 Origins of natural remanent magnetism. 2nd edition ed. Boston: Blackwell Scientific Publications.

CAGNIARD, L. 1953. Basic theory of the magneto-telluric method of geophysical prospecting. Geophysics, 18, 605-635.

ChereVATOVA, M., SMIRNOV, M. Y., JONES, A. G., PEDERSEN, L. B., BECKEN, M., BIOLIK, M., CHEREVATOVA, M., EBBING, J., GRADMANN, S., GURK, M., HÜBERT, J., JONES, A. G., JUNGE, A., KAMM, J., KORJA, T., LAHTI, I., LÖWER, A., NITTINGER, C., PEDERSEN, L. B., SAVVAIDIS, A. \& SMIRNOV, M. 2015. Magnetotelluric array data analysis from north-west Fennoscandia. Tectonophysics, 653, 1-19.

DAI, L. \& KARATO, S.-I. 2014. Influence of FeO and $\mathrm{H}$ on the electrical conductivity of olivine. Physics of the Earth and Planetary Interiors, 237, 73-79.

DAI, L. \& KARATO, S.-I. 2014. High and highly anisotropic electrical conductivity of the asthenosphere due to hydrogen diffusion in olivine. Earth and Planetary Science Letters, $408,79-86$.

DAI, L., LI, H., LI, C., HU, H. \& SHAN, S. 2010. The electrical conductivity of dry polycrystalline olivine compacts at high temperatures and pressures. Mineralogical Magazine, 74, 849-857.

DEMOUCHY, S. \& MACKWELL, S. 2006. Mechanisms of hydrogen incorporation and diffusion in iron-bearing olivine. Physics and Chemistry of Minerals, 33, 347-355.

FREY, F. A. \& PRINZ, M. 1978. Ultramafic inclusions from San Carlos, Arizona: Petrologic and geochemical data bearing on their petrogenesis. Earth and Planetary Science Letters, 38, 129-176.

GALER, S. J. G. \& O'NIONS, R. K. 1989. Chemical and Isotopic Studies of Ultramafic Inclusions from the San Carlos Volcanic Field, Arizona: A Bearing on their Petrogenesis. Journal of Petrology, 30, 1033-1064.

HOLYOKE, C. W. 2000. An experimental study of melt migration mechanism. Masters of Science, The University of Vermont, Burlington, Vermont, USA. 
ICHIKI, M., BABA, K., OBAYASHI, M. \& UTADA, H. 2006. Water content and geotherm in the upper mantle above the stagnant slab: Interpretation of electrical conductivity and seismic P-wave velocity models. Physics of the Earth and Planetary Interiors, 155, 1-15.

INGHAM, M. R., BIBBY, H. M., HEISE, W., JONES, K. A., CAIRNS, P., DRAVITZKI, S., BENNIE, S. L., CALDWELL, T. G. \& OGAWA, Y. 2009. A magnetotelluric study of Mount Ruapehu volcano, New Zealand. Geophysical Journal International, 179, 887-904.

JONES, A. G., FULLEA, J., EVANS, R. L. \& MULLER, M. R. 2012. Water in cratonic lithosphere: Calibrating laboratory-determined models of electrical conductivity of mantle minerals using geophysical and petrological observations. Geochemistry, Geophysics, Geosystems, 13.

KARATO, S. 1989. Grain growth kinetics in olivine aggregates. Tectonophysics, 168, 255-273.

KARATO, S.-I. \& WANG, D. 2013. Electrical Conductivity of Minerals and Rocks. Physics and Chemistry of the Deep Earth. John Wiley \& Sons, Ltd.

KHAN, A., KOCH, S., SHANKLAND, T. J., ZUNINO, A. \& CONNOLLY, J. A. D. 2015. Relationships Between Seismic Wave-Speed, Density, and Electrical Conductivity Beneath Australia from Seismology, Mineralogy, and Laboratory-Based Conductivity Profiles. In: KHAN, A. \& DESCHAMPS, F. (eds.) The Earth's Heterogeneous Mantle. Springer International Publishing.

KHAN, A. \& SHANKLAND, T. J. 2012. A geophysical perspective on mantle water content and melting: Inverting electromagnetic sounding data using laboratory-based electrical conductivity profiles. Earth and Planetary Science Letters, 317-318, 27-43.

KOVÁCS, I., O'NEILL, H. S. C., HERMANN, J. \& HAURI, E. H. 2010. Site-specific infrared OH absorption coefficients for water substitution into olivine. American Mineralogist, 95, 292299.

KUVSHINOV, A., UTADA, H., AVDEEV, D. \& KOYAMA, T. 2005. 3-D modelling and analysis of Dst Cresponses in the North Pacific Ocean region, revisited. Geophysical Journal International, $160,505-526$.

LIBOWITZKY, E. \& ROSSMAN, G. R. 1997. An IR absorption calibration for water in minerals. American Mineralogist, 82, 1111-1115.

NICHOLLS, I. \& RINGWOOD, A. 1973. Effect of water on olivine stability in tholeiites and the production of silica-saturated magmas in the island-arc environment. The Journal of Geology, 285-300.

PADRÓN-NAVARTA, J. A., HERMANN, J. \& O'NEILL, H. S. C. 2014. Site-specific hydrogen diffusion rates in forsterite. Earth and Planetary Science Letters, 392, 100-112.

PATERSON, M. 1982. The determination of hydroxyl by infrared absorption in quartz, silicate glasses, and similar materials. Bulletin de la Societe Francaise de Mineralogie, 105, 20-29.

POE, B. T., ROMANO, C., NESTOLA, F. \& SMYTH, J. R. 2010. Electrical conductivity anisotropy of dry and hydrous olivine at $8 \mathrm{GPa}$. Physics of the Earth and Planetary Interiors, 181, 103-111. 
ROBERTS, J. J. \& TYBURCZY, J. A. 1991. Frequency dependent electrical properties of polycrystalline olivine compacts. Journal of Geophysical Research: Solid Earth, 96, 1620516222.

ROBERTS, J. J. \& TYBURCZY, J. A. 1993. Impedance spectroscopy of single and polycrystalline olivine: Evidence for grain boundary transport. Physics and Chemistry of Minerals, 20, 1926.

ROSS, N. L., AKAOGI, M., NAVROTSKY, A., SUSAKI, J.-I. \& MCMILLAN, P. 1986. Phase transitions among the $\mathrm{CaGeO} 3$ polymorphs (wollastonite, garnet, and perovskite structures): Studies by high-pressure synthesis, high-temperature calorimetry, and vibrational spectroscopy and calculation. Journal of Geophysical Research: Solid Earth, 91, 4685-4696.

RUBIE, D. C. 1999. Characterising the sample environment in multianvil high-pressure experiments. Phase Transitions, 68, 431-451.

SELWAY, K. 2014. On the Causes of Electrical Conductivity Anomalies in Tectonically Stable Lithosphere. Surveys in Geophysics, 35, 219-257.

SELWAY, K., YI, J. \& KARATO, S.-I. 2014. Water content of the Tanzanian lithosphere from magnetotelluric data: Implications for cratonic growth and stability. Earth and Planetary Science Letters, 388, 175-186.

SMYTH, J. R. \& FROST, D. J. 2002. The effect of water on the 410-km discontinuity: An experimental study. Geophysical Research Letters, 29, 123-1-123-4.

SMYTH, J. R., FROST, D. J., NESTOLA, F., HOLL, C. M. \& BROMILEY, G. 2006. Olivine hydration in the deep upper mantle: Effects of temperature and silica activity. Geophysical Research Letters, 33, L15301.

TARITS, P., HAUTOT, S. \& PERRIER, F. 2004. Water in the mantle: Results from electrical conductivity beneath the French Alps. Geophysical Research Letters, 31.

TURNER, M., IRELAND, T., HERMANN, J., HOLDEN, P., PADRON-NAVARTA, J. A., HAURI, E. H. \& TURNER, S. 2015. Sensitive high resolution ion microprobe - stable isotope (SHRIMP-SI) analysis of water in silicate glasses and nominally anhydrous reference minerals. Journal of Analytical Atomic Spectrometry, 30, 1706-1722.

UCHIDA, H., LAVINA, B., DOWNS, R. T. \& CHESLEY, J. 2005. Single-crystal X-ray diffraction of spinels from the San Carlos Volcanic Field, Arizona: Spinel as a geothermometer. American Mineralogist, 90, 1900-1908.

VOZAR, J., JONES, A. G., FULLEA, J., AGIUS, M. R., LEBEDEV, S., LE PAPE, F. \& WEI, W. 2014. Integrated geophysical-petrological modeling of lithosphere-asthenosphere boundary in central Tibet using electromagnetic and seismic data. Geochemistry, Geophysics, Geosystems, 15, 3965-3988.

XU, Y., SHANKLAND, T. J. \& POE, B. T. 2000. Laboratory-based electrical conductivity in the Earth's mantle. Journal of Geophysical Research: Solid Earth (1978-2012), 105, 27865-27875. 
YOSHINO, T. 2010. Laboratory Electrical Conductivity Measurement of Mantle Minerals. Surveys in Geophysics, 31, 163-206.

YOSHINO, T. \& KATSURA, T. 2013. Electrical Conductivity of Mantle Minerals: Role of Water in Conductivity Anomalies. Annual Review of Earth and Planetary Sciences,, 41, 605.

YOSHINO, T., MATSUZAKI, T., SHATSKIY, A. \& KATSURA, T. 2009. The effect of water on the electrical conductivity of olivine aggregates and its implications for the electrical structure of the upper mantle. Earth and Planetary Science Letters, 288, 291-300.

YOSHINO, T., MATSUZAKI, T., YAMASHITA, S. \& KATSURA, T. 2006. Hydrous olivine unable to account for conductivity anomaly at the top of the asthenosphere. Nature, 443, 973-976.

YOSHINO, T., SHIMOJUKU, A., SHAN, S., GUO, X., YAMAZAKI, D., ITO, E., HIGO, Y. \& FUNAKOSHI, K. I. 2012. Effect of temperature, pressure and iron content on the electrical conductivity of olivine and its high-pressure polymorphs. Journal of Geophysical Research: Solid Earth (1978-2012), 117.

ZHANG, J., LI, B., UTSUMI, W. \& LIEBERMANN, R. 1996. In situ X-ray observations of the coesitestishovite transition: reversed phase boundary and kinetics. Physics and Chemistry of Minerals, 23, 1-10.

ZHANG, L., UNSWORTH, M., JIN, S., WEI, W., YE, G., JONES, A. G., JING, J., DONG, H., XIE, C., LE PAPE, F. \& VOZAR, J. 2015. Structure of the Central Altyn Tagh Fault revealed by magnetotelluric data: New insights into the structure of the northern margin of the IndiaAsia collision. Earth and Planetary Science Letters, 415, 67-79. 
Supplementary material:

S.Table 1: Sample of data output from the SMaRT ${ }^{\mathrm{TM}}$ v.3.3.1 software used in conjunction with the Solartron 1260A. " $n$ " refers to the measurement number, Frequency, phase degrees and Impedance magnitude are described in text and correspond with the variables in eq.1.2 and 1.3. $Z_{\text {Real }}$ and $Z_{\text {Imaginary }}$ are the results of eq.1.2 and $\mathbf{1 . 3}$ and are presented in Cole-Cole plots (i.e. Figure 3.4).

\begin{tabular}{|c|c|c|c|c|c|}
\hline$n$ & $\begin{array}{l}\text { Frequency } \\
\qquad(\mathrm{Hz})\end{array}$ & $\begin{array}{c}\text { Phase } \\
\text { degrees } \\
(\varphi)\end{array}$ & $\begin{array}{l}\text { Impedance } \\
\text { magnitude } \\
|\mathrm{Z}| \text { (Ohms) }\end{array}$ & $\begin{array}{c}Z_{\text {Real }} \\
\text { (Ohms) }\end{array}$ & $\begin{array}{c}Z_{\text {Imaginary }} \\
\text { (Ohms) }\end{array}$ \\
\hline 1 & 1000000.00 & -105.04 & 56607.38 & -14690.29 & 54668.01 \\
\hline 2 & 794328.20 & -86.99 & 71306.52 & 3743.55 & 71208.18 \\
\hline 3 & 630957.30 & -92.61 & 76883.07 & -3504.51 & 76803.16 \\
\hline 4 & 501187.30 & -83.50 & 110355.70 & 12485.44 & 109647.14 \\
\hline 5 & 398107.20 & -73.41 & 102464.10 & 29249.42 & 98200.63 \\
\hline 6 & 316227.80 & -86.44 & 135828.20 & 8426.70 & 135566.55 \\
\hline 7 & 251188.60 & -93.01 & 161131.50 & -8468.72 & 160908.80 \\
\hline 8 & 199526.20 & -92.02 & 222584.40 & -7854.93 & 222445.76 \\
\hline 9 & 158489.30 & -89.19 & 288603.70 & 4058.75 & 288575.16 \\
\hline 10 & 125892.50 & -86.84 & 368268.50 & 20327.55 & 367707.06 \\
\hline 11 & 100000.00 & -84.34 & 466162.40 & 45956.83 & 463891.53 \\
\hline 12 & 79432.82 & -81.52 & 584086.60 & 86172.18 & 577695.00 \\
\hline 13 & 63095.73 & -77.45 & 744237.30 & 161722.66 & 726453.67 \\
\hline 14 & 50118.72 & -73.39 & 952219.00 & 272208.78 & 912482.00 \\
\hline 15 & 39810.72 & -68.84 & 1190807.00 & 429839.42 & 1110522.12 \\
\hline 16 & 31622.78 & -61.79 & 1543352.00 & 729519.88 & 1360050.05 \\
\hline 17 & 25118.86 & -47.93 & 1895572.00 & 1269989.16 & 1407238.69 \\
\hline 18 & 19952.62 & -37.50 & 2243961.00 & 1780223.91 & 1366076.05 \\
\hline 19 & 15848.93 & -12.46 & 2636238.00 & 2574102.07 & 568989.75 \\
\hline 20 & 12589.25 & 9.17 & 2175197.00 & 2147400.62 & -346630.28 \\
\hline 21 & 10000.00 & 20.64 & 2129032.00 & 1992336.13 & -750582.44 \\
\hline 22 & 7943.28 & 33.02 & 1485307.00 & 1245406.60 & -809382.04 \\
\hline 23 & 6309.57 & 32.72 & 1226074.00 & 1031481.57 & -662799.53 \\
\hline 24 & 5011.87 & 34.69 & 976332.30 & 802792.86 & -555651.31 \\
\hline 25 & 3981.07 & 36.67 & 847260.80 & 679564.50 & -506006.87 \\
\hline 26 & 3162.28 & 31.96 & 707568.30 & 600335.34 & -374500.18 \\
\hline 27 & 2511.89 & 29.70 & 637766.10 & 554010.70 & -315939.46 \\
\hline 28 & 1995.26 & 25.45 & 591561.00 & 534165.48 & -254188.23 \\
\hline 29 & 1584.89 & 19.87 & 564988.20 & 531367.13 & -191991.25 \\
\hline 30 & 1258.93 & 18.74 & 539721.80 & 511108.44 & -173400.65 \\
\hline 31 & 1000.00 & 18.73 & 508375.10 & 481463.28 & -163212.60 \\
\hline 32 & 794.33 & 11.65 & 475993.30 & 466195.47 & -96080.20 \\
\hline
\end{tabular}


S.Table 1: Continued from page. 66

\begin{tabular}{|c|c|c|c|c|c|}
\hline $\mathrm{n}$ & $\begin{array}{l}\text { Frequency } \\
\qquad(\mathrm{Hz})\end{array}$ & $\begin{array}{c}\text { Phase } \\
\text { degrees } \\
(\varphi) \\
\end{array}$ & $\begin{array}{c}\text { Impedance } \\
\text { magnitude } \\
|\mathrm{Z}| \text { (Ohms) } \\
\end{array}$ & $\begin{array}{c}Z_{\text {Real }} \\
\text { (Ohms) }\end{array}$ & $\begin{array}{c}Z_{\text {Imaginary }} \\
\text { (Ohms) }\end{array}$ \\
\hline 33 & 630.96 & 27.57 & 484721.50 & 429673.15 & -224356.67 \\
\hline 34 & 501.19 & 27.44 & 953203.80 & 845972.51 & -439235.69 \\
\hline 35 & 398.11 & 5.34 & 382099.80 & 380442.22 & -35552.42 \\
\hline 36 & 316.23 & 0.00 & 637868.40 & 637868.40 & -3.15 \\
\hline 37 & 251.19 & 164.87 & 120598.00 & -116420.29 & -31467.33 \\
\hline 38 & 199.53 & 4.84 & 724951.10 & 722366.14 & -61165.80 \\
\hline 39 & 158.49 & -68.54 & 253762.00 & 92834.94 & 236171.18 \\
\hline 40 & 125.89 & -9.17 & 302237.90 & 298371.81 & 48187.26 \\
\hline 41 & 100.00 & 97.57 & 246159.00 & -32439.92 & -244012.10 \\
\hline 42 & 79.43 & 9.35 & 1322664.00 & 1305075.57 & -214983.31 \\
\hline 43 & 63.10 & -33.27 & 396474.80 & 331480.16 & 217515.91 \\
\hline 44 & 50.12 & -88.51 & 8038.56 & 209.54 & 8035.83 \\
\hline 45 & 39.81 & 89.19 & 361105.20 & 5127.65 & -361068.79 \\
\hline 46 & 31.62 & -52.33 & 353470.90 & 216033.01 & 279770.29 \\
\hline 47 & 25.12 & 34.53 & 446147.20 & 367536.82 & -252911.07 \\
\hline 48 & 19.95 & 16.87 & 595588.20 & 569949.40 & -172866.95 \\
\hline 49 & 15.85 & -38.70 & 347197.40 & 270953.37 & 217095.16 \\
\hline 50 & 12.59 & -5.06 & 639425.00 & 636929.98 & 56431.61 \\
\hline 51 & 10.00 & -7.08 & 522384.10 & 518401.14 & 64384.80 \\
\hline
\end{tabular}




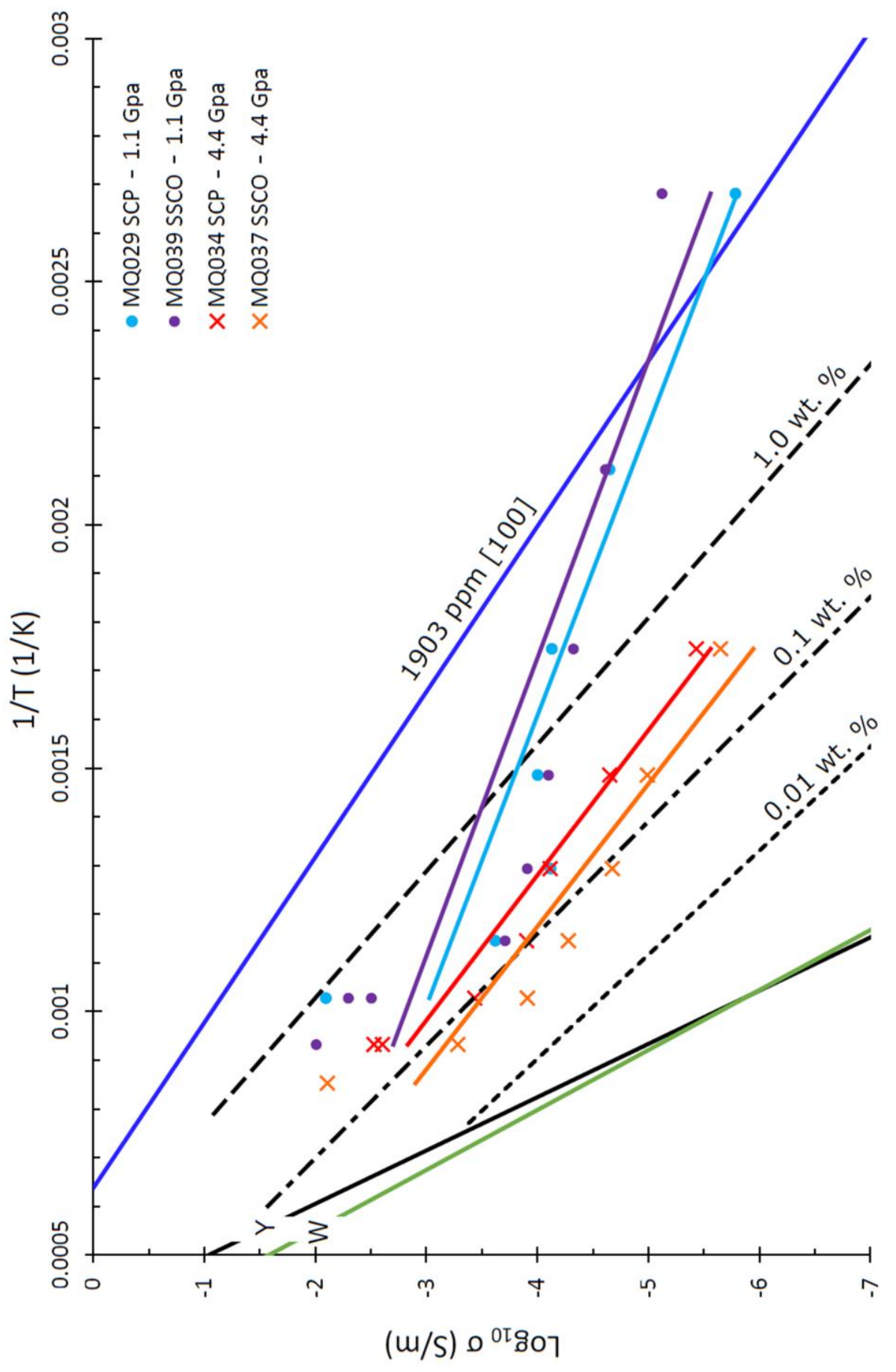

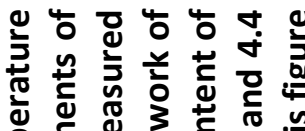

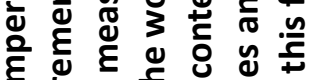

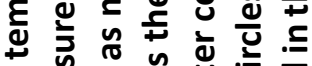
苋

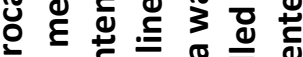
흔 出

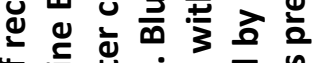

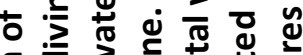
응 3

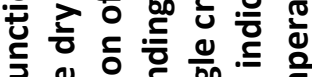

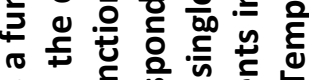
तै येत 施 음 훈 वे 는

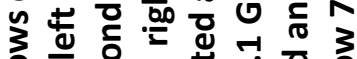

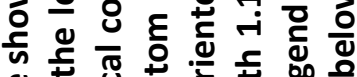

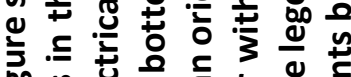

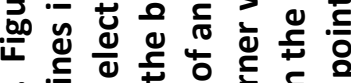

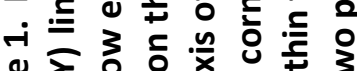
造

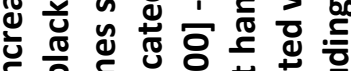
1)

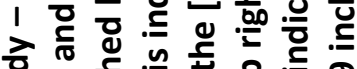

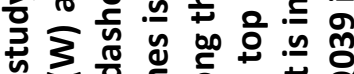
足 co

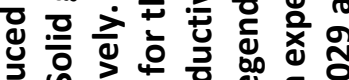

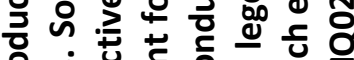
은 要

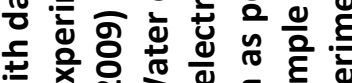

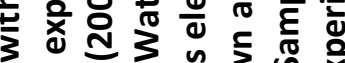
क्षे

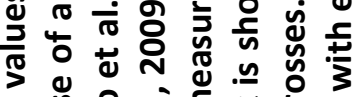

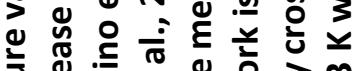

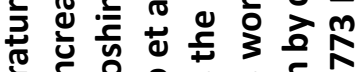

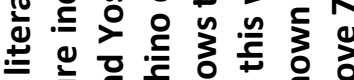

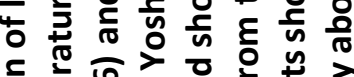

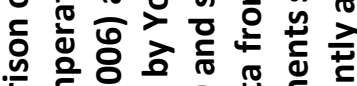
空 年

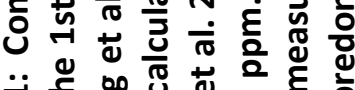

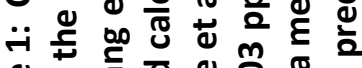

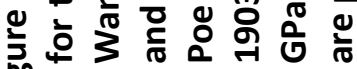
总 


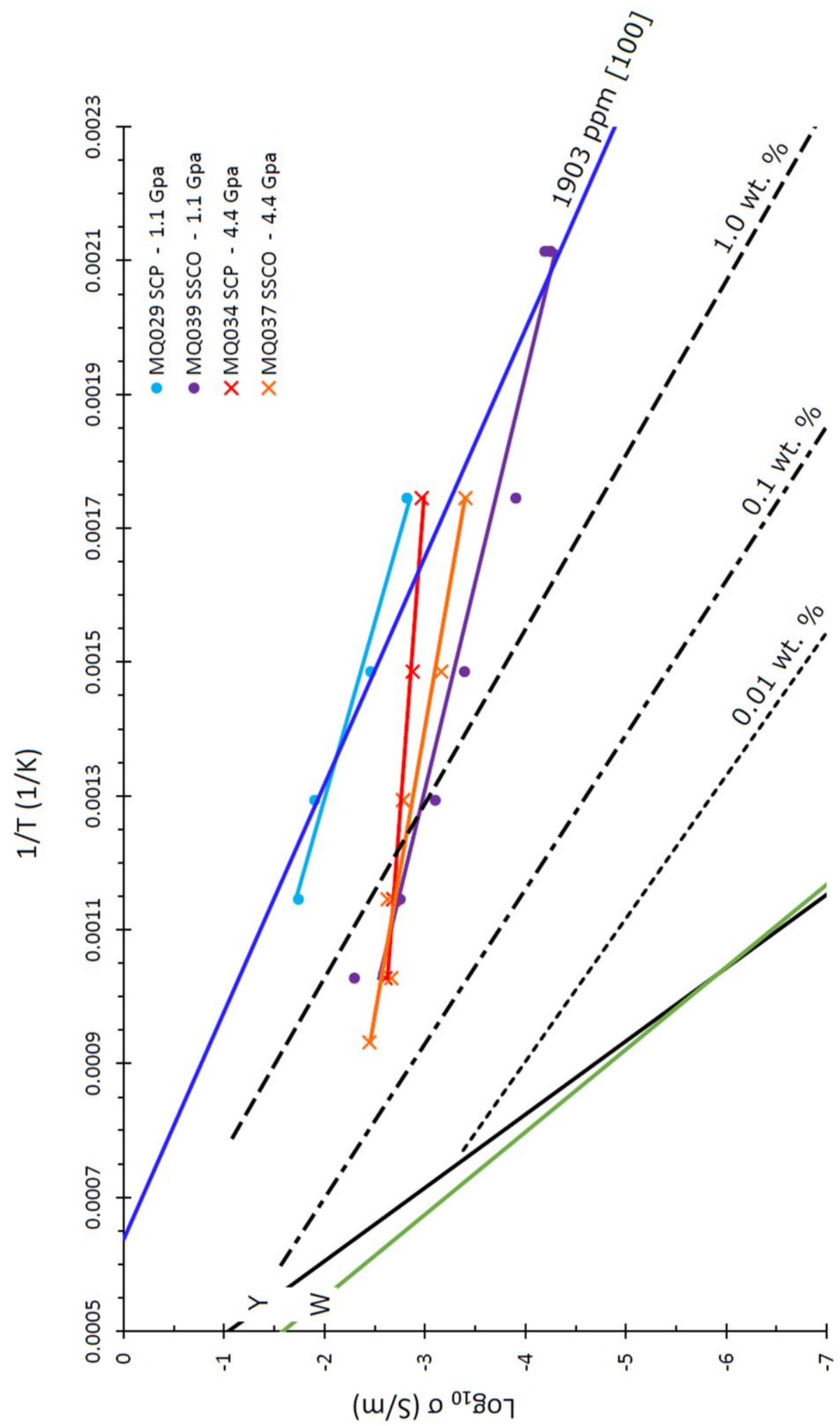

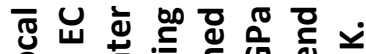
을. 过造论

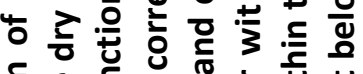

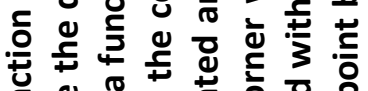
屯ั

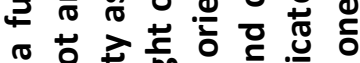

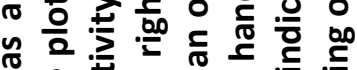

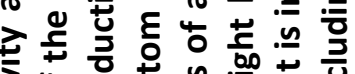

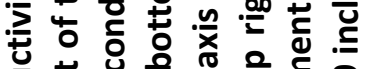

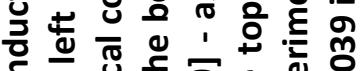

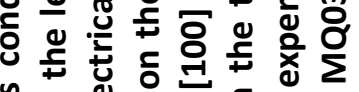

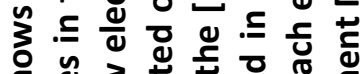

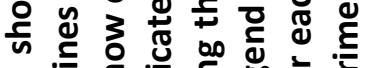
는 高乏造音

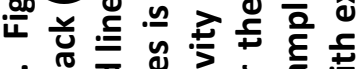

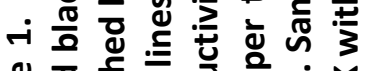
嵌

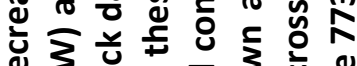

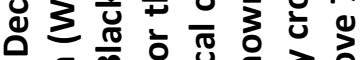
। 긍

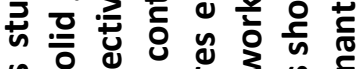

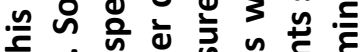

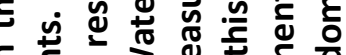
ऽ के है हो ช 텅 웡

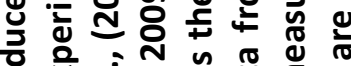

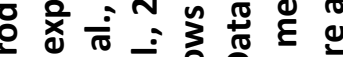

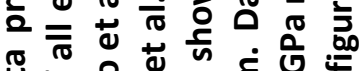
密

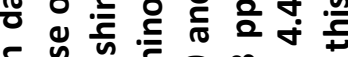
我 잉

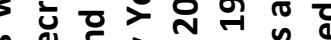
过

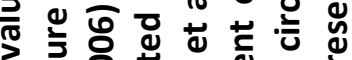

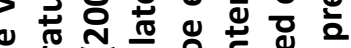

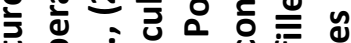
बำ

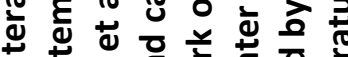

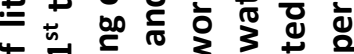
के 들

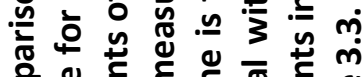

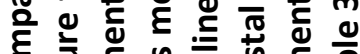

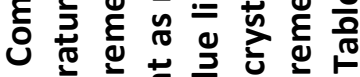

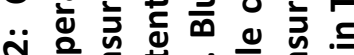

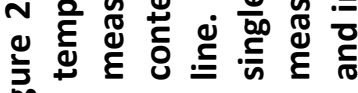
总 


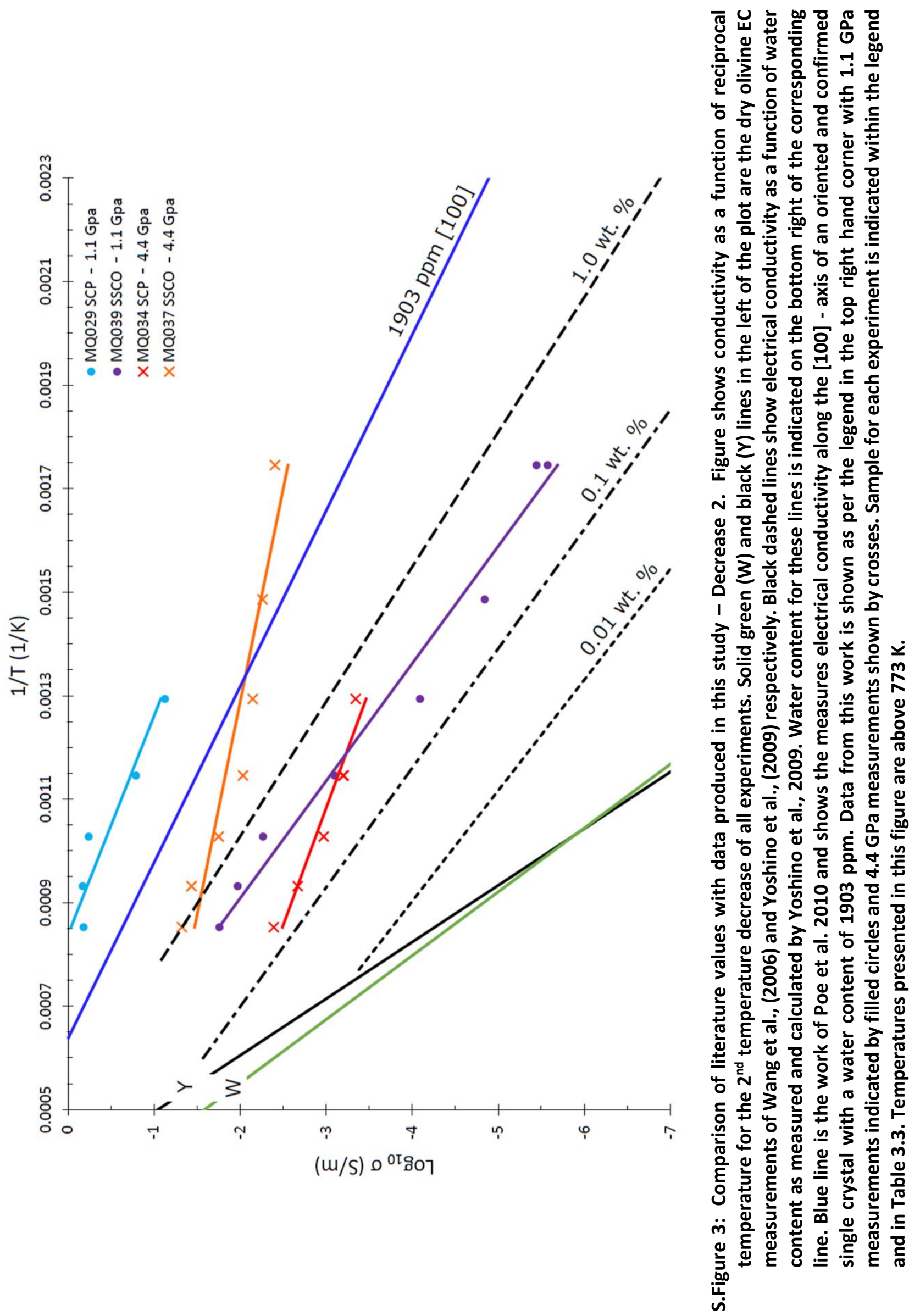




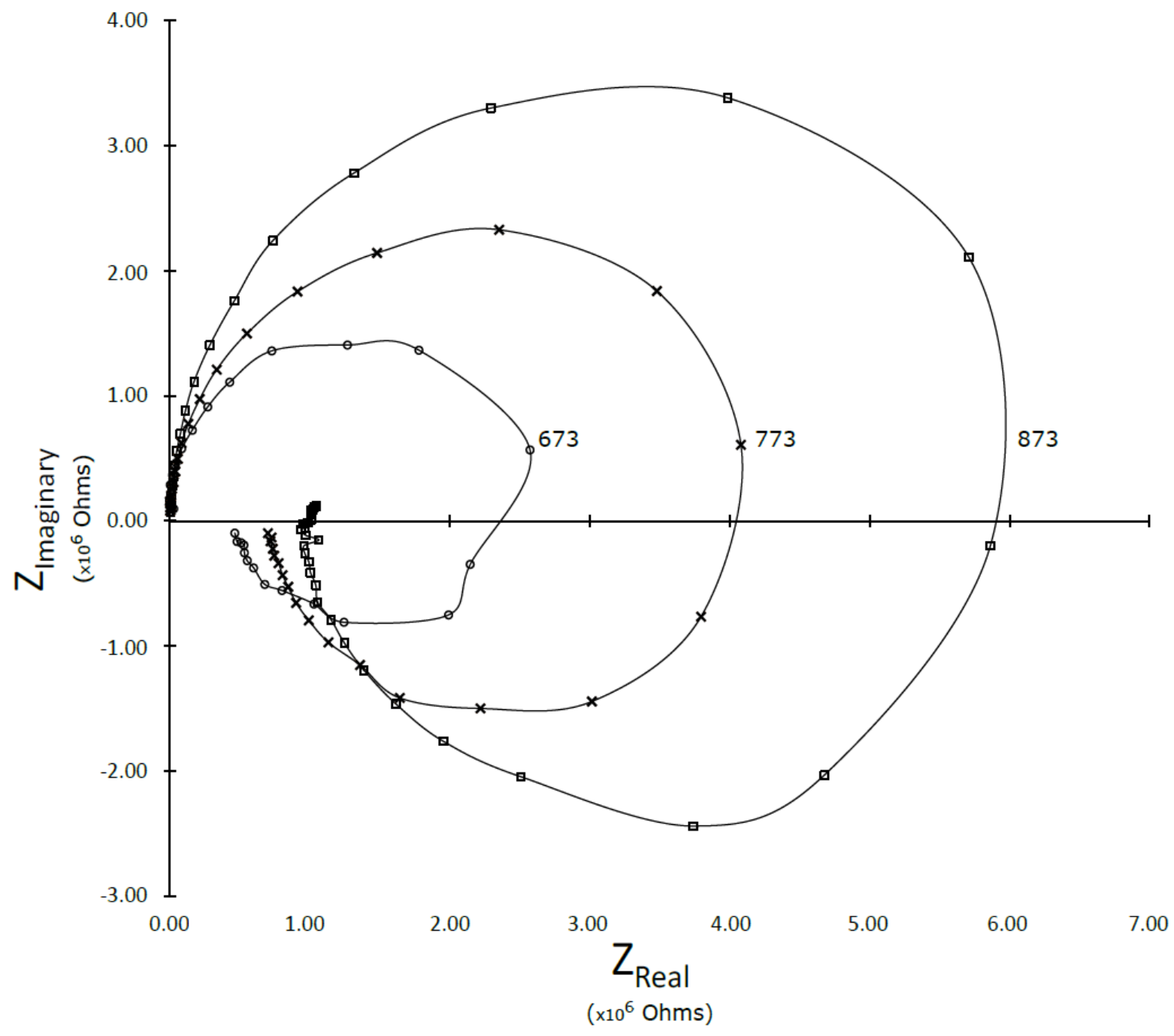

S.Figure 4: Inductive Cole-Cole plot. Negative impedance curves as discussed in section 4 believed to be caused by a hydration or dehydration of starting powders as the solid state buffer ( $\mathrm{Ni}$ ) not having sufficiently oxidised ( $\mathrm{NiO}$ ). 
S.Table 2: Sample measurements taken post experiment. Measurements are in millimetres $(\mathbf{m m})$, and the largest sample geometry during the polishing process is reported. " $L$ " is length of the sample, measured from the orthogonally from the side of the capsule to the opposing side. " $\mathrm{H}$ " is the height of the sample measured orthogonally from the contact between the electrode and sample to the same point on the other electrode.

\begin{tabular}{|c|c|c|c|}
\hline \multirow{2}{*}{ Experiment } & \multirow{2}{*}{ Sample } & \multicolumn{2}{|c|}{ Measurement } \\
\hline & & & $\mathrm{mm}$ \\
\hline \multirow{2}{*}{ MQ029 } & \multirow{2}{*}{$\mathrm{SCP}$} & $\mathrm{L}:$ & 1.289 \\
\hline & & $\mathrm{H}:$ & 1.571 \\
\hline \multirow{2}{*}{ MQ034 } & \multirow{2}{*}{$\mathrm{SCP}$} & $\mathrm{L}:$ & 1.114 \\
\hline & & $\mathrm{H}:$ & 1.644 \\
\hline \multirow{2}{*}{ MQ037 } & \multirow{2}{*}{ SSCO } & $\mathrm{L}:$ & 1.257 \\
\hline & & $\mathrm{H}:$ & $1.210^{\wedge}$ \\
\hline \multirow{2}{*}{ MQ039 } & \multirow{2}{*}{ SSCO } & $\mathrm{L}:$ & 1.304 \\
\hline & & $\mathrm{H}:$ & 1.524 \\
\hline
\end{tabular}

^: Sample suffered severe decompression cracking, resulting in sample loss. 